\title{
ESTRATEGIAS \\ PARA LA FORMACIÓN \\ Y EL EMPLEO \\ EN LA RED MUNICIPAL \\ DE CENTROS SOCIOLABORALES
}

Proyecto \#innovaCSL

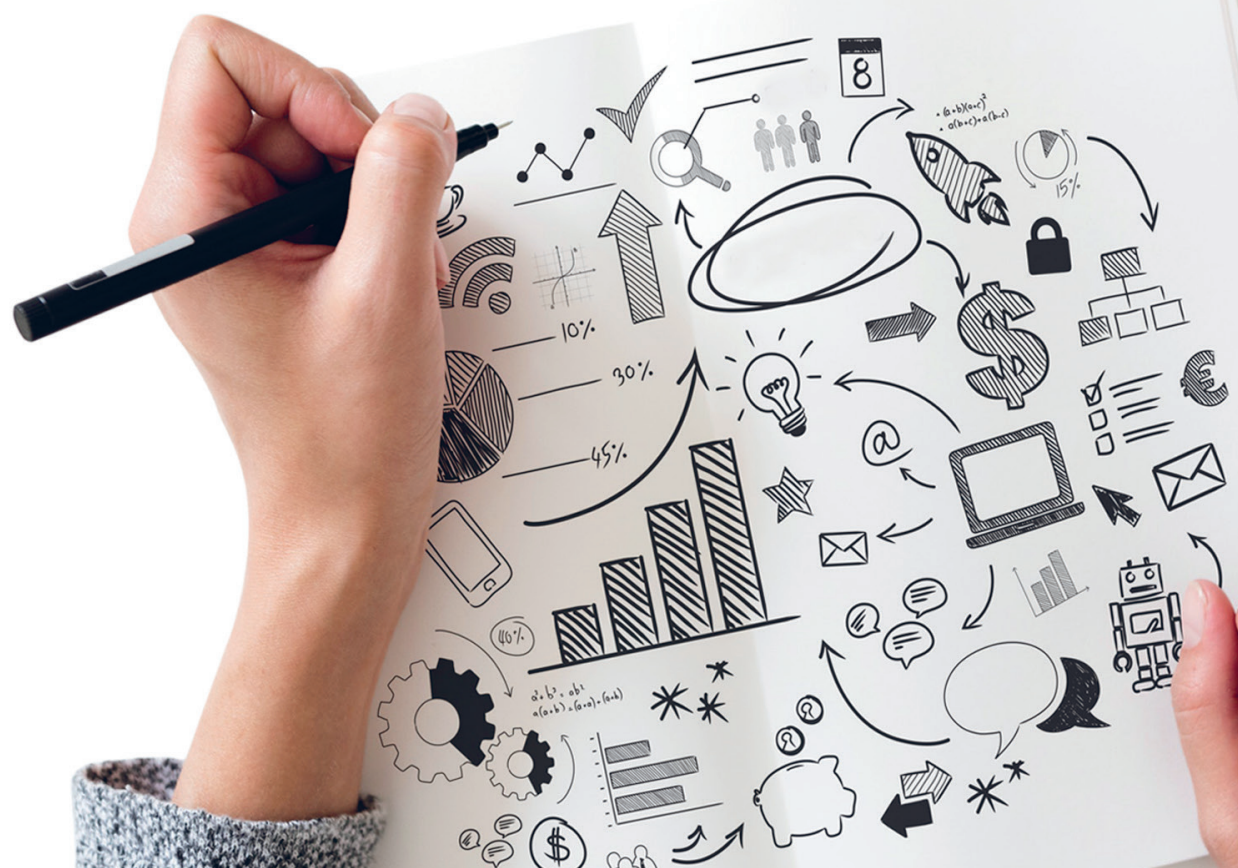



Estrategias para la formación y el empleo en la Red Municipal de Centros Sociolaborales

Chabier Gimeno Monterde (coord.) 
(C) Los autores

(C) 1. ${ }^{\mathrm{a}}$ edición, Zaragoza, 2018

Edita: Servicio de Publicaciones. Universidad de Zaragoza ISBN 978-84-16723-57-7 


\section{ÍNDICE}

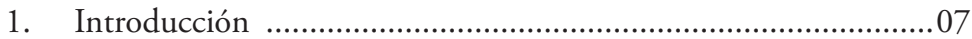

2. Herramientas para la innovación y el éxito educativo en la Red Municipal de Centros Sociolaborales.....................................09

3. Memoria \#innovaCSL.................................................................

4. La aportación de la Red Municipal de Centros Sociolaborales al ejercicio del derecho a la educación. .........................................39

5. Metodología, Aprendizaje y Servicio. Desarrollo curricular en Centros Sociolaborales.

6. Metodología, Aprendizaje y Servicio. Acciones en red entre la Universidad y los Centros Sociolaborales.

7. Intervención con familiares de alumnado de la Red Municipal de Centros Sociolaborales.

8. Propuesta de trabajo con las familias.

9. El espacio educativo no escolar y los estudiantes del pueblo gitano.

10. Alianzas comunitarias por el empleo juvenil en Zaragoza.

11. Metodologías activas en el aprendizaje.

12. Análisis de las percepciones del alumnado en la Red Municipal de Centros Sociolaborales.

13. Programa de Mentoría Social.

14. Comunicación \#innovaCSL. 



\section{INTRODUCCIÓN}

Tienes entre tus manos el resultado de un proceso largo y gestado con mimo que hemos impulsado desde el Ayuntamiento con la Universidad de Zaragoza, y en el que se han involucrado las entidades sociales gestoras de los Centros Sociolaborales y los equipos profesionales que llevan años desarrollando la intervención educativa con menores.

"El proyecto de innovación y éxito educativo en la Red Municipal de centros Sociolaborales" quiere recoger el trabajo realizado, así como las conclusiones o propuestas que se han ido alcanzando.

El Ayuntamiento de Zaragoza tiene una larga trayectoria de compromiso con la red de Centros Sociolaborales ya que en ellos se encuentran dos vías de intervención fundamentales que son la educativa y la de promoción social y laboral. Desde este gobierno creemos fundamental caminar hacía una sociedad con una mayor presencia y protagonismo de la juventud, una sociedad que posibilite su autonomía. Una sociedad en suma que reconozca a la juventud como un valor y ponga los medios para permitir el desarrollo de todas sus potencialidades. Es en este sentido en el que hemos impulsado el IV Plan Joven y en el que entendemos este trabajo de colaboración.

Un trabajo que reúne por un lado, el compromiso de los equipos educativos por el éxito educativo del alumnado de los centros y su empeño en la mejora y la innovación de su hacer educativo. Y, por otro lado, la experiencia de la Universidad en la investigación social y en la actualización del conocimiento, aportando herramientas y metodologías innovadoras. Un trabajo que se basa en la reflexión de la praxis cotidiana sobre un ámbito multifactorial y complejo en el que no caben recetas estándares.

Este proyecto pretende aunar y poner en común enfoques y conocimientos de cara a dar respuesta a la realidad de nuestra juventud más vulnerable para propiciar su empoderamiento, desarrollo e integración en la sociedad.

Espero que sea una herramienta útil que revierta en la juventud y que se mantenga la colaboración como marco de enriquecimiento mutuo. 



\title{
HERRAMIENTAS PARA LA INNOVACIÓN Y EL ÉXITO EDUCATIVO EN LA RED MUNICIPAL DE CENTROS SOCIOLABORALES
}

\author{
Chabier Gimeno Monterde \\ Universidad de Zaragoza
}

\section{INTRODUCCIÓN.}

Para quienes no conocen el contexto de las políticas municipales para el empleo y la formación en la ciudad de Zaragoza, hemos de comenzar diciendo que este libro se centra en el trabajo educativo llevado a cabo por actores no escolares (asociaciones, fundaciones, etc), con jóvenes que, o bien son externalizados desde los institutos antes de acabar su Educación Secundaria, o bien han acabado la misma sin titular. A ellos se dirigen dispositivos que surgen a finales de los años '80 desde el ámbito de la intervención social (Merino, 2013). Centros orientados a favorecer la incorporación al mercado laboral, con perfiles profesionales que a menudo son etiquetados como de "baja cualificación" (Termes, 2012).

El objetivo principal de esta publicación es transferir la investigación aplicada, desarrollada por el equipo científico del proyecto "Innovación y éxito educativo en la Red Municipal de Centros Sociolaborales del Ayuntamiento de Zaragoza”. Y, como objetivo específico, se pretende igualmente abrir un espacio de investigación multidisciplinar, que aporte un enfoque comunitario y de éxito educativo para estos itinerarios formativos. Alejándose de las bajas expectativas de las que parten algunas investigaciones sobre la educación y la población en situación o riesgo de exclusión (Macías y Redondo, 2012).

\section{UNA PERSPECTIVA TRANSFORMADORA.}

Como indicamos en algunos capítulos, nuestro enfoque parte de que existen factores, propios de la metodología educativa y social, que inciden positiva y negativamente en el rendimiento académico, así como en la inclusión educativa (Girbés, Macías y Álvarez, 2015). Desde esta perspectiva transformadora abordamos la situación 
en Zaragoza de los dispositivos educativos y sociales, dentro de la Red de Centros Sociolaborales, que ofrecen un itinerario formativo a aquellos jóvenes, de entre 14 y 25 años, que no titulan en la Educación Secundaria. Jóvenes con diagnósticos socioeducativos muy complejos (Merino, 2013). Que derivan de la falta de motivación, la dificultad para adaptarse al sistema de enseñanza de la Educación Secundaria, etc. Con la oferta formativa de esta Red, muchos jóvenes de entre 14 y 15 años intentan acabar el periodo obligatorio de la Enseñanza Obligatoria, participando en las Aulas Taller. Y otros, ya mayores de 16 años, se forman en los Programas de Cualificación Inicial (PCI) o Formación Ocupacional (FO), en las competencias propias de una cualificación profesional de nivel 1 del Catálogo Nacional de Cualificaciones Profesionales (Cutanda, 2014).

El grado de vulnerabilidad en las trayectorias personales y familiares, como veremos en los capítulos siguientes, sobrerrepresenta en las aulas a quienes están sufriendo no sólo la actual crisis económica, sino a quienes ya estaban excluidos en generaciones anteriores (Macías y Flecha, 2013). Por lo que, con el ciclo migratorio iniciado a finales del siglo pasado, la diversidad cultural de los centros ha sumado nuevos perfiles de jóvenes que no encajan en una educación reglada homogénea y, a la vista de los informes (Choi y Calero, 2013), poco inclusiva. En esta Red pública hay dos perfiles de alumnado que se encuentran también sobrerrepresentados respecto a la Secundaria: los alumnos gitanos (un cuarto del alumnado) y los de origen migrante (un tercio).

Con esta complejidad dentro de las aulas, los datos de los últimos años indican que un $65 \%$ del alumnado obtiene su título en la Red. Y del 28\% de bajas, el $44 \%$ se deben al abandono, siendo el resto por causas objetivas (incorporación a otro curso, a un trabajo o traslado de residencia). Estos resultados se fundamentan en dos factores. La asistencia a los programas: el 73\%, tiene una asistencia superior al $60 \%$ y el $56 \%$ superior al $80 \%$, quedando un $14 \%$ con una asistencia inferior al $40 \%$. Y la vinculación a los programas de la Red: un 37,7\% han continuado formándose en la Red (58\% del alumnado de Aulas Taller).

Estos perfiles sociodemográficos y los resultados socioeducativos son significativamente diferentes a los descritos en estudios locales, previos a la actual crisis económica (Gómez et al., 2004; Gasch, 2006). El desempleo 
juvenil estructural sureuropeo se ha visto agravado por la baja inserción laboral de los jóvenes provenientes de itinerarios formativos como los aquí analizados (Eurofound, 2012). Lo que ha introducido nuevos debates sobre la adecuación de estos dispositivos educativos no escolares, en todas las Comunidades Autónomas (Collet y Tarabini, 2017). Entre otras causas, porque los cambios legislativos, todavía no alineados entre sí, y sumados al efecto refugio, han cambiado la orientación de algunas de las modalidades formativas observadas, hoy más académicas que laborales (Termes, 2012).

Así, aumenta el consenso técnico y académico respecto a dos vías de abordaje de la inclusión educativa del alumnado con estos perfiles. Por un lado, la necesidad de reducir el fracaso escolar de manera "preventiva" (Carabaña, 2010). Pero también, la de potenciar la continuidad formativa de todas las y los jóvenes. Abriendo y no cerrando las puertas a los itinerarios formativos de quienes están en situación de mayor vulnerabilidad y menor nivel curricular. Evitando las vías académicas “muertas" (García et al., 2013).

En este punto, concurren al menos tres perspectivas. La asistencialista, tradicional en el Tercer Sector (Alberich, 2007). La neoliberal, que asume las desigualdades de oportunidades como algo propio del capitalismo postindustrial, evitando transformar el entorno de los jóvenes e interviniendo tan sólo sobre los resultados de la fractura social contemporánea. En ella concurren iniciativas benéficoasistenciales y otras de origen obrerista, al amparo de la nueva filantropía (Saura, 2016). Y, de forma emergente, la perspectiva enraizada en la educación popular que, sin desligarse de su orientación inicial o sumándose a ella como nuevos actores, incorpora al entorno familiar y comunitario en el proceso socioeducativo. Aspirando a superar las desigualdades de oportunidades (Goicoechea, 2004).

En este contexto, desde la Universidad de Zaragoza iniciamos una colaboración orientada a acompañar la innovación en los Centros Sociolaborales (Madroño, 2014). Firmando en 2017 un acuerdo con el Ayuntamiento de Zaragoza, orientado a dotar a la Red Municipal de herramientas para la innovación y el éxito educativo. Este libro refleja parte de los resultados de ese proceso de investigación aplicada. Partiendo del conocimiento sobre la metodología de enseñanza desarrollada en los centros y las expectativas de los jóvenes en formación, el proyecto \#innovaCSL ha 
pretendido generar propuestas para un nuevo modelo formativo, que puedan ser aplicadas progresivamente en los próximos cursos académicos.

Para el equipo investigador, las claves para el éxito escolar en la Red son:

a. Los Centros necesitan a la comunidad: por lo que es preciso incorporar a sus estrategias a las familias y al voluntariado, así como reorientar aprendizajes hacia el territorio.

b. Y la metodología docente debe basarse en evidencias, priorizando las actuaciones educativas de éxito (Flecha y Soler, 2013): apostando por la creatividad en el ámbito de las especialidades formativas (Regalado, 2017) y por altas expectativas en la formación básica.

De esta forma, en sintonía con las nuevas expectativas del alumnado, podrán afrontarse los retos que sus itinerarios biográficos plantean en este siglo: el retorno a la formación reglada (García et al., 2009) y una inserción laboral hoy muy precarizada.

\section{INVESTIGACIÓN APLICADA.}

El proyecto de innovación se ha desarrollado en dos cursos escolares, a los que dedicamos un capítulo a modo de "memoria-resumen" a continuación. Brevemente, señalaremos que durante el curso 2016-2017 se han realizado actividades dirigidas a la puesta en marcha del proceso:

a. Con la creación del Equipo Motor (investigadores, un representante de cada una de las cinco entidades gestoras y un técnico municipal) y presentación del proyecto de innovación a los profesionales.

b. La formación del profesorado de los Centros: primeras y segundas Jornadas "Herramientas para la innovación y el éxito educativo", con talleres y conferencias sobre Actuaciones Educativas de Éxito (Includ-ed, 2011), Aprendizaje y Servicio, pueblo gitano, etc.

c. Y el inicio del diagnóstico: con la presentación de Grupos de Trabajo de profesionales (Aprendizaje y Servicio, diversidad del alumnado, metodología en el aula, intervención con las familias y, a propuesta de las entidades, otro sobre Aula Taller), así como observación participante (en cuatro centros), entrevistas a familiares del alumnado (en tres centros) y un grupo focal sobre "Intervención con familias y su participación en los Centros Sociolaborales" (con profesionales de cuatro centros). 
Visitando también un Centro de Educación Infantil y Primaria que aplica Actuaciones Educativas de Éxito e incorporando a alumnado del Grado de Trabajo Social a la investigación (Trabajo de Fin de Grado "Estudio sobre el contexto familiar del alumnado de los Centros Sociolaborales").

Durante el curso 2017-2018, se ha continuado trabajando en Grupos de Trabajo de profesionales, a los que se han sumado uno sobre la mejora de la empleabilidad, y se ha impulsado el embrión del Campus Rom Aragón. Con el fin de profundizar en la vinculación de la comunidad universitaria al proyecto, se ha ampliado el equipo investigador, implementando:

a. La participación de alumnado universitario en asignaturas de perfil investigador (dos grupos del Practicum de Investigación de Trabajo Social);

b. Ofreciendo actividades de Aprendizaje y Servicio por alumnado de los Grados de Educación y Periodismo;

c. Y creando un cuerpo de voluntariado (y prácticas extracurriculares) disponible para colaborar con las innovaciones promovidas desde los Grupos de Trabajo. Entre otras, la realización de una encuesta sobre competencias interculturales de los profesionales de la Red Municipal.

Estas actividades, que han contado con el acompañamiento de un profesional de la comunicación y los social media, culminan a final de 2018 con la transferencia de las innovaciones en este libro, así como una Conferencia Internacional sobre "Educación, inclusión y territorio. Políticas públicas frente a la exclusión educativa".

\section{DESAFÍOS.}

Cada Grupo de Trabajo ha detectado retos propios, que implican innovacion y elevan las expectativas de éxito educativo y laboral del alumnado. Sobre ellos versan los siguientes capítulos:

a. Diversidad cultural: la necesaria presencia de mediación intercultural profesional, como recurso propio o de la comunidad; así como de una formación estable en competencias profesionales interculturales.

b. Metodología: afrontando las dificultades para formarse desde experiencias de éxito en estos mismos entornos educativos, hoy todavía muy escasas, pero que hemos encontrado y experimentado. 
c. Empleo: incorporando el trabajo como Red, con enfoque comunitario, será más factible abordar un horizonte de mercado laboral muy alejado de las especialidades tradicionales en estos centros (Guash, 2006), vinculadas a oficios que actualmente cuentan con baja empleabilidad.

d. Familias: establecer hitos periódicos y espacios permeables que permitan un acercamiento progresivo de las familias a los Centros (Escuela de Familias, jornadas de puertas abiertas, etc), que deben ofrecerles progresivamente oportunidades de participación viable.

e. Y Aprendizaje-Servicio: abriendo prioritariamente espacios de relación con los recursos de educación obligatoria en el territorio, así como con la Universidad (Tejada, 2013).

De hecho, incorporar a la comunidad a los proyectos educativos de los Centros, según hemos analizado en varios de estos Grupos de Trabajo, también implica que la Universidad sea una herramienta más presente en el futuro. Por un lado, para acercar a esta a la realidad de este colectivo juvenil. Por otro, para nutrir el voluntariado, los programas de mentoring, los liderazgos comunitarios en los grupos minoritarios, etc (Prados et al, 2015).

\section{UN PROCESO, NO UN PROYECTO.}

Conscientes de que el proyecto se engarza en un proceso, que las políticas públicas deben liderar y que, como tal, va más allá de esta investigación, planteamos dos aglomerados de resultados a finales de 2018. Unos que nos indican la fortaleza de las innovaciones planteadas. Otros que nos remiten a las resistencias y debilidades que toda innovación pone de manifiesto.

Entre las fortalezas, destaca la acogida y la iniciativa demostrada por los profesionales para crear y proponer los Grupos de Trabajo, de acuerdo a parámetros de intraemprendimiento, que desbordan el marco institucional y nos remiten a la perspectiva transformadora de la educación popular, ya citada. Esta tendencia se vincula a un giro hacia la comunidad (el barrio) y hacia el éxito educativo (basado en evidencias), y permite ir erosionando los discursos sobre las bajas expectativas y el fracaso vinculado al origen familiar, cultural, económico del alumnado. Desde aquí nuestro agradecimiento al IMEFEZ por su apuesta en esta dirección, así como a las y los profesionales que han remado y seguirán remando hacia ese horizonte. 
Y, del lado contrario, se evidencia la presencia de resistencias al cambio, como en otros entornos profesionales vinculados a la exclusión social y educativa (Macías y Flecha, 2013). Estas dinámicas, instaladas en individuos, equipos educativos o entidades, nunca en todas al mismo tiempo, son alimentadas, durante esta fase del ciclo de privatización del Estado del Bienestar, por la perspectiva neoliberal, también citada anteriormente. Confiamos plenamente en la capacidad de seducción y deserción, propia de la Cultura de Paz, que educadoras y educadores de todos los centros han mostrado estos dos cursos académicos, como garantía de una reversión de estas tensiones hacia una perspectiva de mayor equidad social y educativa.

\section{NUESTRA CONTRIBUCIÓN A UNA POLÍTICA PÚBLICA Y LOCAL.}

Creemos, finalmente, que es necesario, en vista de esa tensión entre perspectivas transformadoras o legitimadoras de la desigualdad, mejorar el impacto de la investigación sobre la educación y los jóvenes. Más allá de la experiencia local observada, y como debatimos en la Conferencia Internacional final. Pues hasta ahora el espacio académico dedicado a quienes transitan los "itinerarios de ausencia de titulación básica", "los jóvenes sin acreditación de la Educación Secundaria Obligatoria, que se presentan al mercado de trabajo como candidatos a ocupar trabajos no cualificados y expuestos a la vulnerabilidad", los "itinerarios ocupacionales" o los "itinerarios de salida avanzada de la escolarización obligatoria” (Termes, 2012), ha tenido un bajo impacto transformador.

De hecho, predomina el enfoque de quienes asumen los resultados actuales en lo educativo (incidiendo en el fracaso, no en el éxito ni en el retorno a lo escolar) o en lo laboral (centrándose en las transiciones al empleo precario, dando por terminada la vía educativa). Por eso mismo, el Trabajo Social, como otras disciplinas de la intervención social (Gasch, 2014), ha resultado clave para complementar la investigación con compañeras de las Ciencias de la Educación, aportando su bagaje desde el enfoque preventivo, de promoción, de lo comunitario. 


\section{Bibliografía:}

Alberich, T. (2007). Contradicciones y evolución de movimientos sociales en España. Documentación social, 145: 183-210.

Carabaña, J. (2010). Tres medidas de eficacia segura contra el fracaso escolar. Participación educativa, 15, 142-150.

Choi, A. y Calero, J. (2013). Determinantes del riesgo de fracaso escolar en España en PISA-2009 y propuestas de reforma. Revista de educación, 362, 562-593.

Collet, J. y Tarabini, A. (2017). Otra oportunidad para aprender. Cuadernos de pedagogía, 478, 48-51.

Cutanda, M. T. (2014). De los Programas de Cualificación Profesional Inicial a la Formación Profesional Básica: algunas consideraciones. Revista educativa Hekademos, 16, 69-79.

Eurofound (2012). NEETs. Young people not in employment, education or training: Characteristics, costs and policy responses in Europe. Luxembourg: Publications Office of the European Union.

Fernández, D. (2011). El Trabajo Social en el Sistema educativo. Madrid: Consejo General del Trabajo Social.

Flecha, R. y Soler, M. (2013). Turning difficulties into possibilities: engaging Roma families and students in school through dialogic learning. Cambridge Journal of Education, 43 (4), 451-465.

García, M. et al. (2009). Las transiciones de los adolescentes después de la escuela obligatoria. Cambios sociales y respuestas socioeducativas en el territorio. Revista de Educación Social, 42, 47-60.

García, M, et al. (2013). Itinerarios de abandono escolar y transiciones tras la enseñanza secundaria obligatoria. Revista de Educación, 361, 65-94.

Gasch, B. (2006). Espacios educativos que ofrecen una alternativa al fracaso escolar. Gestión perversa de un modelo de aprendizaje. Educación social: Revista de intervención socioeducativa, 32, 61-78.

Gasch, B. (2014). El llindar. Escuela de oportunidades. Padres y Maestros, 356, $12-16$. 
Gastañaga, J.L. (2007). Trabajo social, familia y escuela. Cuadernos de Trabajo Social, 17, 255-271.

Girbés, S., Macías, F., \& Álvarez, P. (2015). De la Escuela Gueto a una Comunidad de Aprendizaje: Un Estudio de Caso sobre la Superación de la Pobreza a través de una Educación de Éxito. International and Multidisciplinary Journal of Social Sciences, 4(1), 88-116.

Goicoechea, M.A. (2004). Análisis de los valores de una organización de educación no formal: Pioneros. Tesis doctoral. Logroño: Universidad de La Rioja.

Gómez, C. et al (2004). Elaboración de un diseño de modelo de evaluación para la Red de Centros Sociolaborales del Ayuntamiento de Zaragoza. Zaragoza: Instituto Municipal de Empleo y Fomento Empresarial de Zaragoza.

INCLUD-ED (2011). Strategies for Inclusion and Social Cohesion in Europe from Education. Bruselas: European Commission.

Macías, F. y Flecha, R. (2013). Hacia una formación del profesorado para la igualdad del pueblo gitano. Revista de la Asociación de Enseñantes Gitanos, 30, 75-83.

Macías, F. y Redondo, G. (2012). Pueblo gitano, género y educación: investigar para excluir o investigar para transformar. RISE- International Journal of Sociology of Education, 1 (1), 71-92.

Madroño, B. (2014). Estudio sobre el cambio motivacional de los jóvenes en aulas taller. Trabajo de fin de Grado. Universidad de Zaragoza.

Merino, R. (2013). Las sucesivas reformas de la formación profesional en España o la paradoja entre integración y segregación escolar. Archivos Analíticos de Políticas Educativas, 21 (66).

Prados, M. et al. (2015). Comunidades de aprendizaje: ¿qué aportan a los voluntarios y voluntarias universitarios? Revista complutense de educación, 27(2), 551-570.

Rahona, M. y Morales, S. (2013). Diferencias en el rendimiento educativo de nativos e inmigrantes en España. Revista de la Asociación de Sociología de la Educación, Vol. 6 (1), 72-90.

Regalado, J.M. (2017). Salidas profesionales en Creación Digital con jóvenes en vulnerabilidad social. Madrid: Universidad Europea.

Roselló, E. (1998). Reflexiones sobre la intervención del trabajador social en el contexto educativo. Alternativas. Cuadernos de Trabajo Social, 6, 233-258. 
Sanz, M.E. (2007). El trabajador social en el ámbito educativo. Experiencia de intervención con menores en desventaja social desde la inclusión. Trabajo social hoy, No. Extra 1, 105-118.

Saura, G. (2016). Neoliberalismo como discurso: la evaluación en educación entre tecnologías políticas neoliberales y la nueva filantropía. Revista Educação, Sociedade \& Culturas, 47: 11-30.

Tejada, J. (2013). La formación de las competencias profesionales a través del aprendizaje servicio. Cultura y educación, 25(3), 285-294.

Termes, A. (2012). La recuperación académica en la FP: alcance y potencialidades, riesgos y límites. Revista de la Asociación de Sociología de la Educación, Vol. 5 (1), 58-74. 


\section{MEMORIA.}

\section{Marisa Alcaraz (trabajadora social, Universidad de Zaragoza)}

\section{AÑO 2015-2016.}

El proyecto "Innovación y éxito educativo en los Centros Sociolaborales", \#innovaCSL, surge de la propuesta realizada por los profesores Chabier Gimeno y Cecilia Serrano, ambos miembros del Grupo de Estudios sobre la Sociedad del Riesgo, del Departamento de Psicología y Sociología de la Universidad de Zaragoza. Partiendo de las conclusiones alcanzadas en una colaboración previa con el Ayuntamiento de Zaragoza, y desarrolladas por la alumna del Grado de Trabajo Social, Beatriz Madroño, en 2014.

El 30 de Noviembre de 2015, se presenta el proyecto "Innovación y éxito eduativo en los Centros Sociolaborales" a Arantza Gracia Moreno, Concejala de Educación e Inclusión.

\section{Imagen 1.Propuesta de actuación}

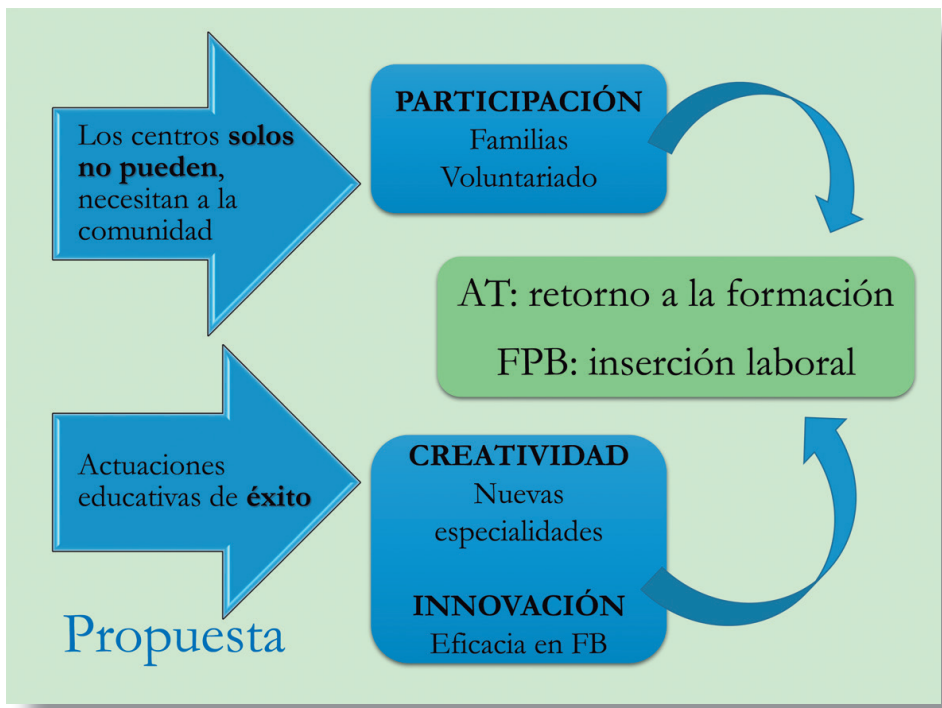


El objetivo del proyecto es implementar mejoras en la inclusión social, educativa y laboral de los jóvenes que participan en estos centros. En 2016 se ponen en marcha las primeras actuaciones y comienza la formación de profesionales.

\section{PUESTA EN MARCHA DEL PROYECTO.}

1. Se crea un Equipo Motor: integrado por los investigadores de la Universidad de Zaragoza, un técnico del Ayuntamiento de Zaragoza y un representante de cada una de las cinco entidades sociales gestoras (la Fundación Picarral, la Asociación Taller Educativo Laboral de Casetas (TELCA), la Fundación Adunare, la Fundación $\mathrm{M}^{\mathrm{a}}$ Auxiliadora y la Fundación San Valero).

2. Primera reunión Técnica de Entidades Gestoras (13 de Julio de 2016). Cada centro realiza una presentación acerca de la experiencia exitosa con: inserción laboral, escolar, trabajo con familias y con la comunidad.

3. Presentación del proyecto de innovación a las y los profesionales: el 24 de octubre de 2016 se les presentó y se debatió la investigación en una sesión grupal, con la presentación del Trabajo Fin de Grado de la alumna de la Universidad de Zaragoza, Beatriz Madroño.

\section{FORMACIÓN DE PROFESIONALES.}

Primeras Jornadas "Herramientas para la innovación y el éxito educativo", en el Centro Ibercaja Actur, 30 de noviembre y 1 de diciembre de 2016. Con la participación en la inauguración de representantes de la Obra Social de Ibercaja, la Dirección General de Innovación Educativa, Equidad y Participación (Gobierno de Aragón) y Dña. Arantza Gracia, concejala de Educación e Inclusión del Ayuntamiento de Zaragoza.

La conferencia inaugural "Aplicación de Actuaciones Educativas de Éxito en Aragón: organización del aula, participación de familias y de voluntariado" fue impartida por la catedrática en sociología Carmen Elboj (Universidad de Zaragoza). La conferencia plenaria "Grupos interactivos: Organización y Metodología en el Aula", fue a cargo de la profesora Henar Rodríguez (Universidad de Valladolid). A continuación hubo una presentación de Buenas prácticas en los Centros Sociolaborales. 
Imagen 2. Presentación de buenas prácticas.

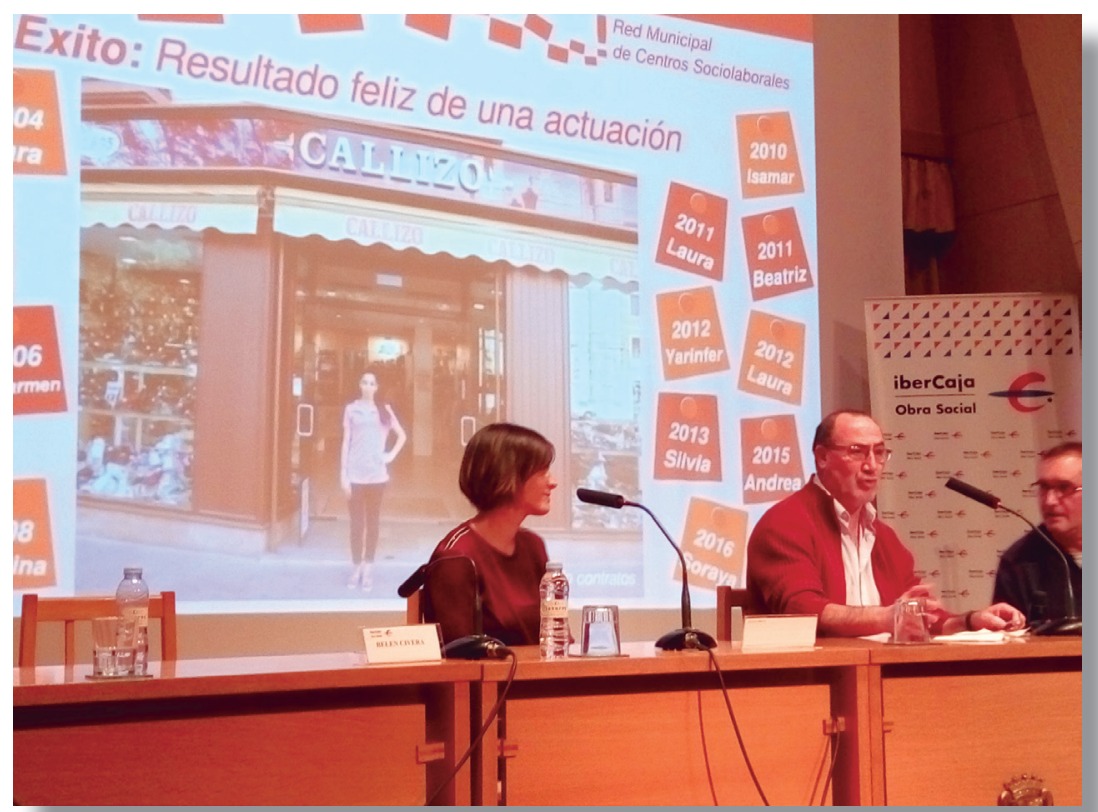

El segundo día, se realizaron cuatro talleres, impartidos por:

1. La Fundación Pioneros (Logroño):

a. Aprendizaje y Servicio.

b. Las familias, un imprescindible en nuestro centro.

2. Y Fernando Macías (CREA-Universitat de Barcelona):

a. Participación decisiva y educación del pueblo gitano.

b. Hacia una formación del profesorado para la igualdad del Pueblo Gitano. 
Imagen 3. Talleres con la Fundación Pioneros.

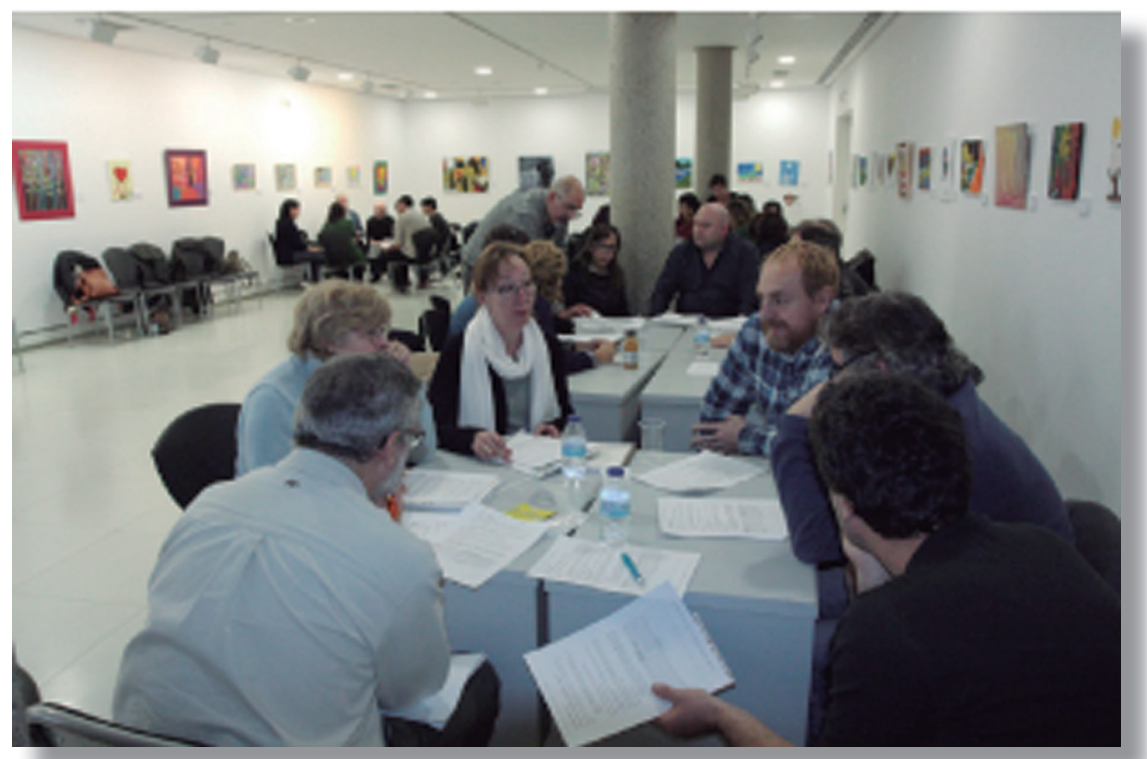




\section{AÑO 2017}

El 27 de Enero de 2017. se firma un acuerdo para desarrollar el proyecto, entre la Universidad de Zaragoza y el Ayuntamiento de Zaragoza. En él participan también las entidades sociales que gestionan los Centros Sociolaborales: La Fundación Picarral, la Asociación Taller Educativo Laboral de Casetas (TELCA), la Fundación Adunare, la Fundación $\mathrm{M}^{\mathrm{a}}$ Auxiliadora y la Fundación San Valero.

Imagen 4. Firma de acuerdo de colaboración.

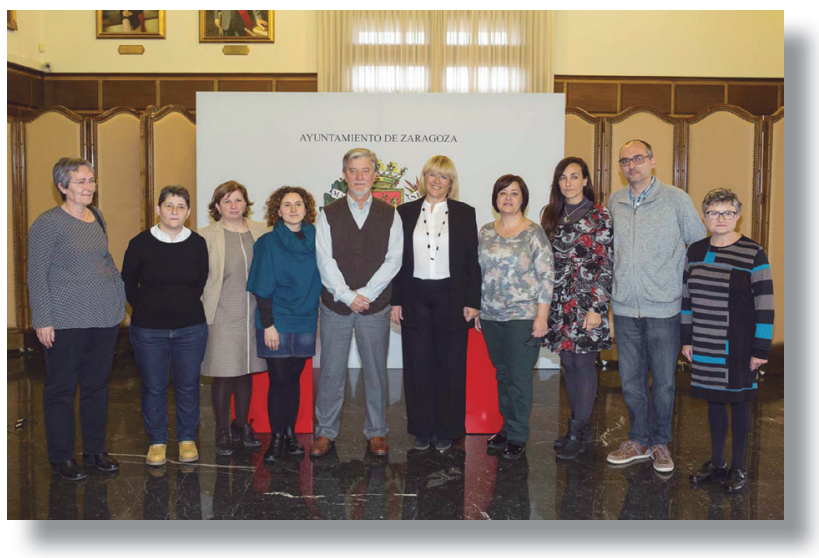

En febrero de 2017 se pusieron en marcha los grupos de trabajo y se realizaron varias actividades de investigación y formación con los Centros.

1. GRUPOS DE TRABAJO DE PROFESORADO: con 44 participantes, acompañamiento del equipo investigador y una reunión mensual entre febrero y junio:
a. Intervención con familias.
b. Diversidad.
c. Metodología en el aula.
d. Aprendizaje y Servicio (APS).
e. Aula Taller. 
Imagen 5. Presentación de los grupos de trabajo (febrero 2017).

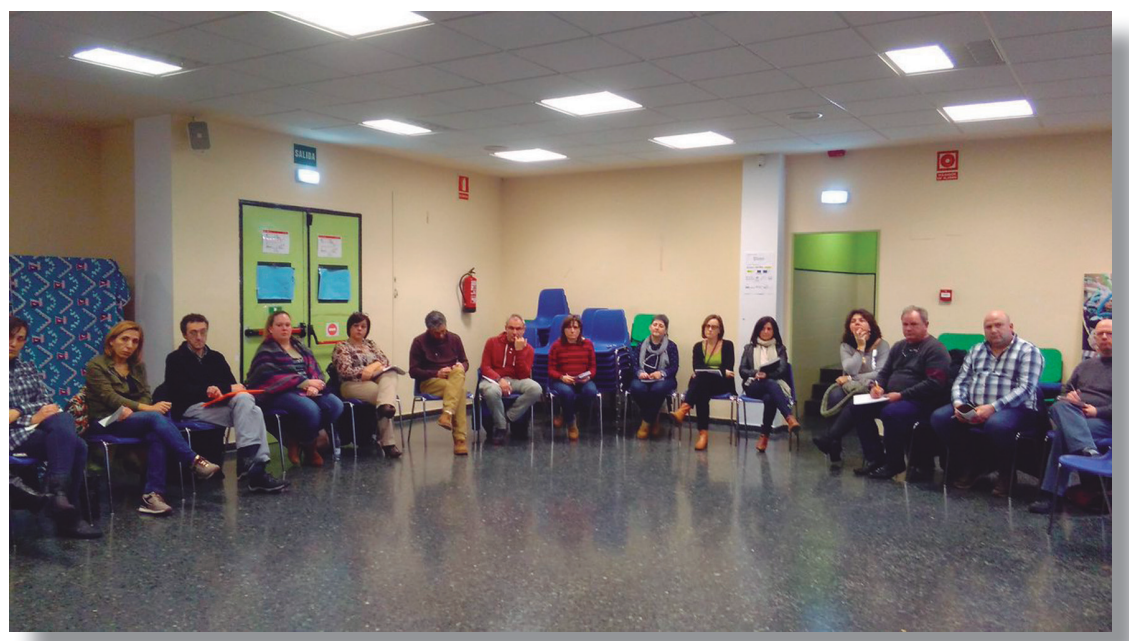

Imagen 6. Reunión del Grupo de Trabajo de Metodología.

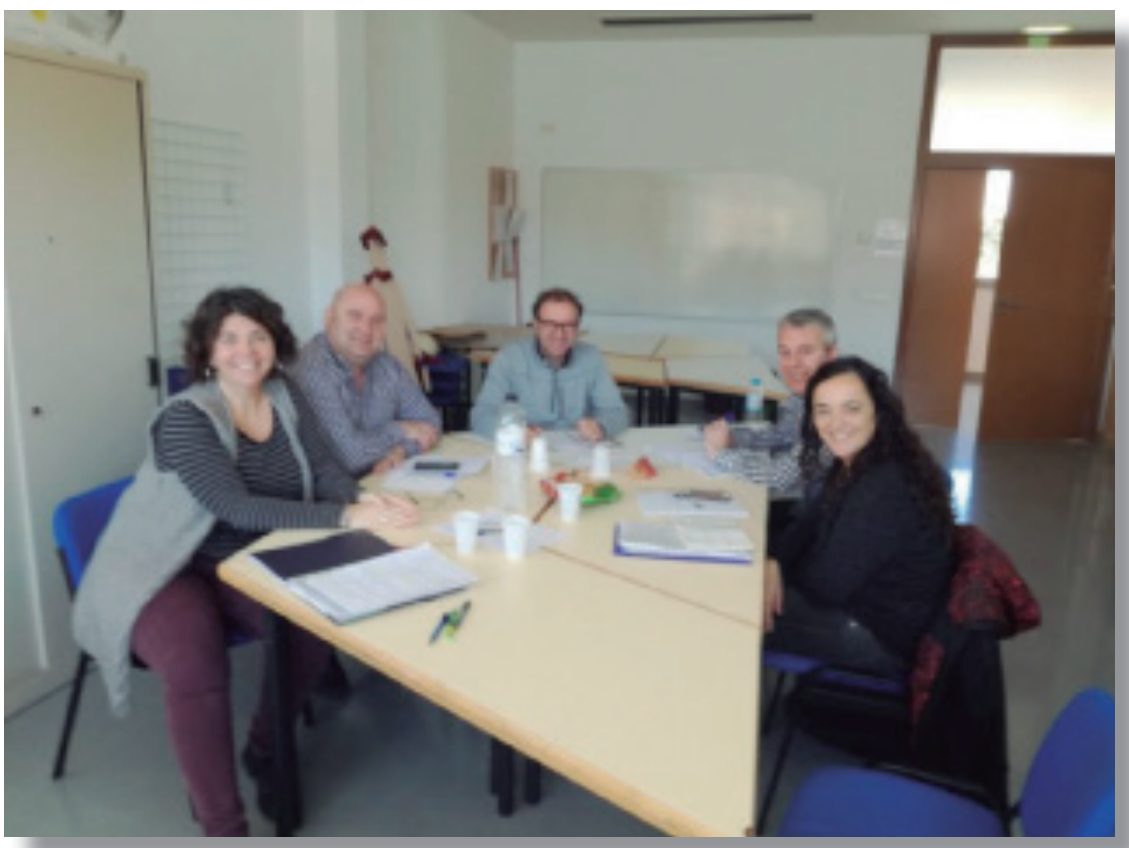




\section{INVESTIGACIÓN CUALITATIVA:}

a. Observación participante (en CSL Delicias, Valdefierro, Actur y Casco Viejo): acompañamiento en el aula de formación básica y en el taller profesional, con mayores y menores de 16 años.

b. Entrevistas a familiares del alumnado: en CSL de Picarral, Delicias y Almozara.

c. Grupo focal sobre "Intervención con familias y su participación en los Centros Sociolaborales": con profesionales de cuatro centros.

d. Investigación con alumnado del Grado de Trabajo Social (Universidad de Zaragoza): Trabajo fin de Grado "Estudio sobre el contexto familiar del alumnado de los Centros Sociolaborales".

3. VISITA AL CEIP RAMIRO SOLANS (MAYO 2017): modelo de centro orientado al éxito educativo.

Imagen 7. Visita a colegio con proyecto de innovación de centro.

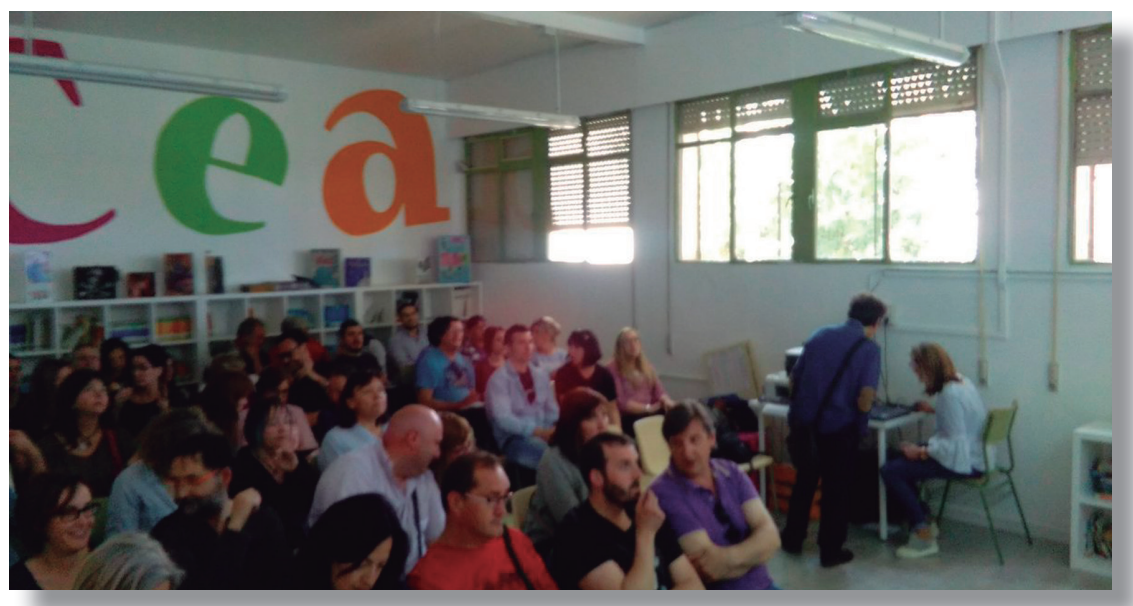

\section{SEGUNDAS JORNADAS "HERRAMIENTAS PARA LA INNOVACIÓN Y EL ÉXITO EDUCATIVO” (29 Y 30 DE JUNIO DE 2017), EN EL CENTRO SAN VALERO.}

a. Conferencia inaugural: "La Tecnología como herramienta educativa con jóvenes en riesgo de exclusión”, José María Regalado (inmersiontic.es). 
b. Presentación de resultados de los Grupos de Trabajo.

c. Talleres Formativos

1. APRENDIZAJE Y SERVICIO: Pilar Arranz (Universidad de Zaragoza) y Fundación Pioneros (Logroño).

2. EDUCANDO EN LA DIVERSIDAD: Alfonso Troya (Rioja Acoge) y Grupo de Trabajo sobre Educación y pueblo Gitano'.

3. APRENDIZAJE BASADO EN PROBLEMAS: Javier Blasco (Universidad de Zaragoza).

4. LA FAMILIA EN EL PROCESO EDUCATIVO DE ÉXITO: Ángel Estalayo (Instituto de Reintegración Social de Euskadi).

Imagen 8. Segundas jornadas.

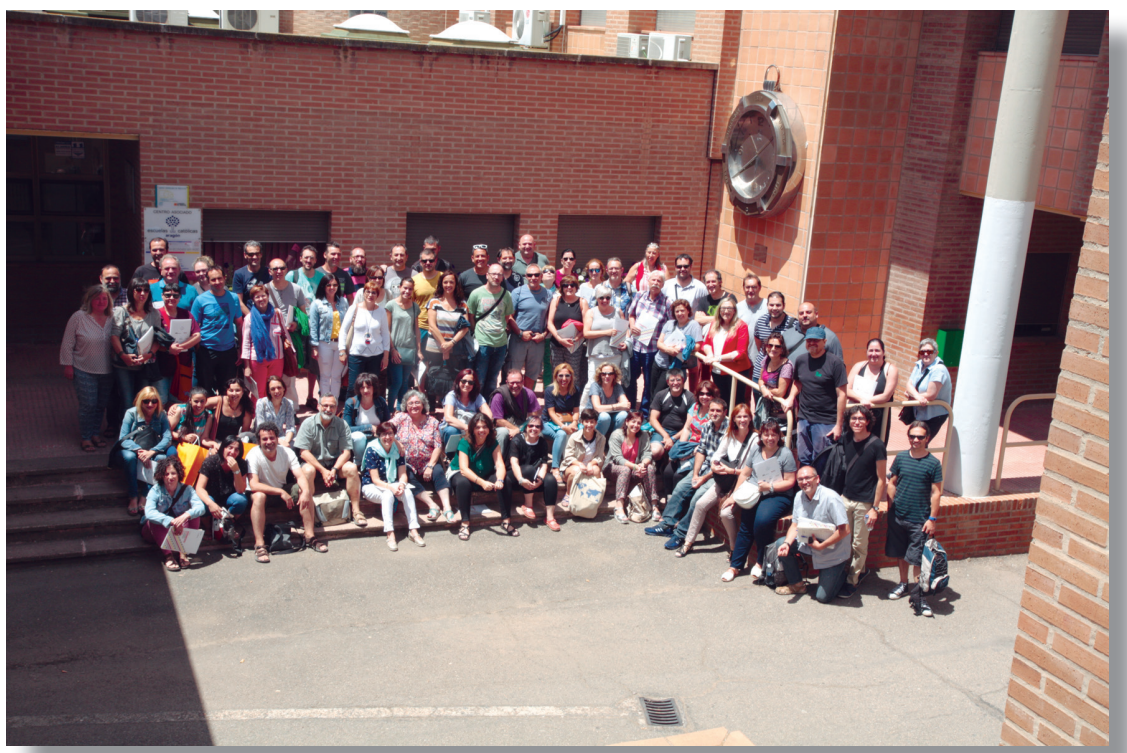

1 Carmen Jiménez (educadora del Ayuntamiento de Zaragoza), Carmelo Giménez (mediador), Tamara Clavería (licenciada en Educación y trabajadora de la Fundación Secretariado Gitano) y José Antonio Jiménez (Graduado en Trabajo Social y CNP). 


\section{AÑO 2018}

Desde septiembre de 2017, la investigación ha cerrado su periodo de diagnóstico participado, trabajando en:

a. Análisis de los datos del curso anterior.

b. Redacción participativa de propuestas de innovación

c. Y puesta en marcha de primeras acciones de innovación.

El equipo responsable de analizar la información recogida y elaborar las propuestas finales ha estado compuesto, en esta segunda fase del proyecto, por profesorado de la Universidad de Zaragoza, de las Facultades de Ciencias Sociales y del Trabajo y de Educación: Chabier Gimeno (investigador principal), Ana Cristina Blasco, Belén Dieste, Daniel García y Cecilia Serrano (Universidad de la Rioja), colaboradora del proyecto.

El equipo ha sido responsable de apoyar y orientar el proyecto de innovación, incorporando producción científica que permita su difusión académica y valorización, mediante:

a. Artículos en revistas.

b. Comunicaciones en congresos.

c. Informe final.

d. Publicación final de transferencia.

e. Actividades de difusión: jornadas, etc.

Los grupos de trabajo formados en febrero y ampliados en octubre de 2017, se complementaron con consultores profesionales, buscando objetivos operativos.

a. Intervención con familias.

b. Diversidad.

c. Metodología en el aula.

d. Aprendizaje y Servicio (APS).

e. Empleabilidad, nuevo grupo incorporado en esta fase. 


\section{GRUPOS DE TRABAJO}

\section{INTERVENCIÓN CON FAMILIAS:}

Este grupo, acompañado por Luis Vilas (sociólogo, Universidad de Zaragoza), terminó su reflexión sobre cómo establecer hitos periódicos y espacios permeables que permitan un acercamiento progresivo de las familias a los Centros (Asociación de Madres y Padres de alumn@s, jornadas de puertas abiertas, etc). Estos deben ofrecerles progresivamente oportunidades de participación viable, integrando, en mayor medida, a las familias en el funcionamiento de los Proyectos y de los Programas.

También ha reflexionado sobre las estrategias para potenciar la Red Municipal como elemento integrador de las familias, independientemente del Centro Sociolaboral en el que esté matriculado el joven.

Imagen 9. Reunión del Grupo de Trabajo de Familias.

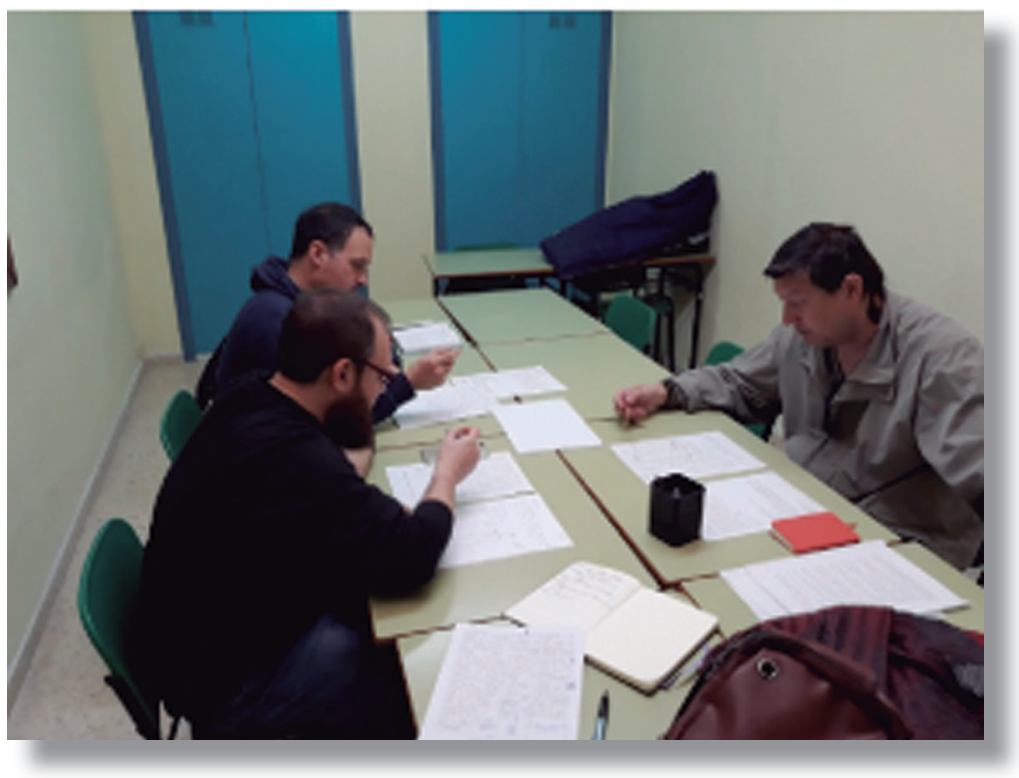




\section{DIVERSIDAD.}

Durante el curso 2017-2018 el Grupo de Trabajo abordó las necesidades detectadas a partir de dos tipos de acciones:

a. Formación para profesionales.

b. Y mediación con alumnado gitano: elaborando un diagnóstico específico y redactando un proyecto de intervención.

En cuanto a las acciones formativas, se impartieron tres sesiones de formación:

a. Introducción a las competencias profesionales interculturales, impartida por Chabier Gimeno (Universidad de Zaragoza), con la colaboración de Joaquín Moso (profesor jubilado de Educación Secundaria y voluntario).

b. Introducción a la mediación con alumnado de origen magrebí y subsahariano, impartida por dos mediadoras del CAREI (Consejería de Educación, Gobierno de Aragón).

c. Y estrategias para atender la diversidad funcional, impartida por Luis Vilas (Universidad de Zaragoza).

De cara a diagnosticar las necesidades y fortalezas de la Red, en cuanto al Pueblo Gitano, se contó con la colaboración de las profesionales participantes en el Grupo de Trabajo, así como voluntariado y alumnado en prácticas extracurriculares de los Grados de Educación y Trabajo Social (Universidad de Zaragoza). Entre todas, se ha diseñado un protocolo de acogida a familiares y alumnado gitano.

Imagen 10. Reunión del Grupo de Trabajo de Diversidad.

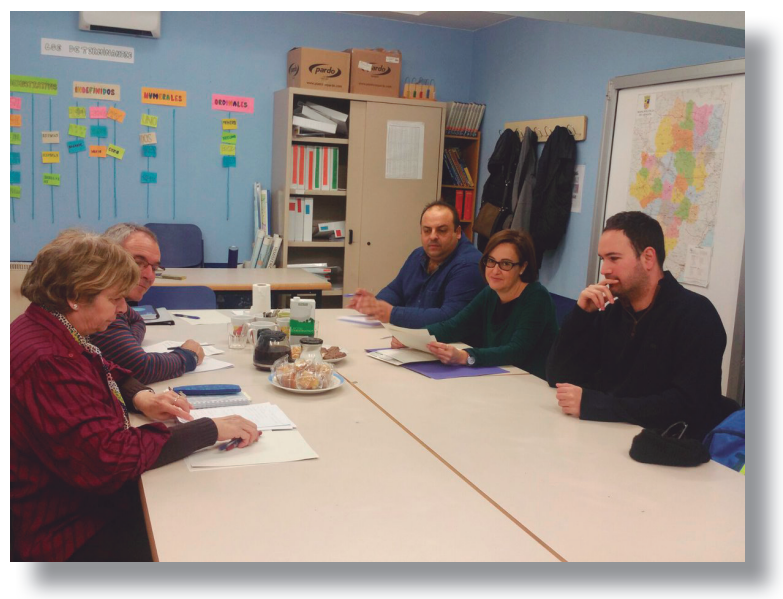


Por otra parte, a partir de su participación en las segundas jornadas, se ha constituido formalmente Campus Rom Aragón, como delegación de esta asociación catalana.

Imagen 11. Presentación de Campus Rom Aragón a familias y alumando de primaria.

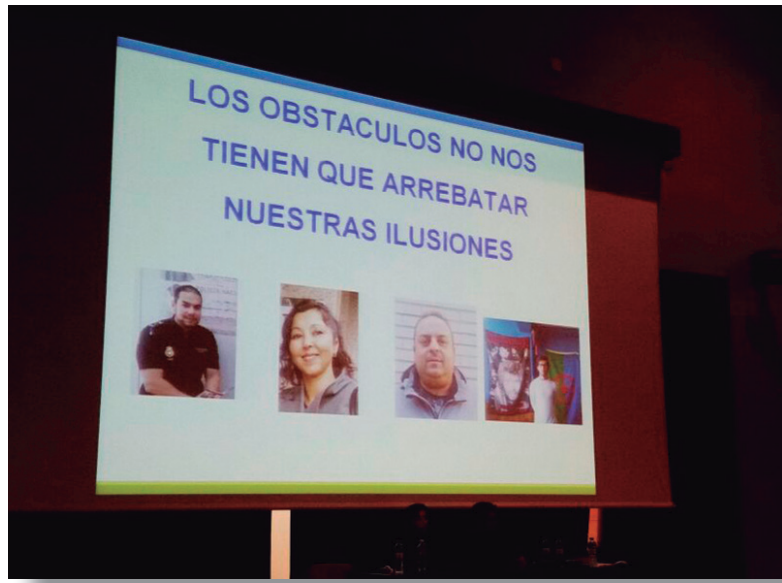

\section{METODOLOGÍA EN EL AULA:}

Se ha trabajado para poner en marcha un programa de formación continua sobre actuaciones educativas de éxito. Creando una vinculación entre la RED con los dispositivos de formación del Gobierno de Aragón y con la puesta en marcha de experiencias piloto de trabajo en el aula con grupos heterogéneos.

Entre estas acciones, destacamos:

a. Una sesión de formación sobre Aprendizaje Basado en Proyectos, con profesorado del proyecto Tod@s somos profes, del IES Río Gállego: sobre su experiencia en Formación Profesional Básica.

b. Reunión con la dirección técnica del Centro de Innovación para la Formación Profesional de Aragón (CIFPA).

c. Participación en formación sobre APS en FP, en el CIFPA.

d. Y experiencias piloto sobre grupos interactivos (CSL La Jota) y ABP (CSL Valdefierro). 
Cabe destacar finalmente, la conclusión a la que llegan los educadores que exponen su experiencia. En los CSL se puede trabajar con el alumnado de la misma manera que se puede en los institutos, con metodologías activas e innovadoras.

Imagen 12. Grupo de Trabajo de metodología, en las terceras jornadas.

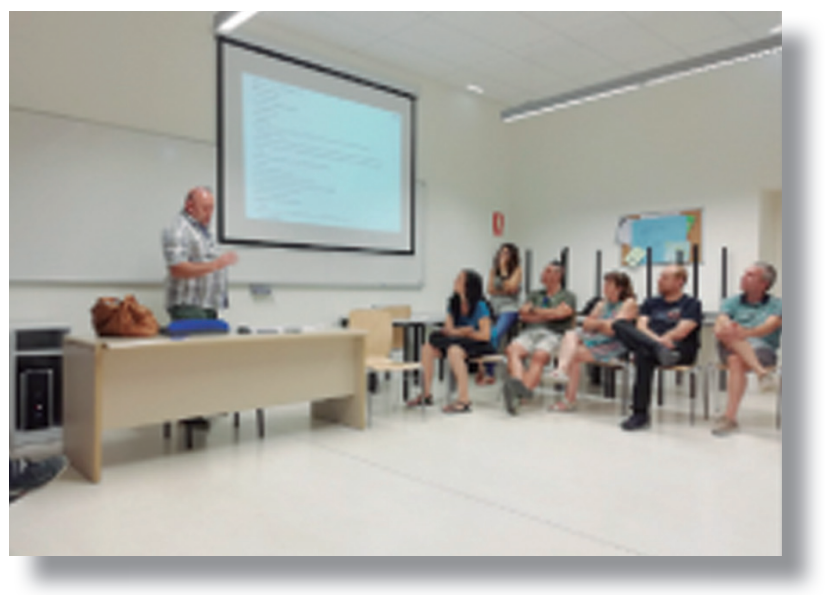

\section{APRENDIZAJE Y SERVICIO.}

Las profesoras Ana Cristina Blasco y Belén Dieste, de la facultad de Educación, han coordinado el Grupo de Trabajo de Aprendizaje y Servicio (ApS). Preparando con las profesionales proyectos de colaboración con el entorno de los CSL. Y ofrecen, además, posibilidades para que el alumnado de la Universidad de Zaragoza realice actividades para y con los CSL, creando una experiencia entre los alumnados de ambos centros. Entre otras actividades en esa línea, destacamos:

a. Materiales y Recursos en Educación Infantil

Alumnado del $2^{\circ}$ curso del Grado de Educación Infantil y los alumnos de los CSL (Programas de Cualificación Inicial de Carpintería, Soldadura y de Aulas Taller), realizaron materiales educativos para Colegios Públicos de Educación Infantil y Primaria. A partir de las necesidades detectadas en aulas de Educación Infantil, alumnado universitario y de CSL se encargaron 
del diseño, fabricación y decoración de estos materiales. En su mayoría se realizaron mesas de luz, juegos de madera y materiales de decoración.

Imagen 13. Elaboración de recursos materiales

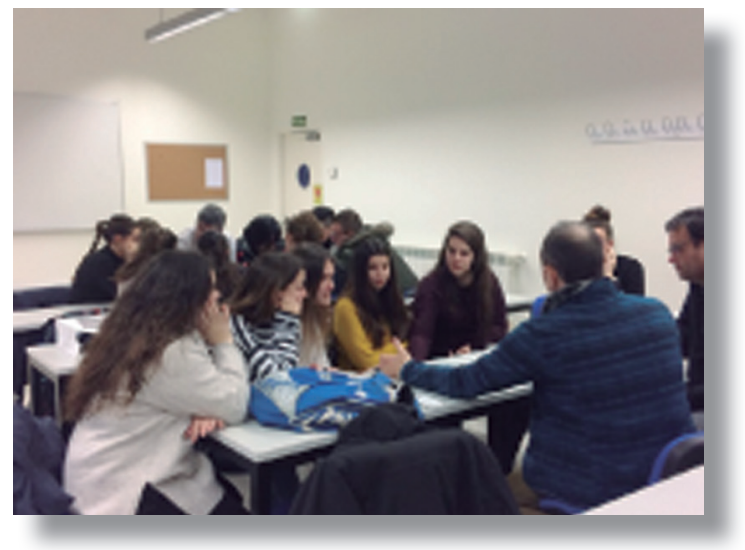

b. Reportajes Gráficos de promoción y difusión de los Centros Sociolaborales La profesora Elena Bandrés, de la Facultad de Periodismo, realizó pequeños reportajes sobre los centros, tratando temas como la diversidad cultural del alumnado, innovación de metodología en el aula, aprendizaje y servicio, etc.

Imagen 14. Alumnado de CSL y universidad preparando un reportaje.

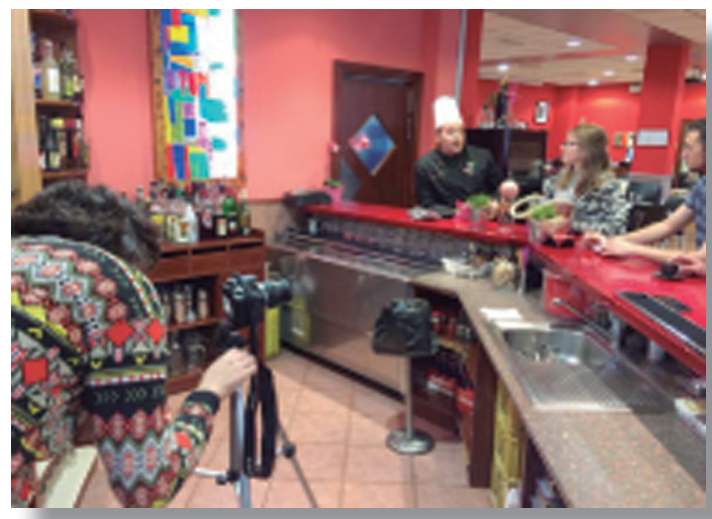




\section{EMPLEABILIDAD.}

Este grupo de trabajo continuó reflexionando sobre un "Modelo de prácticas de la Red de Centros Sociolaborales de Zaragoza", con el consultor José María Regalado (trabajador social). Entre otras líneas de actuación, se continuó valorando cómo identificar empresas que quieran desarrollar con ciertas especialidades proyectos más amplios que la propia FCT (prácticas).

También se ha trabajado hacia la puesta en marcha de una estrategia de vinculación de la Red Municipal con el tejido técnico y empresarial del territorio. Y sobre una propuesta de prospección de nuevas especialidades.

Imagen 15. Grupo de empleabilidad en las terceras jornadas.

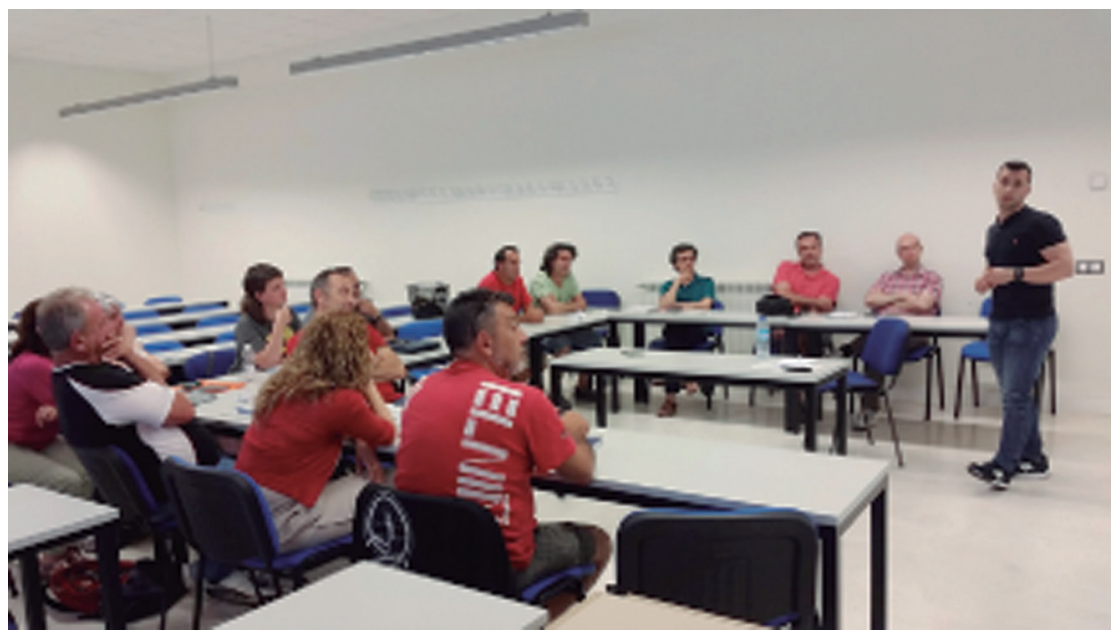

\section{PRACTICUM DE INVESTIGACIÓN}

Con el fin de ofrecer a la Red Municipal propuestas de innovación, se realizaron dos investigaciones por parte de profesorado y alumnos de la Facultad de Ciencias Sociales y del Trabajo:

a. "La mentoría social en la Red Municipal de Centros Sociolaborales del Ayuntamiento de Zaragoza". Dirigido por Jose Antonio Guallar (área de Psicología Básica) junto con su alumnado, analizó cómo se puede introducir en próximos cursos un programa de mentoría en la red municipal de Centros Sociolaborales. 
b. "Análisis de las percepciones del alumnado en la Red Municipal de Centros Sociolaborales: evolución educativa y personal". La investigación fue dirigida por Ana Cristina Tesán (área de Psicología Social) que, junto con sus alumnos, identificó los aspectos en los que el alumnado siente que les ha beneficiado su paso por el Centro Sociolaboral. No sólo se ha evaluado los conocimientos adquiridos y su utilidad para el futuro, sino también la incidencia que este programa ha tenido en su evolución personal.

\section{COMUNICACIÓN}

Con la colaboración de Valentín García (@gafolito), experto en comunicación de entidades y proyectos sociales, se quiso situar la Red Municipal en el plano local y estatal de la formación para el empleo que apuesta por la innovación y por las actuaciones educativas de éxito.

Las herramientas utilizadas para la difusión, han sido:

a. Blog: para difundir el trabajo de los diferentes grupos de trabajo del proyecto, con la subida de un post resumen al mes contando los avances realizados y cada dos meses contando experiencias de los participantes.

b. Canal de Twitter@innovaCSL: se cuentan y comparten noticias, tanto del proyecto, como de otros afines. Se ha dado cobertura a jornadas y reuniones, así como, el seguimiento de cuentas relacionadas con la línea de trabajo del proyecto.

c. Y el canal de Youtube, con videos producidos como ApS.

\section{TERCERAS JORNADAS.}

Se llevaron a cabo el 25 de junio de 2018, en la Facultad de Educación de la Universidad de Zaragoza, dónde se presentó todo el trabajo realizado en el proyecto \#innovaCSL durante el curso 2017-2018.

Comenzamos con la presentación de Alejandra Cortés Pascual (Vicedecana de Innovación, Investigación y Comunicación de la Facultad de Educación) y Ma José Marco Bes (Gerente del Instituto Municipal de Empleo).

Se presentaron los resultados de los dos Practicum de Investigación del Grado de Trabajo Social. 
Imagen 16. Presentación de Practicum de Investigación.

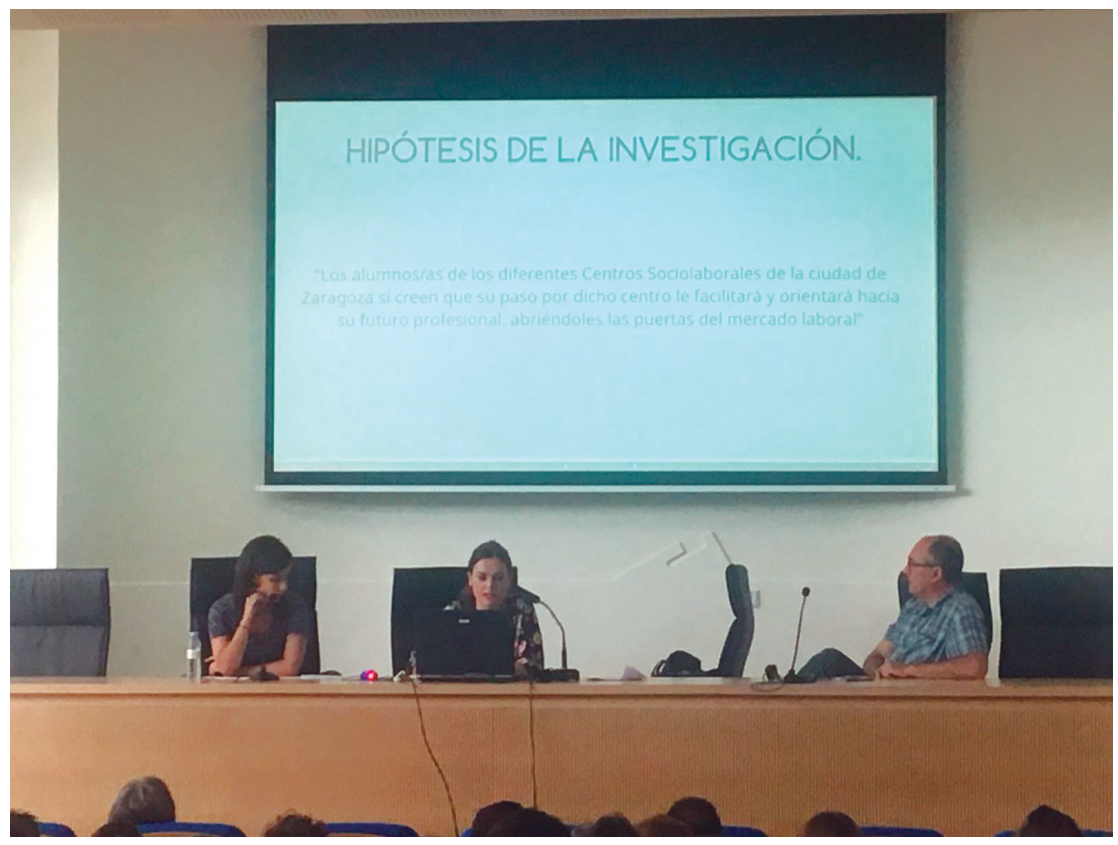

Como final de esta introducción a la jornada, presentamos brevemente algunos resultados obtenidos a nivel general del proyecto, compartiendo los diferentes puntos de éxito que ya se pueden visibilizar..

Al final de estas presentaciones se incorporó a la jornada la profesora Pilar Arranz, Directora del Secretariado de Proyección Social e Igualdad y del Observatorio de la Igualdad de la Universidad de Zaragoza. Y que ha colaborado con el proyecto a través de varias experiencias de Aprendizaje Servicio con la Facultad de Educación. Después de ponernos en contexto, pasamos a los talleres por grupos de trabajo. 
Imagen 17. Grupo de Trabajo de Metodología en las terceras jornadas.

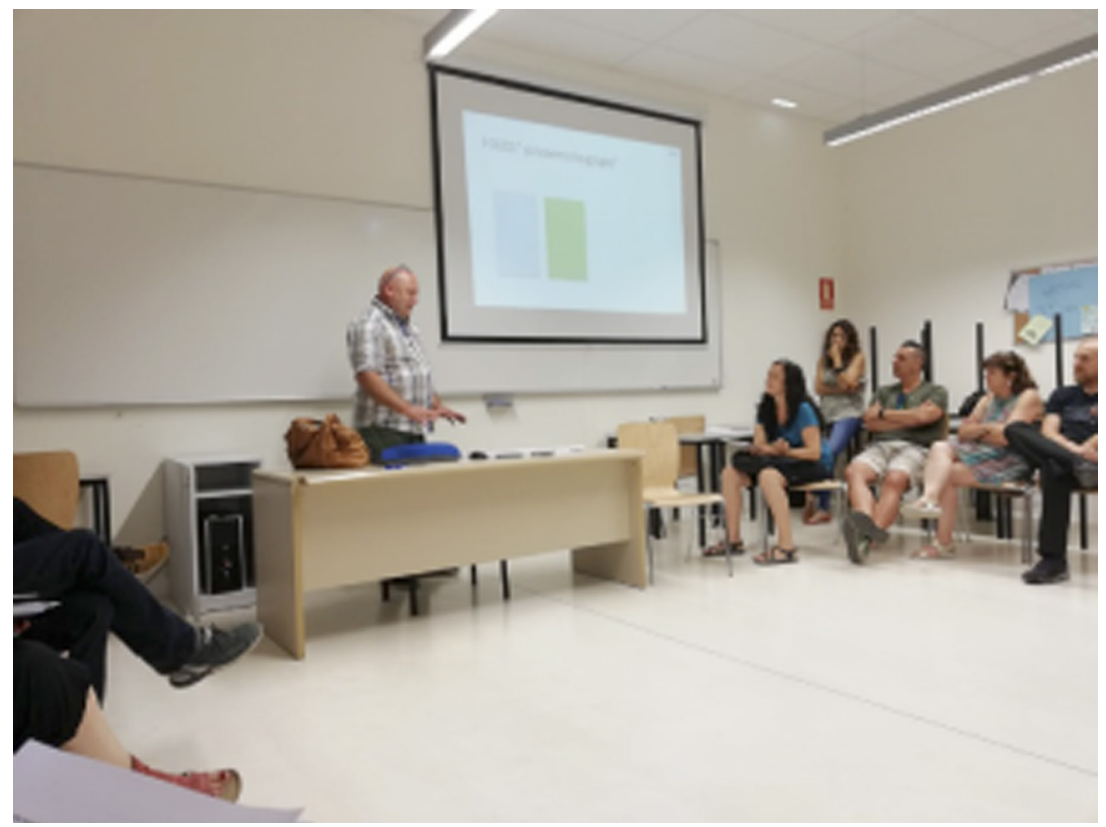

Cada uno de ellos llevó a cabo durante cuatro horas la devolución de lo trabajado y también se amplió la reflexión con educadoras y educadores que no han podido estar presentes en sesiones anteriores. Hubo debate y propuestas que se pueden transferir en el funcionamiento educativo de los Centros Sociolaborales en próximos cursos.

\section{CONFERENCIA INTERNACIONAL}

En diciembre de 2018 se desarrolló la Conferencia Internacional "EDUCACIÓN, INCLUSIÓN Y TERRITORIO. POLÍTICAS PÚBLICAS FRENTE A LA EXCLUSIÓN EDUCATIVA". Organizada por el equipo científico del proyecto, por Zaragoza Dinámica y con la colaboración del Secretariado de Proyección Social e Igualdad de la Universidad de Zaragoza, así como su Vicerrectorado de Política Científica.

Entre los participantes, se anunciaron ponencias de Juan Manuel Escudero Muñoz, Catedrático de Didáctica y Organización Escolar en la Universidad de Murcia; 
Alejandro Tiana Ferrer, Catedrático de Teoría e Historia de la Educación en la UNED y Secretario de Estado de Educación y Formación Profesional en el Ministerio de Educación y Formación Profesional; Tamara Díaz Fouz, Secretaria Técnica del Instituto de Evaluación y Seguimiento de las Metas Educativas (IESME), en la Organización de Estados Iberoamericanos para la Educación la Ciencia y la Cultura (OEI); Aina Tarabini-Castellani Clemente, profesora del Departamento de Sociología en la Universitat Autónoma de Barcelona y Xavier Besalú i Costa, profesor del Departamento de Pedagogía en la Universitat de Girona.

En la segunda parte de la Conferencia, hubo un seminario sobre "Empleabilidad, formación y territorio: claves para la inclusión”, con dos mesas:

a. Mesa de experiencias: ¿hacia dónde vamos? Transferencia de proyectos y acciones orientadas a la mejora de la empleabilidad juvenil y la innovación educativa. Con Fundación Orange y Fundación Telefónica.

b. Mesa de actores locales: Empleabilidad juvenil en Aragón, alianzas y responsabilidad social, con Confederación de Empresarios de Zaragoza, Zaragoza Dinámica, Servicio de Formación Profesional y Enseñanzas de Régimen Especial y la Dirección Provincial del INAEM.

Terminando la jornada con una presentación de resultados del Proyecto de Innovación y éxito educativo en la Red Municipal de Centros Sociolaborales del Ayuntamiento de Zaragoza. 


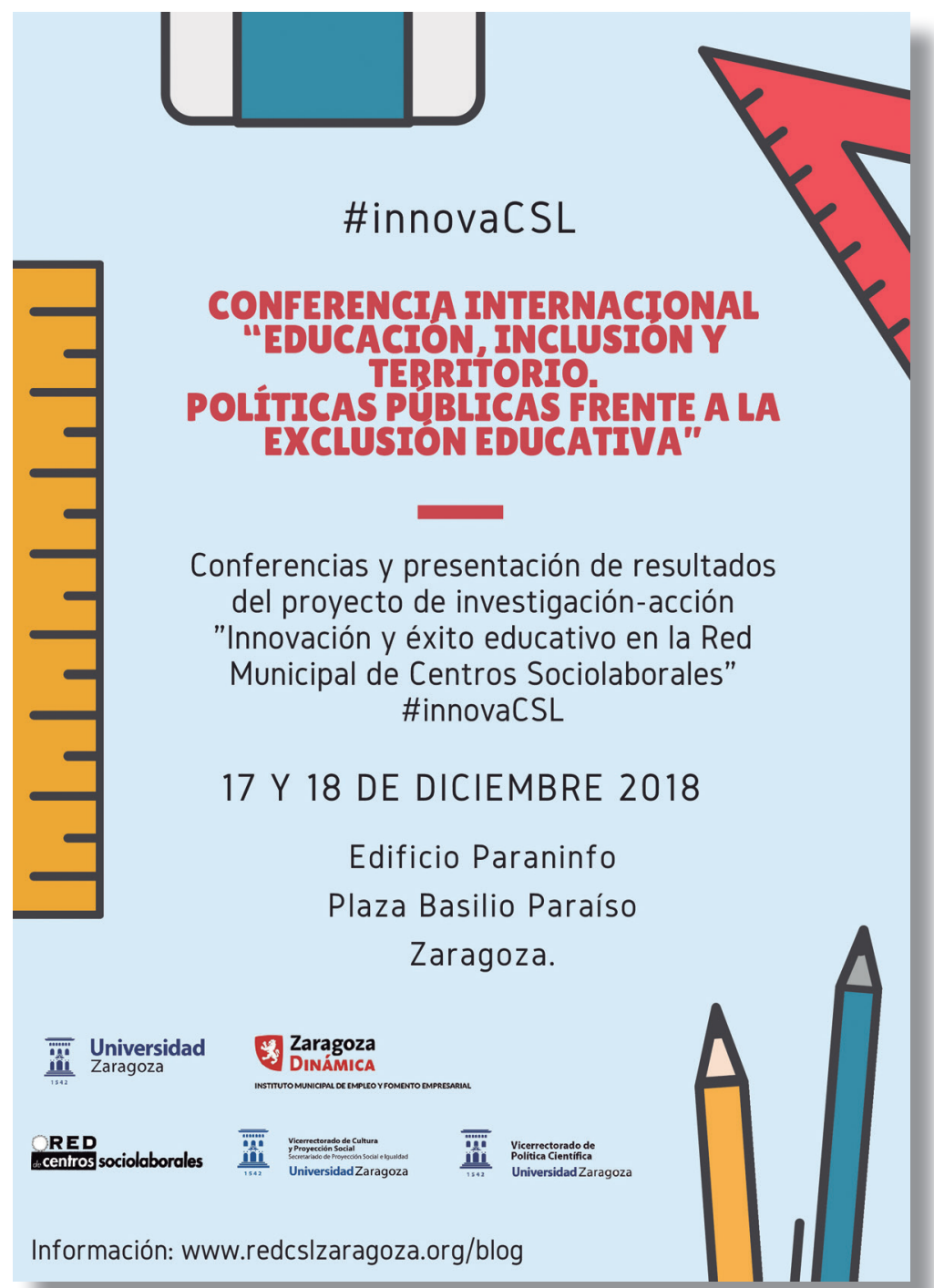




\title{
LA APORTACIÓN DE LA RED MUNICIPAL DE CENTROS SOCIOLABORALES AL EJERCICIO DEL DERECHO A LA EDUCACIÓN. POLÍTICAS EDUCATIVAS Y FORMATIVAS DESDE UNA PERSPECTIVA LOCAL.
}

\author{
Daniel García Goncet ${ }^{1}$ \\ ${ }^{1}$ Departamento de Ciencias de la Educación. Universidad de Zaragoza.
}

\section{EL DERECHO A LA EDUCACIÓN.}

El 10 de diciembre de 1948 la Asamblea General de las Naciones Unidas aprobó, a través de la Resolución № 217 A (III), la Declaración Universal de los Derechos Humanos. Con dicha proclamación, la relación entre los Estados y su ciudadanía sufría una transformación transcendental a la luz de la consideración de los derechos humanos como inalienables. Según esto, nadie puede desposeer a una persona de sus derechos, pues son inherentes a la propia condición de persona; al tiempo que son universales, es decir, independientes de cualquier atributo con el que cuente cada persona concreta (nacionalidad, credo, lengua, capacidad...); e inviolables, haciendo que cualquier amenaza, ataque y/o vulneración de los mismos constituya un acto injusto que, llegado el caso, puede ser penado por la ley. Entre esos derechos, el artículo 26 de la Declaración consagra el derecho a la educación.

Esta transformación de la definición del derecho a la educación como derecho humano fundamental conlleva la instauración de un tipo de relación específica que se ha de establecer entre el Estado y la persona. Dicha relación ha de ser la propia entre un sujeto de derechos (la persona) y un garante de derechos (el Estado), donde la primera tiene unos derechos a respectar, proteger y garantizar por parte del segundo. Desde la proclamación de esta legislación internacional -de obligado cumplimiento para los Estados-, se ha reforzado el consenso existente en torno a la conceptualización del derecho a la educación como un derecho humano fundamental e irrenunciable, extendiéndose ampliamente el acceso a los sistemas educativos. 
En Europa el acceso a la educación para toda la ciudadanía tuvo lugar en un contexto de expansión de los estados de bienestar europeos que trataban de reconstruirse después de los estragos de la Segunda Guerra Mundial. Esta expansión educativa ha sido calificada como uno de los mayores cambios sociales que se han producido en el viejo continente durante la segunda mitad del siglo XX (Planas, 2004). El acceso universal a la educación iba acompañado de la gran promesa de un nuevo modelo de sociedad democrática e igualitaria (Judt, 2010). Junto a ello, se ha extendido ampliamente la consideración del acceso a la educación como valor en sí mismo. Cuestión esta última no menor, pues el derecho a la educación se ha configurado como condición de posibilidad para el pleno ejercicio de otros derechos de ciudadanía. De este modo, el ejercicio de los derechos civiles y políticos (como el disfrute de la libertad de expresión o la participación activa en la vida política y social), son posibles - al menos, en buena medida- gracias a los recursos a los cuales una persona accede a través de la educación. Como manifiesta el Comité de Derechos Económicos, Sociales y Culturales de Naciones Unidas en su Observación General n¹1:

"El derecho a la educación, reconocido en los artículos 13 y 14 del Pacto [Internacional de los Derechos Económicos, Sociales y Culturales -PIDESC], así como en otros tratados internacionales (...) es de vital importancia. Se ha clasificado de distinta manera como derecho económico, derecho social y derecho cultural. Es todos esos derechos al mismo tiempo. También, de muchas formas, es un derecho civil y un derecho político, ya que se sitúa en el centro de la realización plena y eficaz de esos derechos. A este respecto, el derecho a la educación es el epítome de la indivisibilidad y la interdependencia de todos los derechos humanos".

Sin embargo, la mera facilitación del acceso a los sistemas educativos no ha conseguido que toda la población se beneficie de su paso por ellos. Así, los sistemas de educación en todo el mundo se encuentran con el reto de alcanzar la equidad. En algunos países, este reto implica conseguir que toda su población esté alfabetizada, mientras que en otros países el reto supone hacer frente al hecho de que "muchos jóvenes dejan la escuela sin ningún título significativo, otros son enviados a distintos tipos de centros especiales alejados de experiencias educativas ordinarias, y algunos simplemente eligen dejar unas clases que parecen totalmente irrelevantes para sus vidas." (Aiscow et al. 2013) 
En el contexto europeo, la tasa de abandono educativo temprano es una de las expresiones más visibles de estos retos. En 2017 torno al 10,6\% de la juventud de entre 18 y 24 años contaba con una formación académica correspondiente únicamente a la primera etapa de la educación secundaria como máximo y no realizaba formación alguna (Eurostat, 2018). No obstante, existe una gran diversidad de situaciones entre los distintos países, que van desde una presencia mínima del abandono escolar temprano en el caso de Eslovenia, con un 4,3\%, a afectar a casi un quinto

de este sector de la población joven en España, con un 18,3\% (Eurostat, 2018). Otra expresión de estos retos acuciantes que enfrentan los sistemas educativos tienen que ver con los resultados obtenidos por parte de su alumnado en la etapa de educación obligatoria. Según los últimos datos oficiales disponibles y a nivel estatal, en el curso 2015-2016 la cifra de alumnado que al finalizar ESO era propuesto para el título de Graduado en ESO suponía una tasa bruta del 79,3\%, respecto de la población que tiene la edad teórica de finalizar este nivel educativo (MEFP, 2018). Por su parte, en Aragón, la tasa bruta era ligeramente inferior en ese curso, alcanzado únicamente el $77,2 \%$, si bien la cifra para las jóvenes aragonesas ascendía al $83,2 \%$, mientras que para sus compañeros se quedaba en el $71,8 \%$.

Finalmente, y visibilizando que nos encontramos ante una realidad que se va gestando a lo largo de un largo proceso vinculado a la experiencia y trayectoria escolar del alumnado, la tasa de idoneidad ofrece datos que permiten dimensionar el reto al que nos enfrentamos. Este indicador muestra el alumnado que realiza el curso que corresponde a su edad. En Aragón, en el curso 2015-2016, a los 12 años el 81\% del alumnado estaba en el curso que le corresponde, si bien a los 14 años ya sólo lo estaba el 61\%, y a los 15 años, únicamente el 57\% (MEFP,2018).

Situaciones como las que expresan estos indicadores podrían ser consideradas, en su mayor parte, como situaciones de exclusión educativa siguiendo la propuesta de autores como Juan Manuel Escudero, en tanto que "fenómeno relativo a formas y contenidos de privación de la educación debida a ciertos sujetos o colectivos de estudiantes" (2005). Desde dicha perspectiva se superaría el enfoque más habitual y reducido del llamado "fracaso escolar" o "abandono escolar temprano", para situarnos en una perspectiva que reivindica, especialmente y por un lado, el carácter 
procesual y relacional de estos fenómenos y, por otro lado, los analiza desde una perspectiva de derechos.

\subsection{Haciendo efectivo el derecho a la educación para todo el alumnado.}

El Comité de Derechos Económicos, Sociales y Culturales de Naciones Unidas en su Observación General n 13 sobre el derecho a la educación en todas sus formas y en todos los niveles debe tener las siguientes cuatro características interrelacionadas: disponibilidad, accesibilidad, aceptabilidad y adaptabilidad.

Como bien resume Néstor López (2014), para garantizar el derecho a la educación no basta con que haya instituciones y programas de enseñanza en cantidad suficiente (disponibilidad), ni con que no haya ningún tipo de discriminación en el acceso a dichas instituciones y programas (accesibilidad), ni con que la forma y el fondo de los programas de estudio y los métodos pedagógicos sean pertinentes, adecuados culturalmente y de buena calidad (aceptabilidad). A todo ello, además, hay que sumar el que esa educación ha de tener la flexibilidad necesaria para adaptarse a necesidades sociales en constante transformación y responder, al mismo tiempo, a las necesidades y variadas particularidades del alumnado en función de sus contextos culturales y sociales, capacidades...

La adaptabilidad, este último aspecto mencionado, es de una importancia capital para garantizar el derecho a la educación, especialmente en nuestra realidad más cercana.

En el marco legislativo estatal vigente, la Ley Orgánica 8/2013, de 9 de diciembre, para la mejora de la calidad educativa (LOMCE, en adelante) hacen mención a expresa a esa necesidad de adaptabilidad. De este modo, entre sus principios, en el artículo 1. b) menciona "la equidad, que garantice la igualdad de oportunidades para el pleno desarrollo de la personalidad a través de la educación, la inclusión educativa, la igualdad de derechos y oportunidades que ayuden a superar cualquier discriminación y la accesibilidad universal a la educación, y que actúe como elemento compensador de las desigualdades personales, culturales, económicas y sociales, con especial atención a las que se deriven de cualquier tipo de discapacidad". Igualmente, en el apartado e) de ese mismo artículo especifica la necesidad de introducir "flexibilidad para adecuar la educación a la diversidad de aptitudes, intereses, expectativas y necesidades del alumnado, asi como a los cambios que experimentan el alumnado y la sociedad". 
De este modo, la normativa vigente de ámbito estatal establece que la educación primaria y la secundaria obligatoria se organizarán de acuerdo con los principios de educación común y de atención a la diversidad del alumnado, correspondiendo a las Administraciones educativas regular las medidas de atención a la diversidad.

En Aragón, la necesidad de esta adaptabilidad queda recogida en su normativa. Actualmente es el Decreto 188/2017, de 28 de noviembre, el que se regula la respuesta educativa inclusiva. Con esta respuesta inclusiva se establecen, entre otros principios de actuación, la equidad y la inclusión, como vía para garantizar la igualdad de derechos y oportunidades para el pleno desarrollo de la personalidad y la superación de cualquier tipo de discriminación entre el alumnado, al tiempo que se favorece la accesibilidad universal a la educación.

Desarrolla este Decreto la Orden ECD/1005/2018, de 7 de junio, que regula las actuaciones de intervención educativa inclusiva a implementar. De entre las diferentes actuaciones de intervención educativa que se recogen, vamos a mencionar únicamente dos de ellas, pues cobran especial relevancia en el contexto en el que nos encontramos. Por un lado, el artículo 37 de la Orden regula los Programas de promoción de la permanencia en el sistema educativo, dirigidos al alumnado de ESO y que tienen como objetivos facilitar la continuidad del alumnado en el sistema educativo, prevenir el abandono escolar temprano y favorecer el desarrollo de las competencias clave del currículo. Por su parte, mencionaremos el artículo 38, por el que se reglan los Programas de Cualificación Inicial de Formación Profesional (PCI), dirigidos a jóvenes de entre 16 y 21 años sin cualificación profesional o con necesidades educativas especiales, y mediante los cuales se ofrece la posibilidad tanto de adquirir o desarrollar competencias clave que les permita proseguir estudios en otras enseñanzas, como acceder a las competencias profesionales propias de una cualificación profesional de nivel uno del Catálogo Nacional de Cualificaciones Profesionales y con ello, a su certificación oficial.

De este modo, podemos comprobar cómo a fin de hacer frente a situaciones de exclusión educativa como la que evidenciaban los indicadores anteriormente expuestos, se ha ido generando, con más o menos acierto, distintos programas, medidas y/o actuaciones dirigidos a incrementar la adaptabilidad de la oferta educativa. Es decir, a aumentar la capacidad del conjunto del sistema educativo y 
formativo (de los centros escolares y formativos que lo conforman), para promover el desarrollo, el aprendizaje, los intereses y el bienestar personal de la totalidad del alumnado. Precisamente, esta decidida intervención en favor de la adaptabilidad explica el desarrollo de los sistemas educativos de nuestro entorno en las últimas décadas. Como afirma Jordi Planas (2004), el principal motor de desarrollo educativo se basa, en todos los países, en la idea de equidad.

\section{POLÍTICAS PÚBLICAS VINCULADAS AL DERECHO A LA EDUCACIÓN.}

Existe un amplio consenso internacional en torno a los beneficios que supone la mejora de los niveles educativos de la población en general en el contexto de la sociedad del conocimiento. Esto ha supuesto que las políticas educativas cobren una especial relevancia en el marco de las políticas públicas. Así lo demuestran, por ejemplo, la Estrategia de Lisboa-aprobada por el Consejo Europeo en el año 2.000- y su continuadora Europa 2020, mediante las cuales se trata de establecer las líneas maestras de las políticas púbicas de la Unión Europea para convertir a Europa en la mayor economía mundial del conocimiento, con el fin de aumentar la productividad y la competitividad, en el primer caso; y establecer las bases para un crecimiento inteligente, sostenible e integrador, en el segundo caso.

De manera coherente con estos grandes alineamientos de las políticas públicas, distintas instituciones y actores sociales alertan sobre las nefastas consecuencias que tienen para alcanzar dichos objetivos el fracaso escolar y el abandono escolar temprano. Así, lo pone de manifiesto el informe conjunto elaborado por Eurydice y CEDEFOP:

"early leaving has costs and consequences for the individual, in terms of a bigher risk of unemployment, social exclusion and poor health, and for society through increased public expenditure, for example on social welfare as well as the intergenerational transmission of educational and socio- economic attainment." (European Commission, 2014).

Ante esta realidad, el Marco Estratégico para la cooperación europea en el ámbito de la educación y la formación (ET2020) establece reducir la tasa de abandono educativo temprano, tomando como indicador el porcentaje de población de 18 a 24 años que no ha completado la Educación Secundaria de segunda etapa y no 
sigue ningún tipo de educación o formación. Así, el objetivo es conseguir que menos del 10\% de esta población joven en Europa se encuentre en esta situación en el año 2020, mientras que para España se establece como objetivo el 15\%.

A partir de este marco compartido, los estados miembros han puesto en marcha distintas políticas encaminadas a la consecución de los objetivos fijados. Como exponente de los desarrollos realizados dentro de este marco de referencia, a nivel estatal, podemos mencionar el Plan para la reducción del abandono educativo temprano elaborado por el Ministerio de Educación, Cultura y Deporte para el periodo 2014-2016. Su misión queda recogida como "impulsar y garantizar una educación y formación de calidad para todos los ciudadanos a lo largo de sus vidas que facilite su desarrollo integral y éxito en el proceso educativo, implantar medidas de intervención educativa que incidan en los factores de riesgo de abandono temprano, detectar casos de riesgo e intervenir para facilitar la reincorporación de los que ya abandonaron prematuramente el sistema educativo" (MECD, 2014). Entre otras cuestiones, el Plan aconseja contemplar medidas encaminadas a:

a. Fomentar la prevención e intervención en el abandono educativo temprano.

b. Concienciar a la ciudadanía de la importancia y el valor de la educación y formación.

c. Desarrollar actuaciones dirigidas a mejorar la flexibilidad y accesibilidad del sistema educativo a través del desarrollo de normativa educativa dentro de los distintos ámbitos de competencia.

d. Impulsar la coordinación entre las distintas administraciones estatales, autonómicas y locales en las políticas educativas relacionadas con los jóvenes y adultos.

\subsection{Distribución de competencias para la intervención coordinada y compartida.}

En materia educativa, la Constitución Española de 1978 reserva al Estado "la regulación de las condiciones de obtención, expedición y homologación de títulos académicos y profesionales y normas básicas para el desarrollo del artículo 27 de la Constitución, a fin de garantizar el cumplimiento de las obligaciones de los poderes públicos en esa materia" (artículo 149.1.30. ${ }^{2}$. Junto a ello, las Comunidades Autónomas cuentan competencias en materia educativa, reguladas en los correspondientes estatutos de autonomía. 
Por su parte, la propia legislación educativa ya recoge la necesidad de esta coordinación e intervención compartida. Así, la LOMCE recoge entre sus principios "la cooperación y colaboración de las Administraciones educativas con las corporaciones locales en la planificación e implementación de la politica educativa" (artículo 1.p); si bien cuenta con un artículo específico dirigido a la cooperación entre administración, señalando que "las Administraciones educativas y las Corporaciones locales coordinarán sus actuaciones, cada una en el ámbito de sus competencias, para lograr una mayor eficacia de los recursos destinados a la educación y contribuir a los fines establecidos en esta Ley" (art. 8.1.).

En este sentido, la etapa de educación infantil y la educación de adultos son ámbitos en los que presta especial atención en la legislación vigente. Por el contrario, desaparece en la redacción actual la mención explícita a la colaboración de las corporaciones locales y de los agentes sociales y económicos, para programar la oferta de las enseñanzas de formación profesional, recogida en el art. 42.1. de la Ley Orgánica 2/2006, de 3 de mayo, de Educación (LOE); así como la mención a la participación de administraciones locales, organizaciones no gubernamentales y otras entidades en el desarrollo de programas de cualificación profesional inicial. (artículo 30.5. de la LOE).

Adicionalmente, las Administraciones locales también contaban con ciertas competencias en materia educativa. La Ley 7/1985, de 2 de abril, Reguladora de las Bases de Régimen Local recogía que podrían "participar en la programación de la enseñanza y cooperar con la Administración educativa en la creación, construcción y sostenimiento de los Centros Docentes públicos, intervenir en sus órganos de gestión y participar en la vigilancia del cumplimiento de la escolaridad obligatoria" (art. 25. n.), así como "realizar actividades complementarias de las propias de otras Administraciones Públicas y, en particular, las relativas a la educación..." (art. 28.). Actualmente, con aprobación de la Ley 27/2013, de 27 de diciembre, de racionalización y sostenibilidad de la Administración Local, las competencias locales en este ámbito quedan circunscritas a "participar en la vigilancia del cumplimiento de la escolaridad obligatoria y cooperar con las Administraciones educativas correspondientes en la obtención de los solares necesarios para la construcción de nuevos centros docentes. La conservación, mantenimiento y vigilancia de los edificios de titularidad local destinados a centros públicos 
de educación infantil, de educación primaria o de educación especial'; al tiempo que la realización de actividades complementarias deja de contemplarse (eliminación del art. 28 mencionado anteriormente).

No obstante, y a pesar de la reciente reducción de atribuciones competenciales en materia educativa para las Administraciones locales y de la reducción de los ámbitos en los que se menciona explícitamente la colaboración entre administraciones en la legislación educativa actual; podemos afirmar que esto no imposibilita necesariamente la articulación de la necesaria colaboración que posibilite el incremento de la adaptabilidad de la oferta educativa. De esta manera y en relación a la genérica mención a la "cooperación y colaboración con las administraciones educativas en la planificación de la política educativa y su implementación" prevista en la legislación educativa, o la realización de actividades complementarias recogidas en la anterior regulación del régimen local; podemos afirmar, siguiendo a Tardío (2010, 2014), que ese contenido competencial real se puede conseguir sin ni siquiera considerarlo como competencia de los entes locales. "Tras la nueva Ley $27 / 2013$, no puede afirmarse que la prestación de tales actividades y servicios [actividades complementarias] por los municipios encuentren cobertura alguna en las competencias municipales propias, pero gran parte de ellas encajan como competencias delegables" (Tardío, 2014, 127) u otras fórmulas existentes.

Como ejemplo de esas posibilidades de colaboración, transcendiendo los marcos competenciales estrictos, la ORDEN ECD/946/2016, de 4 de agosto, por la que se regulan los Programas de Cualificación Inicial de Formación Profesional dirigidos a personas sin cualificación profesional o con necesidades educativas especiales en la Comunidad Autónoma de Aragón, estipula los términos para la intervención coordinada. En su art. 19 establece cómo solicitar autorización para desarrollar programas de cualificación inicial a la Dirección General competente en materia de Formación Profesional, lo que permite la participación de entidades locales o entidades promovidas por ellas, las organizaciones empresariales o sindicales y entidades privadas sin ánimo de lucro interesadas en colaborar incrementando la oferta existente e incrementando su adaptabilidad. 


\section{LA RED MUNICIPAL DE CENTROS SOCIOLABORALES.}

El Excmo. Ayuntamiento de Zaragoza, a través de su organismo autónomo, el Instituto Municipal de Empleo y Fomento Empresarial de Zaragoza (Zaragoza Dinámica), promueve los Centros Sociolaborales de la ciudad. La propia administración local define los Centros Sociolaborales como centros públicos de servicios, cuyas actividades tienen un carácter formativo y socioeducativo, siendo una plataforma de promoción social para que los jóvenes accedan a los sistemas generales de educación, empleo, cultura y participación social.

Concretamente, existen 12 Centros Sociolaborales distribuidos por la ciudad, compartiendo una serie de características comunes definidas por el propio ente local:

a. Integrar los programas formativos y de empleo con los de intervención social, en un único proyecto educativo adaptado a las necesidades del grupo de jóvenes destinatarios.

b. Utilizar una pedagogía activa, adaptada y flexible a los procesos individuales y grupales de las personas participantes.

c. Desarrollar Itinerarios Integrados de Inserción que contemplen procesos formativos integrales con áreas de trabajo que abordan las competencias básicas, la formación profesional (ya sea a partir de la formación inicial o la formación para el empleo), la animación sociocultural, la educación compensatoria, la orientación educativa y el trabajo social, desde una filosofía de educación permanente.

d. Ser proyectos socioeducativos que plantean acciones positivas de transición hacia la cualificación y la integración laboral, la vuelta al sistema educativo reglado y la socialización y atención a conflictos familiares y sociales.

De este modo, los Centros Sociolaborales pretenden incrementar la adaptabilidad de la oferta educativa a fin de facilitar la inserción social de jóvenes en situación de dificultad para completar con éxito su transición a la vida activa.

El conjunto de los 12 Centros Sociolaborales conforma una Red Municipal (la Red, en adelante) articulada, desde la que se da respuesta coordinada a las dificultades de inserción social y laboral de los jóvenes, que por condiciones sociales y personales quedan al margen de los sistemas generales de educación, formación y empleo, siendo esta intervención municipal complementaria y coordinada con la que se realizan en otras instituciones y administraciones, como la propia Administración educativa entre otras. 


\subsection{Orígenes de la Red de Centros Sociolaborales.}

La Red surge a principios de los años ochenta del siglo pasado. El germen fue una iniciativa ciudadana impulsada por el Centro Obrero de Formación, más conocido como CODEF. En 1984 inicia su andadura focalizando su atención en ofrecer educación a los sectores socialmente más desfavorecidos, así como formación permanente, y proponiéndose el fomento de la participación como medio para hacer posible el desarrollo personal y comunitario. Entre la población destinataria, los y las jóvenes ocupaban un papel central.

Junto a esta primera iniciativa, el tejido asociativo de la capital aragonesa comienza a movilizarse para poner en marcha actuaciones similares. Se trata de proyectos dirigidos a la juventud que enfrenta mayores dificultades, a aquella parte de la misma que ha vivido procesos de exclusión educativa y se encuentra, en la mayoría de los casos, en condiciones de vulnerabilidad social.

Por las características de estos orígenes y el grupo destinatarios, podemos afirmar que se trata de iniciativas ciudadanas vinculadas a la educación popular, entendida esta como "el conjunto de los procesos que pretenden la educación de las clases populares (o grupos sociales dominados, subalternos e instrumentales de toda la sociedad, recogiendo la expresión gramsciana) -jóvenes no escolarizados en el circuito escolar, adultos no alfabetizados o deseando un complemento de formación-, realizados fuera -o paralelamentede los circuitos y procesos escolares". (Guereña et al.,1994, p. 142). Iniciativas que se fueron configurando con el compromiso de la ciudadanía que daba vida al tejido asociativo de los barrios más activos de Zaragoza.

En esta situación el Excmo. Ayto. de Zaragoza pone en marcha su Plan Joven en 1987. La coincidencia de intereses y la vitalidad de las propuestas ciudadanas y municipales facilitará la confluencia de la política municipal de juventud y los proyectos del tejido asociativo. De esta confluencia surge la matriz de la actual Red, la primigenia Red de Talleres Ocupacionales.

En este periodo se va configurando una propuesta propia de formación orientada a incrementar la adaptabilidad de la oferta formativa existente en el momento. En este sentido, hay que recordar que la formación profesional no reglada o formación para el empleo en España presenta algunas características que la alejan de otros modelos internacionales, y entre esas características es pertinente remarcar, por un 
lado, su desarrollo tardío y por otro, el que los dos principales componentes de la formación profesional para el empleo (la ocupacional o para desempleados, y la continua o para trabajadores/as ocupados/as), nacieron independientemente. Así, la formación ocupacional surge a partir de la entrada de España en la UE (1986); mientras que la formación continua comienza tras los acuerdos de comienzos de la década de 1990 entre patronal y sindicatos sobre el destino de las cuotas para la formación de las cotizaciones sociales (Brunet, 2017a, 100).

En este sentido, la Red primitiva encuentra un ecosistema propicio para su configuración de su propia propuesta de intervención y para el establecimiento de relaciones de colaboración entre los distintos actores implicados, a pesar de su manifiesta diversidad. A partir de estos momentos comenzó su andadura, constituyéndose como Red de centros Sociolaborales en a partir de 1998, tras haberse aprobado el II Plan Joven de la ciudad.

\subsection{La Red Centros Sociolaborales en el presente.}

La actual Red está configurada por 12 Centros Sociolaborales que, si bien se conciben como un servicio público dependiente de la administración local, su gestión está en manos de entidades privadas sin ánimo de lucro, entidades que o bien son propias las figuras jurídicas que articularon la iniciativa ciudadana inicial o bien se trata de sus herederas. Concretamente, en la actualidad la Red está gestionada por cinco entidades sociales: Asociación Telca, Fundación Adunare, Fundación $\mathrm{M}^{\mathrm{a}}$ Auxiliadora Fundación San Valeroy Fundación Picarral. Cada una de ellas gestiona un Centro Sociolaboral, excepto Fundación Adunare que, al ser el fruto de la adición y fundición de las entidades sociales previas, gestiona ocho Centro Sociolaborales.

La oferta formativa es variada, mostrando una importante panoplia de fórmulas de colaboración entre los propios Centro Sociolaborales con otras administraciones, fundamentalmente responsables autonómicas de las políticas educativas y de empleo. De este modo, la oferta formativa de la Red contempla tanto formaciones vinculadas al Subsistema de Formación Profesional Inicial o reglada, dependiente de la Autoridad educativa, como del Subsistema de Formación Profesional para el Empleo, dependiente de la autoridad en materia de empleo. 
La oferta de la Red puede clarificarse en tres grandes tipologías de propuestas formativas:

a. Programas de promoción de la permanencia en el sistema educativo, conocidas habitualmente como "Aulas taller". Ofrecen formación a alumnado en edad de escolarización obligatoria y tienen como objetivos facilitar la continuidad del alumnado en el sistema educativo, prevenir el abandono escolar temprano y favorecer el desarrollo de las competencias clave del currículo de Educación Secundaria Obligatoria (ESO). Al tratarse Centros Sociolaborales, estos programas se fuera del centro educativo de referencia del alumnado. Únicamente un Centro Sociolaboral de la Red no cuenta con este tipo de oferta formativa.

b. Programas de Cualificación Inicial de Formación Profesional (PCI). Van dirigidos igualmente a personas que no han encontradorespuesta en otros ámbitos del sistema educativo, sufriendo en la mayoría de los casos exclusión educativa. Su objetivo, en consecuencia, es dar una respuesta educativa a las personas sin cualificación profesional o con necesidades educativas especiales una vez superada la edad de escolarización obligatoria y mientras tienen, en principio, entre 16 y 21 años. Cuenta con dos modalidades: Talleres profesionales (Modalidad I) y. Talleres profesionales especiales (Modalidad II). En ambas modalidades, los objetivos son, por un lado, proporcionar a los alumnos las competencias profesionales propias de una cualificación profesional de nivel uno del Catálogo Nacional de Cualificaciones Profesionales y certificar oficialmente dichas competencias; y por otro lado, facilitar el desarrollo y la adquisición de competencias clave que les permita proseguir estudios en otras. Cada Centro Sociolaboral cuenta, al menos, con uno de estos PCI, de manera que la Red ofrece una amplia oferta de especialidades de este tipo de formación.

c. Formación profesional para el empleo. Se trata de una oferta formativa para jóvenes desempleados, cuyo objetivo es ofrecerles una formación ajustada a las necesidades e intereses individuales y que permita adquirir las competencias requeridas por el sector productivo al que se dirige, mejorando la empleabilidad de las y los participantes. En ellas tienen prioridad las personas con baja cualificación, así como aquellas formaciones conducentes a certificados de profesionalidad. Esta tipología formativa es la menos numerosa de entre la que ofrece la Red, pues la oferta menos del 60\% de los Centros Sociolaborales. 
Como muestra el gráfico 1, entre el curso 2008-2009 y el curso 2017- 2018 el promedio de jóvenes participantes en las distintas acciones formativas de la Red ha sido ligeramente superior a las 500 personas. De entre ellas, el número de hombres ha sido siempre mayoritario, representado las mujeres únicamente en torno a un tercio de las personas en formación. Probablemente, esta fuerte masculinización de las personas en formación tenga relación con las especialidades profesionales ofertadas, en su mayoría vinculadas a trabajos percibidos tradicionalmente como masculinos.

Gráfica 1. Evolución del número de jóvenes en formación desagregados por sexos.

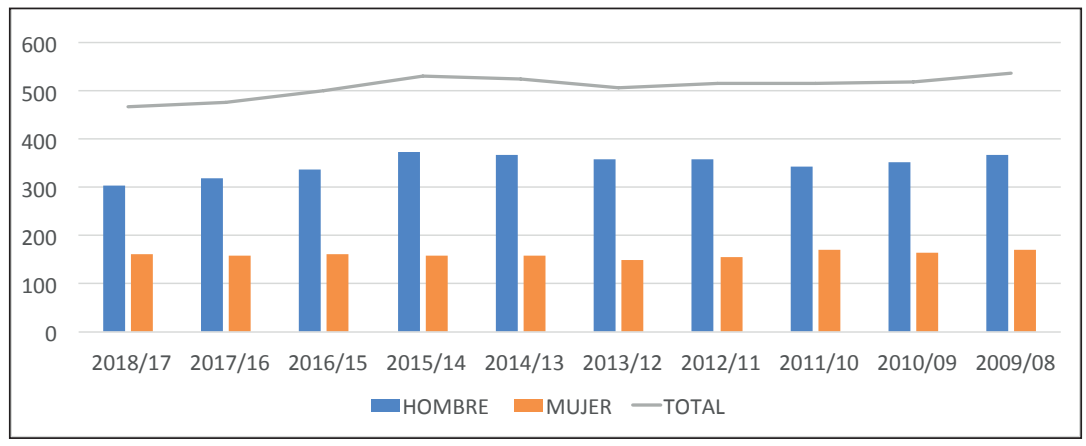

En relación a la diferente acogida de las tres tipologías de formación ofertadas por la Red, los datos longitudinales referidos al periodo anteriormente mencionado evidencian un reparto bastante equilibrado del número de participantes. De este modo, a lo largo de los diez años de referencia, la proporción de jóvenes participantes en los programas de promoción de la permanencia en el sistema educativo (Aulas taller) y formación para el empleo ha sido muy similar con respecto al total de participantes, representado el 30\% los primeros y el 31\% los segundos. Así, el grupo mayoritario con un 39\% lo conformaban aquellos jóvenes que seguían los actuales programas de Cualificación Inicial de Formación Profesional (anteriormente, PCPI). No obstante, y como muestra el gráfico 2, el número de participantes en los programas de promoción de la permanencia en el sistema educativo ha venido sufriendo una caída significativa continuada a lo largo de todo el periodo. 
Gráfica 2. Participantes totales por tipología formativa.

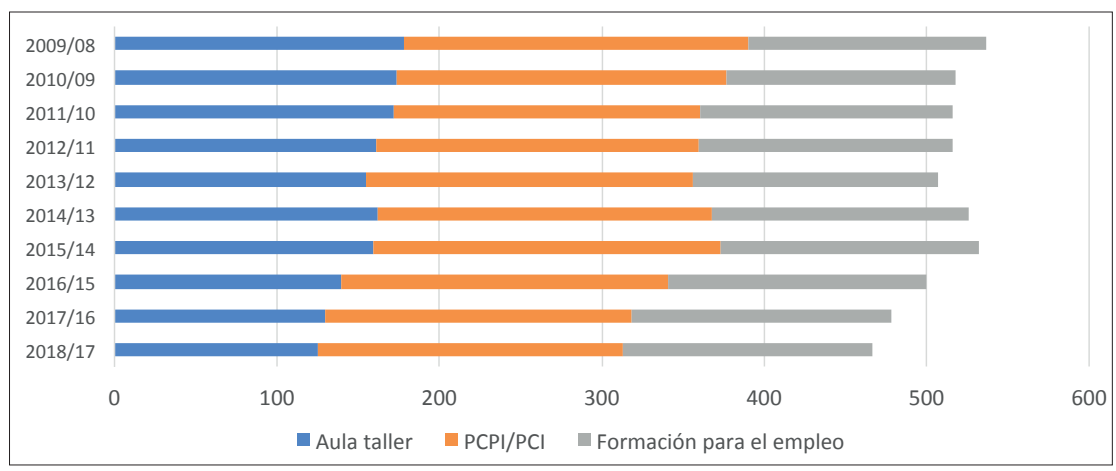

Finalmente, y para culminar esta breve presentación de la situación actual de la Red, el análisis de la distribución de las y los jóvenes participantes en función del sexo y por tipología de formación (Gráfica 3), nos ofrece una imagen clara de la importantísima masculinización de la Red. Como se puede observar, únicamente las personas que siguen una formación para el empleo alcanza una situación de equilibrio en la representación de sexos, siendo las mujeres mayoría por la mínima $(51 \%)$ a lo largo del periodo estudiado. Frente a ello, las otras dos tipologías de formaciones presentan una sobre representación de hombres frente a mujeres, siendo estas últimas entre un cuarto y un quinto de las personas participantes. $\mathrm{Al}$ analizar esta fuerte masculinización de estos dos tipos de formación (Aula taller y PCPI/PCI), además de tener en cuenta una posible oferta formativa vinculada a especialidades profesionales tradicionalmente masculinas, habrá de contemplar en la propia sobrepresentación del alumnado masculino entre aquel que se encuentra en situaciones de mayor riesgo de exclusión educativa. En este sentido, basta recordar que estas dos tipologías de formaciones contemplan como requisito casi imprescindible dicha condición. 
Gráfica 3. Participantes medios entre 2008 y 2018 según sexos y tipologías formativas

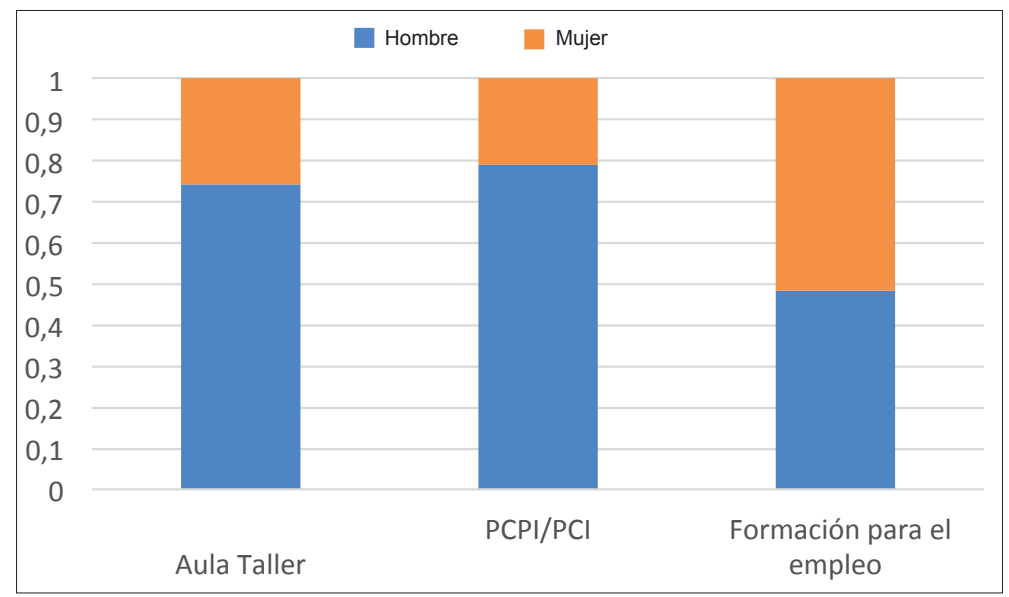

\section{A MODO DE CIERRE PROVISIONAL.}

A lo largo de este capítulo hemos podido ofrecer un marco amplio y de referencia en el que la acción de la Red Municipal de Centros Sociolaborales desarrolla su intervención educativa y socioformativa. En este sentido, se evidencia la importancia de la aportación de la propia Red en la búsqueda de salidas que luchen contra la situación de exclusión social que vive una parte significativa de la población juvenil. Salidas y alternativas que han ofrecido una mayor adaptabilidad a la oferta formativa preexistente, desarrollando gracias a la cooperación y colaboración de distintos y múltiples actores una propuesta singular, válida y sostenida en el tiempo.

En este sentido, cabe recordar que la propuesta formativa de la Red cumple con buena parte de los criterios propios de la educación popular: a) basada en los intereses reales de las personas, b) comprometida con el cambio social, c) Enfoque colectivo y d) Conectando a la educación y la acción social (Crowther et al., 2006, cit. Lucio-Villegas, 2017).

Por otro lado, la longevidad de la propia Red y la buena salud que demuestra, al menos, en lo que tiene que ver con la acogida que su oferta formativa tiene entre las y los jóvenes zaragozanos viene a confirmar el valor de la intervención desplegada. 
Así y dado el fuerte compromiso del Excmo. Ayuntamiento de Zaragoza en la Red, más allá de cambios y distintos partidos en el gobierno de la ciudad, podríamos afirmar que esta política local es congruente con el modelo de autorresponsabilidad política en la prestación de servicio a las personas (Subirats, 2002). En dicho modelo se situarían aquellos municipios que han sido capaces de definir autónomamente qué servicios esperan ofrecer a la ciudadanía y el sentido de los mismos, más allá de las competencias estrictamente establecidas por la normativa (modelo normativista) y de las fluctuaciones de la demanda (modelo pragmatista).

Sin embargo, no podemos obviar el riesgo que conlleva para la consecución de los objetivos marcados por la Red la concentración de un número muy significativo de jóvenes procedentes de la exclusión educativa, situación a la que suman en buena parte de ellos, otros factores exclusógenos. En este sentido y frente a definiciones basadas únicamente en la composición del alumnado de los Centros Sociolaborales y sus características vinculadas a distintas vunerabilidades, recordamos la defición que de una escuela gueto hace Jordi Collert: "una escuela se puede considerar como una escuela gueto, no por su composición, sino porque hay abandono institucional, económico y profesional, desconfianza en la capacidad integradora de la escuela por parte del profesorado y familias, y aislamiento sociocultural, étnico o racial" (Collert, 2017, 122). Así pues, esperamos constatar en futuras aproximaciones cómo dichas circunstancias siguen alejadas de los Centros Sociolaborales que conforman la Red.

Finalmente, pensamos que la Red contiene capacidades y potencialidades aún no exploradas, especialmente en todo lo que tiene que ver con la aproximación, junto el resto de actores educativos, al contexto más cercano, integrando el territorio en las acciones formativas y convirtiendo ese mismo contexto y sus recursos en opciones educativas y formativas de primer orden. 


\section{REFERENCIAS BIBLIOGRÁFICAS}

Aiscow, M. et al. (2013). Promoviendo la equidad en educación. Revista de Investigación en Educación (11 3), 44-56.

Brunet i Icart, I. y Böcker, D. (2017a). El modelo de formación profesional en España. Revista Internacional de Organizaciones (18), 89-108.

Brunet i Icart, I. y Moral Martín, D. (2017b). Origen, contexto, evolución y futuro de la Formación Profesional. Tarragona: Publicacions de la Universitat Rovira i Virgili.

Collert Sabé, J. y Tort Bardolet, A. (2017). Escuela, familias y comunidad. Barcelona: Octaedro.

Escudero Muñoz, J.M. (2005): Fracaso escolar, exclusión educativa: ¿de qué se excluye y cómo?. Profesorado, revista de currículum y formación del profesorado (1), 1-24.

Escudero Muñoz, J.M. (Comp) (2016): Inclusión y exclusión educativa: Realidades, miradas y propuestas. Valencia: Nau Libres.

Guereña, J.L., Tiana Ferrer, A. y Ruiz Berrio, J. (coord.) (1994). Historia de la educación en la España contemporánea. Madrid: Ministerio de Educación, Cultura y Deportes.

Instituto Nacional de Evaluación Educativa (2018). Panorama de la educación Indicadores de la OCDE 2018. Madrid: Ministerio de Educación y Formación Profesional.

Instituto Nacional de Evaluación Educativa (2018). Sistema estatal de indicadores de la educación 2018. Madrid: Ministerio de Educación y Formación Profesional.

Judt, T. (2010). Ill Fares the Land. London: Penguin Press.

López, N. (2014). Mercado o Garantía de derechos. Modelos en debate para la educación escolar en Chile. Buenos Aires: Instituto Internacional de Planeamiento de la Educación (IIPE) / Unesco.

Lucio-Villegas Ramos, E. (2017). La desaparición - o tal vez no - de la educación de personas adultas. El caso de Andalucía. educação | Santa Maria (42 n. 1), 3344.

Planas Coll, J. (2011). La relación entre educación y empleo en Europa. Paper(96/4), 1047-1073.

Planas Coll, J. et al (2004). La escuela y la nueva ordenación del territorio. Barcelona: Octaedro. 
Tardío Pato, J.A. (2010). Las competencias educativas de los entes locales en España. Madrid: Iustel.

Tardío Pato, J.A. (2014). La reforma local española de 2013 y las competencias educativas. Revista de Educación (366), 113-135.Planas Coll, J. et al (2004). La escuela y la nueva ordenación del territorio. Barcelona: Octaedro.

Tardío Pato, J.A. (2010). Las competencias educativas de los entes locales en España. Madrid: Iustel.

Tardío Pato, J.A. (2014). La reforma local española de 2013 y las competencias educativas. Revista de Educación (366), 113 



\title{
METODOLOGÍA APRENDIZAJE SERVICIO. DESARROLLO CURRICULAR EN CENTROS SOCIOLABORALES
}

\author{
Belén Dieste Gracia, Ana Cristina Blasco Serrano, Pilar Arranz Martínez \\ Ciencias de la Educación /Facultad de Educación \\ (Universidad de Zaragoza)
}

\section{INTRODUCCIÓN}

En la literatura, encontramos numerosas definiciones sobre qué es AprendizajeServicio (ApS) y cómo se desarrolla en distintas etapas y contextos educativos.

En este capítulo podríamos decir que ApS en los Centros Sociolaborales (CSL) ha sido:

a. Realizar recursos educativos para aulas de Educación Infantil.

b. Crear un huerto escolar.

c. Hacer un vídeo promocional para una entidad social.

d. Hacer un taller de repostería.

Todos estos son ejemplos de lo que pueden ser proyectos de Aprendizaje-Servicio. A partir de estas sencillas ideas, los estudiantes han realizado experiencias prácticas en cada una de las cuales sus aprendizajes y competencias se han desarrollado al mismo tiempo que desarrollaban el proyecto que, en cada caso, suponía una aportación o una mejora en ese entorno (aula de infantil, entidad social...). Aprendizaje y servicio se han complementado y retroalimentado. Los participantes de los CSLs han visto favorecida la adquisición y calidad de sus aprendizajes, puesto que en cada proyecto incluía competencias académicas y también transversales, como son, entre otras, la competencia social y ciudadana (Arranz, 2011; Arranz, Dieste, Aristizábal y Abán, 2016). Y es que cada proyecto de aprendizaje-servicio conlleva un elenco de aprendizajes para los estudiantes que lo llevan a cabo y una muestra de responsabilidad social de sus promotores y actores con el entorno más próximo (Arranz, Dieste, Aristizábal y Abán, 2016; Santos, Sotelino y Lorenzo, 2016). Así, las actuaciones de los CSLs mencionadas han tenido como propósito 
central promover actividades educativas con proyección social con el objetivo de que el alumnado de dichos centros mejore su dominio de los contenidos curriculares mediante un servicio de utilidad social en su entorno más cercano.

En este marco, consideramos que se puede hablar de experiencias de aprendizajeservicio cuando en el desarrollo de un proyecto están presentes simultáneamente la intención pedagógica y la intención solidaria. En consecuencia, tanto el alumnado como la comunidad adquieren protagonismo y se produce un enriquecimiento mutuo. Deseamos subrayar que estos servicios conllevan el desarrollo planificado de las competencias y contenidos curriculares del plan de estudios, lo que muchas veces se convierte en una labor ardua para el docente. Por ello, pueden surgir dudas y preguntas sobre cómo abordar nuestro trabajo:

Tabla 1. ¿Cómo abordamos nuestro trabajo?

¿Estoy haciendo algo parecido?

¿Qué cosas habría que tener en cuenta en mi programación?

¿Qué podría aportar el ApS a mi materia?

¿Qué problemas veo?

¿POR DÓNDE EMPIEZO?

\section{PARTIMOS DE UNA NECESIDAD}

No podemos exponer con detalle todas las variantes de las propuestas de ApS que se pueden realizar, pero señalaremos al menos algunos tipos de proyectos que se pueden desarrollar desde esta metodología. En cualquier caso, se trata de actividades reales que lleva a cabo el alumnado y que siempre se completan mediante la reflexión tras dar por finalizado el proyecto (Arranz, Dieste y Blasco, 2018).

Para abordar la IDEA que será el eje del proyecto, es necesaria una visión lo más clara posible acerca de la realidad sobre la que se va a actuar. Para ello, habrá que partir de una necesidad del entorno/comunidad que pensamos que podrá cubrir 
nuestra institución educativa, y que ofrecerá una oportunidad para el aprendizaje de los estudiantes.

La identificación de estas necesidades no siempre resulta sencilla. Se pueden llevar a cabo investigaciones sobre problemas sociales a partir de material periodístico o bibliografía especializada, debates en distintos ámbitos de la comunidad educativa, entrevistas, etc.. En otras ocasiones las necesidades nos pueden llegar dadas a través de miembros del equipo docente, de las familias o del propio alumnado.

Algunos ejemplos de servicios que se pueden trabajar desde los Proyectos de Aprendizaje-Servicio son:

Tabla 2. Ámbitos

\begin{tabular}{|c|c|c|c|}
\hline $\begin{array}{c}\text { Medio } \\
\text { ambiente }\end{array}$ & Salud & $\begin{array}{c}\text { Participación } \\
\text { ciudadana }\end{array}$ & Patrimonio \\
\hline $\begin{array}{l}\text { Ahorro energético } \\
\text { Reducción residuos } \\
\text { Reciclaje } \\
\text { Conservación / limpieza de entornos } \\
\text { Prevención de contaminación acústica } \\
\text { Protección fauna o flora }\end{array}$ & $\begin{array}{l}\text { Promoción } \\
\text { hábitos } \\
\text { saludables } \\
\text { Ayuda a } \\
\text { personas con } \\
\text { problemas de } \\
\text { salud } \\
\text { Sensibilización } \\
\text { Prevención }\end{array}$ & $\begin{array}{l}\text { Promoción del civismo } \\
\text { Intervención en tiempo } \\
\text { libre } \\
\text { Animación sociocultural } \\
\text { Promoción de la cultura } \\
\text { Urbanismo } \\
\text { Interculturalidad }\end{array}$ & $\begin{array}{l}\text { Recuperación } \\
\text { construcciones históricas } \\
\text { Fomento del patrimonio } \\
\text { Proyectos arqueológicos } \\
\text { Recuperación historia, } \\
\text { "memoria viva" }\end{array}$ \\
\hline $\begin{array}{c}\text { Colectivos } \\
\text { vulnerables }\end{array}$ & & \multicolumn{2}{|c|}{$\begin{array}{l}\text { Apoyos } \\
\text { escolares }\end{array}$} \\
\hline $\begin{array}{l}\text { Actividades intergeneracionales } \\
\text { Apoyos } \\
\text { Acompañamiento }\end{array}$ & & $\begin{array}{l}\text { Repaso escolar } \\
\text { Tutoría y Orientación } \\
\text { Narración de cuentos } \\
\text { Actividades lúdicas }\end{array}$ & \\
\hline
\end{tabular}

En la Red de Centros Sociolaborales de Zaragoza durante el curso 2017-2018 se han llevado a cabo una serie de proyectos de Aps relacionados con distintos ámbitos y áreas. En los Anexos puede verse un resumen de algunos de ellos, presentados en las VII Jornadas de Aprendizaje Servicio de la Universidad de Zaragoza (Anexo I) 


\section{DESARROLLO DE UN PROYECTO DE APRENDIZAJE SERVICIO}

Los docentes son los actores clave en la implementación del Proyecto ApS, y son coprotagonistas en la ejecución, tanto los estudiantes como los receptores del servicio. No obstante, es deseable el protagonismo de todos los agentes implicados en el planeamiento, desarrollo y evaluación del proyecto. Si los estudiantes no se involucran, sienten y viven la necesidad para la que van a trabajar a la vez que aprenden, el impacto en los aprendizajes no va a ser el mismo.

Para el desarrollo de un Proyecto ApS, siguiendo el esquema de Batlle (2017), mostramos un modelo de guía de trabajo con los principales pasos y actuaciones. Desarrollamos el ejemplo teniendo en cuenta las características organizativas y didácticas de un Centro Socio Laboral.

Tabla 3. Esquema de trabajo (Batle,2017)

\begin{tabular}{|c|c|l|}
\hline \multirow{2}{*}{1} & $\begin{array}{l}\text { ESBOZO DE LA IDEA: Necesidad atendida } \\
\text { Servicio que se llevaria a cabo } \\
\text { Pprendizajes relacionados con el servicio (relación con el } \\
\text { curriculo ) }\end{array}$ \\
\cline { 2 - 4 } & 2 & RELACION CON ENTIDADES \\
\cline { 2 - 4 } & 3 & $\begin{array}{l}\text { PLANIFICACION DEL PROYECTO: Definir el servicio } \\
\text { Definir los aprendizajes } \\
\text { Implicación del profesorado y la familia }\end{array}$ \\
\hline
\end{tabular}




\begin{tabular}{|c|c|c|}
\hline \multirow[t]{3}{*}{ REALIZACIÓN } & 4 & $\begin{array}{l}\text { PREPARACION CON EL GRUPO: Motivación } \\
\text { Investigación de la necesidad } \\
\text { Definición del servicio; qué, para qué por qué... } \\
\text { Compromiso de la realización } \\
\text { Definir los aprendizajes que vamos a adquirir o utilizar } \\
\text { PARA LLEVAR A CABO EL SERVICIO. Organización } \\
\text { Forma de registro } \\
\text { Reflexión sobre la planificación }\end{array}$ \\
\hline & 5 & EJECUCIÓN Y REFLEXIÓN SOBRE LA EJECUCIÓN \\
\hline & 6 & CIERRE: RECOJIDA DE DATOS, FOTOS, REGISTROS \\
\hline EVALUACIÓN & 7 & $\begin{array}{l}\text { EVALUACION: Grupo } \\
\text { Trabajo en red } \\
\text { Servicio, la Experiencia... } \\
\text { Nosotros mismos. }\end{array}$ \\
\hline
\end{tabular}

Tabla 4. ¿Por dónde empiezo?

\section{RECUERDA}

Un proyecto de Aprendizaje y Servicio exige la presencia de proceso planificado (Tapia, 2007):

- En base al Proyecto Educativo del Centro.

- Con la participación de toda la comunidad educativa.

- Para atender una demanda real y que pueda ser resuelta por el alumnado.

- Dando la misma importancia al servicio que al aprendizaje curricular.

Una vez conocidos los pasos de un proyecto ApS y poder saber "por dónde empiezo", otro problema que encuentran los docentes es saber cómo plasmar este trabajo en los documentos de centro. Por ello, adjuntamos una ficha que puede ser utilizada para plasmar las distintas acciones que se van realizando (Anexo II) y una 
plantilla para poder relacionar el proyecto ApS con la planificación curricular en la Programación Didáctica y/o Unidades Didácticas y de Trabajo (Anexo III)

\section{EVALUACIÓN}

La evaluación es un aspecto central de todo Proyecto ApS y uno de los desafíos más importantes. Debe considerarse como un proceso de mejora, de búsqueda de alternativas de acción. Debemos analizar aspectos comolos siguientes: si se están cumpliendo las etapas previstas y la planificación, la coherencia entre los objetivos iniciales y las actividades que se están desarrollando, la asignación eficiente de recursos, tiempos disponibles, ...

A través de los proyectos APS, es posible incidir en los aprendizajes que constituyen los 4 pilares de la educación del siglo XXI (Delors, 1996):

- Aprender a conocer

- Aprender a hacer

- Aprender a ser

- Aprender a convivir

Imagen 1. Pilares de la Educación (Delors,1996)

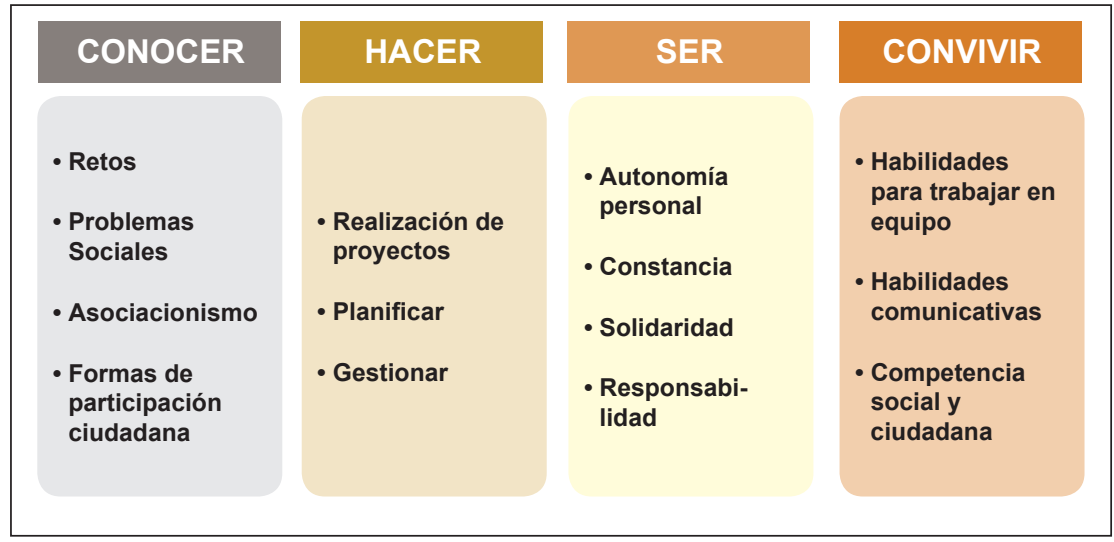

De acuerdo con los objetivos fijados al inicio del proyecto, se evaluarán, por un lado, los resultados educativos de la experiencia (currículum) y, por otro, el cumplimiento de los objetivos fijados en cuanto al servicio a la comunidad. 
Los aspectos básicos que evaluar en un proyecto de aprendizaje-servicio, pueden ser:

a. Cumplimiento de los objetivos curriculares planificados.

b. Efectiva satisfacción de los destinatarios.

c. Calidad de las competencias, habilidades y actitudes desarrolladas.

d. Impacto personal del proyecto en cada estudiante (autoestima, seguridad y confianza en sus propias capacidades, reconocimiento, etc.)

Un elemento importante en la evaluación de los proyectos ApS que permite una mayor implicación de los protagonistas es la autoevaluación. Permite incluir la percepción y las opiniones del alumnado, de los destinatarios del proyecto, así como la de los coordinadores de las entidades con las que se hayan establecido alianzas.

La evaluación que se realiza tanto en el desarrollo del proceso como al finalizar el proyecto implica reflexionar sobre efectos de las acciones realizadas, tanto en los estudiantes, como en la comunidad destinataria, para poder corregir errores, valorar los aciertos y hacer las modificaciones que se consideren necesarias.

Además de la evaluación curricular de los propios objetivos planteados en las Programaciones Didácticas, es importante realizar planillas de registro e informes que den cuenta de la evolución de la acción desde la perspectiva de todos los agentes implicados (Anexo, IV).

Existen también distintas herramientas que pueden ser utilizadas tanto para la evaluación del propio proyecto como para las distintas competencias personales y profesionales de los agentes implicados.

- Rúbrica para la autoevaluación y la mejora de proyectos ApS: http:// www.aprenentatgeservei.cat/intra/aps/documents/aps_autoevaluacio_ cast_IMP_A5.pdf

- El K-12 Service-Learning Standards for Quality Practice, 2008. En https://nylc.org/standards/

- Propuesta de 15 criterios de Calidad (Batlle, 2006), que son elementos para mejorar la calidad de un proyecto de aprendizaje-servicio, así como para tener en cuenta a la hora de realizar un proyecto de ApS de alta calidad. https://roserbatlle.net/ 


\section{REFERENCIAS BIBLIOGRÁFICAS}

Centre Promotor d'aprenentatge servei; Zerbikas Fundazioa. (2010). jPráctica APS! Guía práctica de aprendizaje-servicio para jóvenes. Bilbao: zerbikas.

Delors, J. (1996). Informe Delors. La educación encierra un tesoro. Comisión Internacional sobre la Educación para el siglo XXI: UNESCO

Santos, M. A., Sotelino, A., y Lorenzo, M. (2016). El aprendizaje-servicio en la educación superior: una vía de innovación y de compromiso social. Educación y diversidad: Revista inter-universitaria de investigación sobre discapacidad e interculturalidad 10(2), 17-24.

Tapia, M. N. (2006). Aprendizaje y servicio solidario: en el sistema educativo y las organizaciones juveniles. Buenos Aires: Ciudad Nueva.

Arranz, P. (2011). La Universidad de Zaragoza en materia de responsabilidad social. En I. Saz (coord.). Contribución de las organizaciones a la consecución de los objetivos del milenio, pp: 103-116. Valencia: Tirant lo Blanch.

Arranz, P; Dieste, B.; Aristizábal, D.; Abán, A. (2016). Aprendizaje-Servicio Universitario como una evidencia de la Responsabilidad Social Universitaria. Congreso Internacional Interuniversitario contra la Pobreza Infantil en el Mundo. Zaragoza, 6 de abril 2016. Disponible en http://www.unizar.es/aprendizaje_servicio/ formacion.html

Arranz, P.; Dieste, B.; Blasco, A.C. (2018). Programa de Innovación Aprendizaje - Servicio, Universidad de Zaragoza. En http://www.unizar.es/aprendizaje_servicio/index.html 
ANEXO I

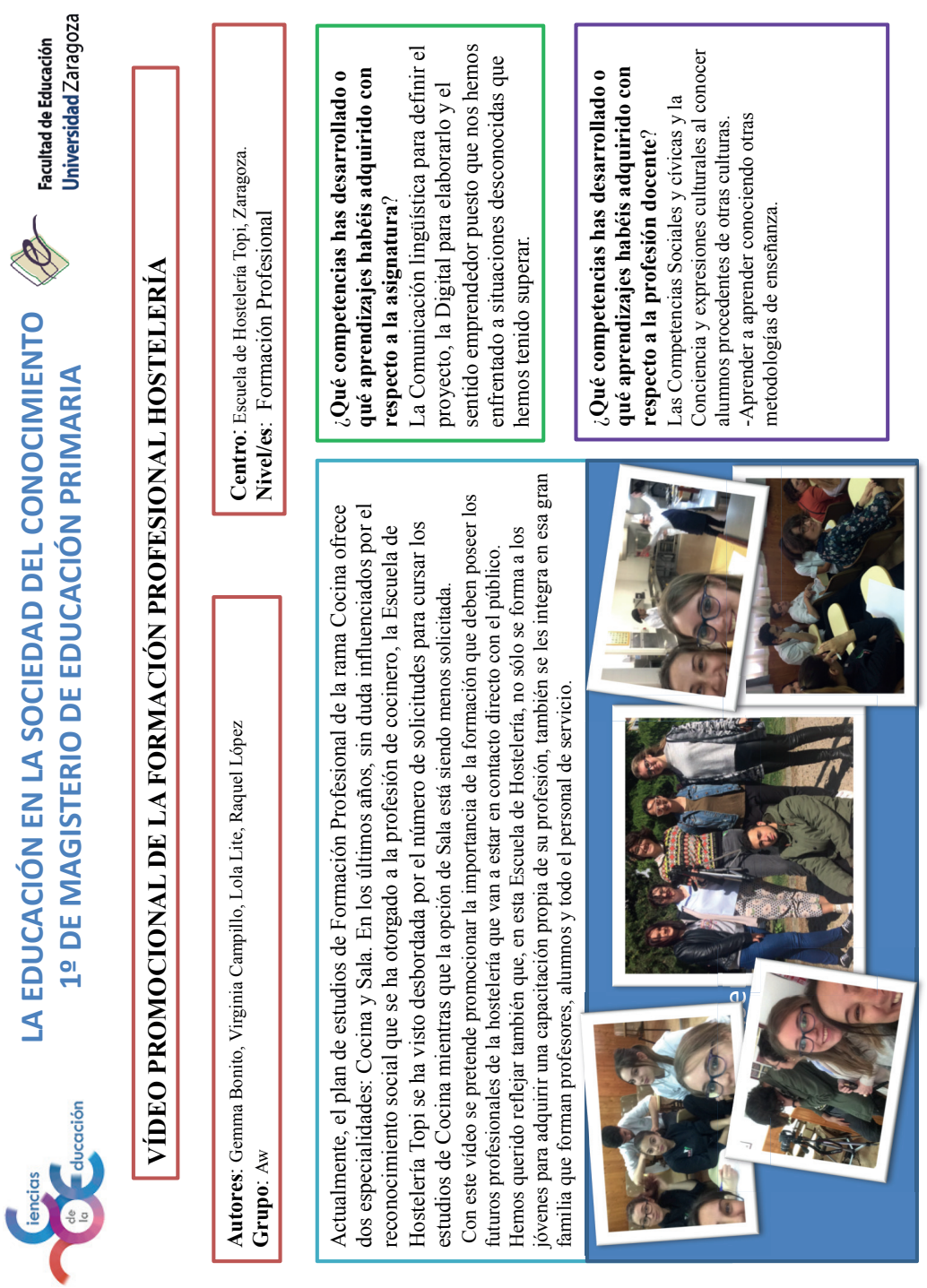




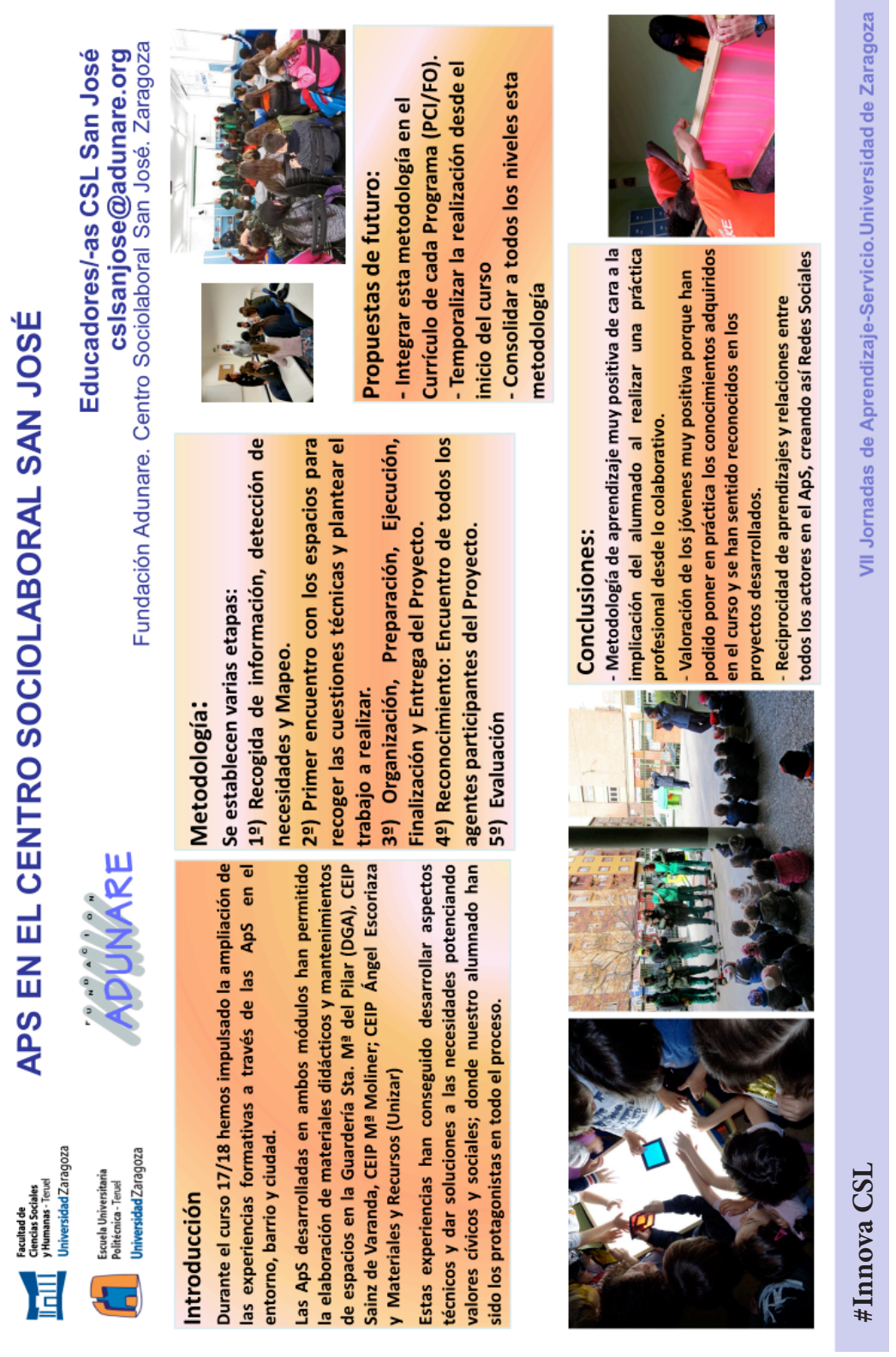




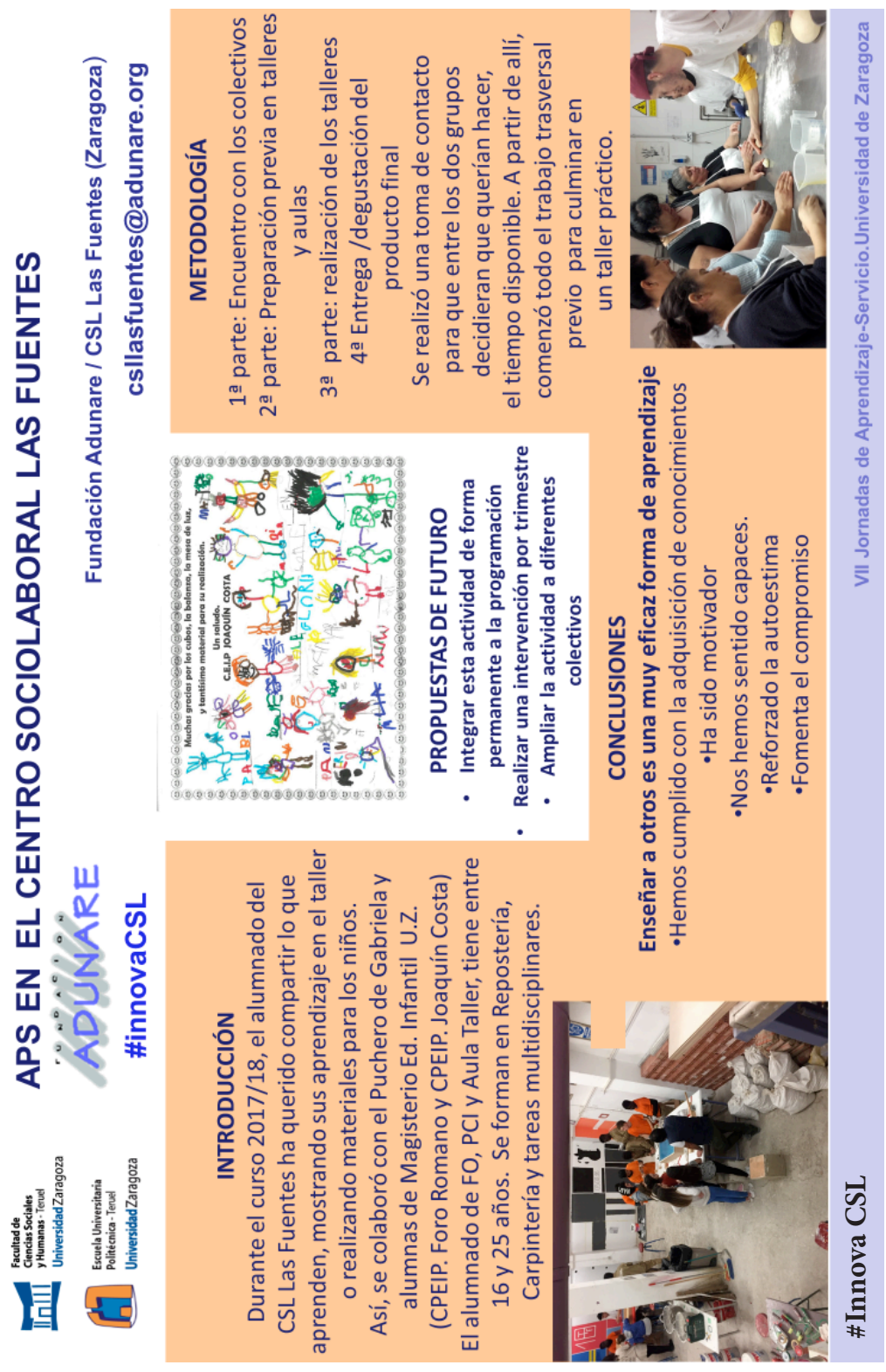


ANEXO II

Actividad/Proyecto:

TITULACIÓN:

Área/ Módulo vinculada/as:

Profesorado responsable:

Curso:

Necesidad detectada en la comunicad:

Entidades/colaboradores:

Responsable:

Servicio/Propuesta del centro

(objetivos, finalidades principales del proyecto ApS)

Organización del Proyecto. Justificación dentro de la Programación.

Este proyecto forma parte de....

Unidades formativas vinculadas:

\section{FASES DEL PROYECTO}

-Contacto con la entidad (centro educativo)

-Detección de necesidades

-Diseño del proyecto-Introducción en la Programación

-Desarrollo del proyecto-sesiones

-Celebración

-Evaluación proyecto

\section{SESIONES}

CELEBRACIÓN

EVALUACIÓN 


\section{ANEXO III}

Plantilla 1. Planificación curricular de un Proyecto ApS en un área o materia

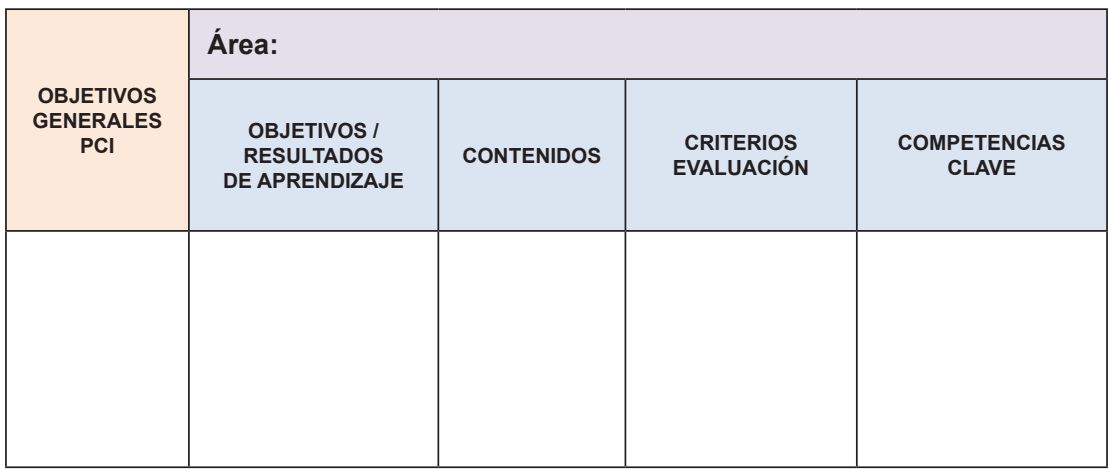

Plantilla 2. Planificación curricular de un proyecto ApS en un módulo-Plantilla planificación curricular de un Proyecto Aps en un Módulo.

\begin{tabular}{|l|l|l|}
\hline OBJETIVOS GENERALES PCI & \multicolumn{2}{|l|}{} \\
\hline \multirow{2}{*}{} & MÓDULO: & \multicolumn{2}{|l|}{ Unidades de trabajo: } \\
\cline { 2 - 4 } & & Unidades de trabajo: \\
\cline { 2 - 4 } & MÓDULO: & \\
\hline
\end{tabular}




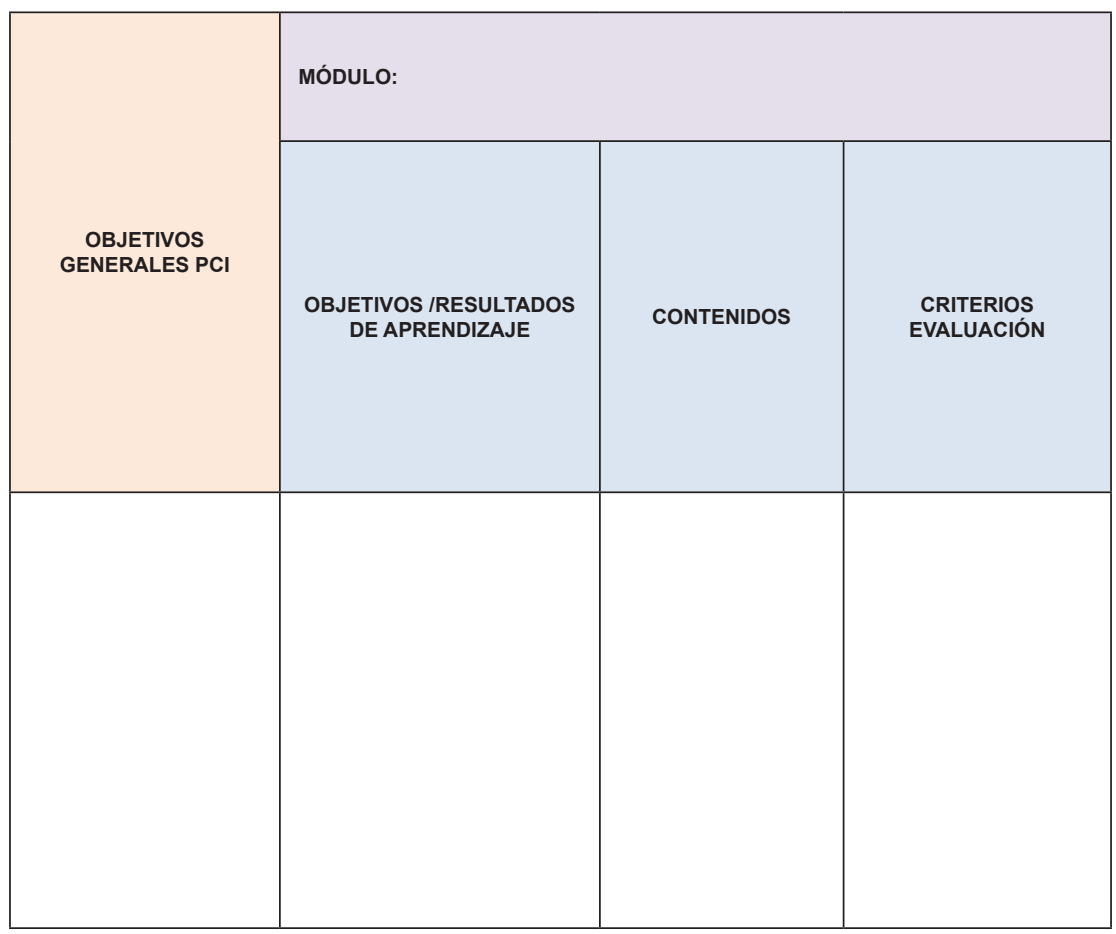




\section{ANEXO IV.}

Cuestionario de Evaluación.

Encuesta de satisfacción del proyecto ApS

(ALUMONS/AS)

\section{VALORA DE 1 A 4 (1 VALORA DE 1 A 4}

(1: desacuerdo total, 4: acuerdo total)

\begin{tabular}{|c|c|}
\hline $\begin{array}{l}\text { El proyecto me ha ayudado a entender mejor algunos } \\
\text { contenidos del módulo }\end{array}$ & (1) (2) (3) \\
\hline $\begin{array}{l}\text { Me ha gustado poner en práctica los conocimientos } \\
\text { en mi entorno }\end{array}$ & (1) (2) (3) \\
\hline $\begin{array}{l}\text { Me ha gustado planificar y organizar el trabajo en } \\
\text { un huerto escolar }\end{array}$ & (1) (2) (4) \\
\hline El trabajar con niños y niñas ha aumentado mi motivación & (1) (2) (4) \\
\hline Me gustaría volver a realizar un proyecto similar & (1) (2) (3) (4) \\
\hline
\end{tabular}

¿Qué has aprendido al realizar este proyecto?

¿Qué has sentido al ver que eres capaz de explicar lo que sabes a otras personas/niños? 
¿Qué es lo que más te ha gustado de

este proyecto? Puedes señalar varias opciones:

Trabajar con niños/as

O Aportar tus conocimientos para mejorar el colegio de tu barrio

P Poder organizar y planificar el diseño-cuidado de un huerto

O Realmente no ha habido nada que me haya gustado

¿Qué cambiarías o añadirías en la realización del proyecto? 


\title{
METODOLOGÍA APRENDIZAJE SERVICIO. ACCIONES EN RED ENTRE LA UNIVERSIDAD DE ZARAGOZA Y CENTROS SOCIOLABORALES
}

\author{
Belén Dieste Gracia, Ana Cristina Blasco Serrano, Pilar Arranz Martínez Ciencias de \\ la Educación/Facultad de Educación/Universidad de Zaragoza
}

\section{INTRODUCCIÓN}

En la Universidad de Zaragoza, a través de prácticas de aprendizaje-servicio (ApS), pretendemos aportar mayor significado y aplicación a las enseñanzas que se imparten en distintas materias y titulaciones y que están empelando esta estrategia metodológica. Según evidencian las experiencias e investigaciones, el ApS activa el ejercicio de todas las competencias del currículum, contemplando, como no, la iniciativa personal y la competencia social y ciudadana, es decir, la responsabilidad social (Arranz, 2015 y 2018).

En este capítulo se describe y reflexiona acerca de la consecución de las citadas competencias, mediante el trabajo conjunto y en red entre un grupo de profesoras investigadoras de la Universidad de Zaragoza y un total de once Centros Sociolaborales de la ciudad de Zaragoza.

\section{RED DE TRABAJO UNIVERSIDAD DE ZARAGOZA - CENTROS SOCIOLABORALES.}

En el año 2010, se inicia la andadura de un grupo de profesoras (todas mujeres) de la Universidad de Zaragoza, en el desarrollo y difusión de la metodología ApS en las distintas titulaciones. Cada año y cada curso se va uniendo al grupo más profesorado que desea aproximarse a esta metodología, movidos por la promoción del conocimiento y del compromiso social, bien desde alguna de sus asignaturas, bien desde la perspectiva investigadora.

En el curso 2017-2018, el interés por la promoción del conocimiento y, a su vez, por la propuesta metodológica aprendizaje-servicio, da lugar al inicio de un trabajo 
conjunto entre distintas asignaturas y titulaciones de la Universidad de Zaragoza y la Red Municipal de Centros Sociolaborales (CSL) de Zaragoza a través del proyecto \#InnovaCSL.

Esta asociación se crea a partir de la inquietud y demanda de los CSLs de incluir el ApS como metodología de enseñanza-aprendizaje. Los educadores interesados forman un Grupo de trabajo, al que se le ofrece la oportunidad de ser acompañados por profesoras de la Facultad de Educación con experiencia en actuaciones de aprendizaje-servicio.

A partir de aquí, los propios educadores solicitan un asesoramiento individualizado para cada uno de los proyectos. Así, durante los primeros meses del curso 20172018 se realizó un seguimiento a cada uno de los centros en la planificación didáctica y el establecimiento y consolidación de las relaciones con las instituciones de la comunidad. A lo largo del curso, los CSL van solicitando participar en el Grupo de trabajo, llegando a ser finalmente, 11 de los 12 centros educativos.

Por otra parte, y al mismo tiempo, desde la Universidad de Zaragoza, las asesoras del Grupo de Trabajo de ApS realizan proyectos con esta metodología incardinados en los procesos de enseñanza-aprendizaje de las asignaturas que imparten en distintas titulaciones. En definitiva, se propone como novedad que alumnado universitario y alumnado de los CSLs trabajen conjuntamente en proyectos de ApS., una colaboración que, desde nuestro punto de vista, ha contribuido, sin duda, a una mayor dinamización de competencias, tanto de los CSLs como universitarios.

A continuación, se exponen algunos de los proyectos ApS desarrollados durante el curso 2017-2018.

\section{ACCIONES CONJUNTAS DE APRENDIZAJE SERVICIO UNIZAR - CENTROS SOCIOLABORALES}

\subsection{Materiales y Recursos en Educación Infantil}

En la Asignatura de Materiales y Recursos en Educación Infantil de $2^{\circ}$ curso del Grado en Maestro en Educación Infantil, y con la ventaja de que en esta asignatura se tiene una sólida trayectoria de empleo del ApS (Dieste, Arranz y cols., 2013), se realizaron materiales educativos para Colegios Públicos de Educación Infantil. 
En este proyecto alumnas de Educación Infantil colaboraron con alumnado de Programas de Cualificación Inicial y de Aulas Taller. A partir de las necesidades detectadas en aulas de Educación Infantil, alumnado universitario y de CSL se encargaron del diseño, fabricación y decoración de estos materiales. En su mayoría se realizaron mesas de luz, juegos de madera y materiales de decoración.

Imagen 1. Planificación elaboración de recursos (Universidad).

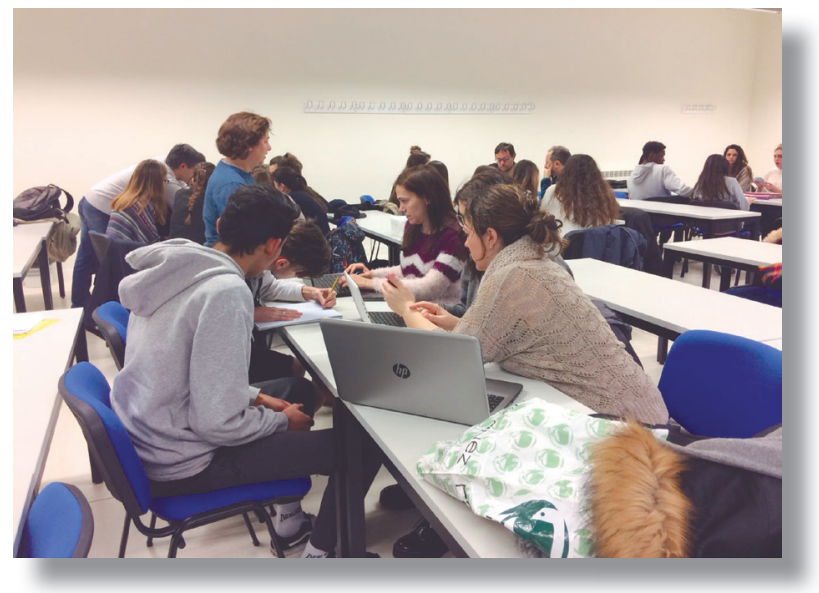

Imagen 2. Elaboración de Recursos Materiales (Aula Taller).

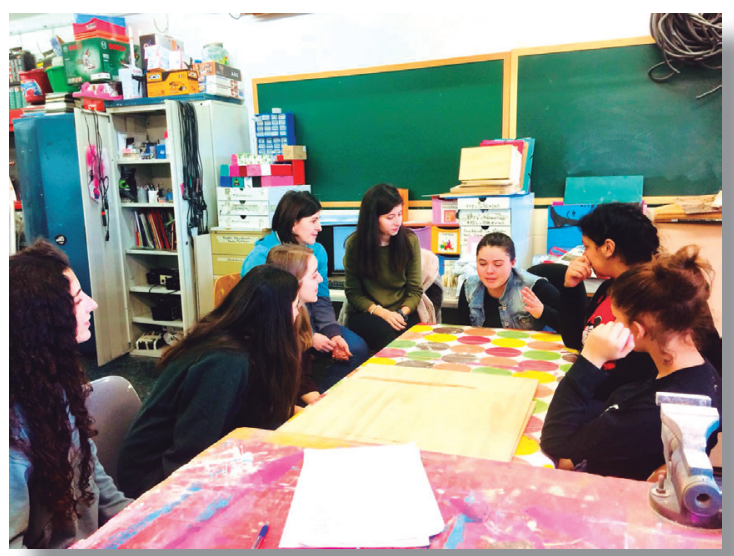


Finalmente, como "celebración" alumnado universitario y de los CSLs acudieron a las aulas de Educación Infantil a entregarles los materiales y a "disfrutarlos" con los niños y niñas de 3-5 años.

Imagen 3. Mesa de Luz para Aula de Educación Infantil.

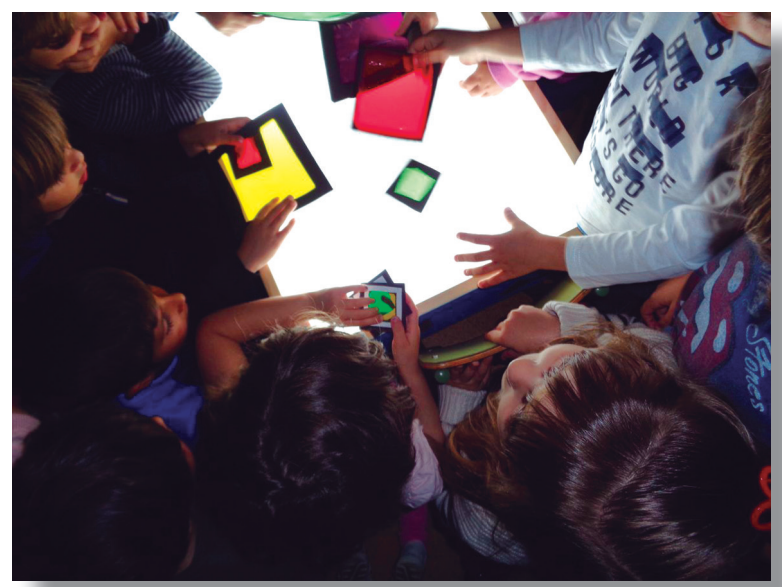

Imagen 4. Pared de Música para CP de Educación Infantil y Primaria.

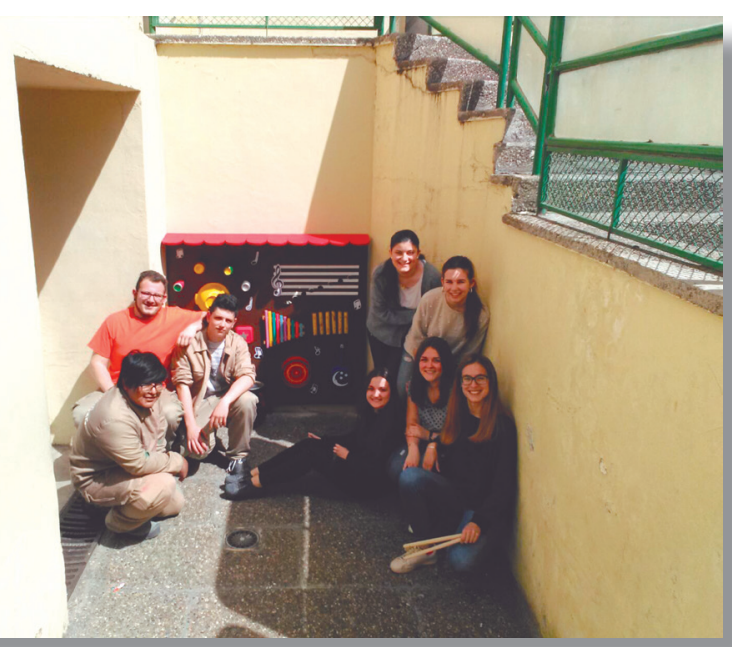




\subsection{Reportajes Gráficos de promoción y difusión de los Centros}

\section{Sociolaborales}

Otro de los proyectos llevados a cabo fue la realización de reportajes gráficos de promoción y difusión de la formación en los CSLs. En este caso los CSLs fueron los receptores del servicio, pero su alumnado realiza un trabajo conjunto con el alumnado universitario. El proyecto se desarrolló en el primer curso del Grado en Maestro de Educación Primaria, en la asignatura de Educación en la Sociedad del Conocimiento.

El alumnado de los CSLs intervenía en los reportajes como actores, y los alumnos y alumnas de la Universidad realizaron los guiones y la grabación.

Con estos vídeos se pretendió promocionar la importancia de la formación, en este caso de la Formación Profesional a través de los centros Programas de Cualificación Profesional. El alumnado universitario, tuvo que conocer a fondo estos centros para transmitir cómo funcionaban y qué tipo de educación imparten. En sus reportajes, involucrando al propio alumnado del CSLs, reflejaban que no sólo se forma a los jóvenes para adquirir una capacitación propia de su profesión, sino que también se les integra en la vida y funcionamiento del propio centro como comunidad educativa.

Imagen 5. Alumnado Universidad y CSL preparando reportajes.

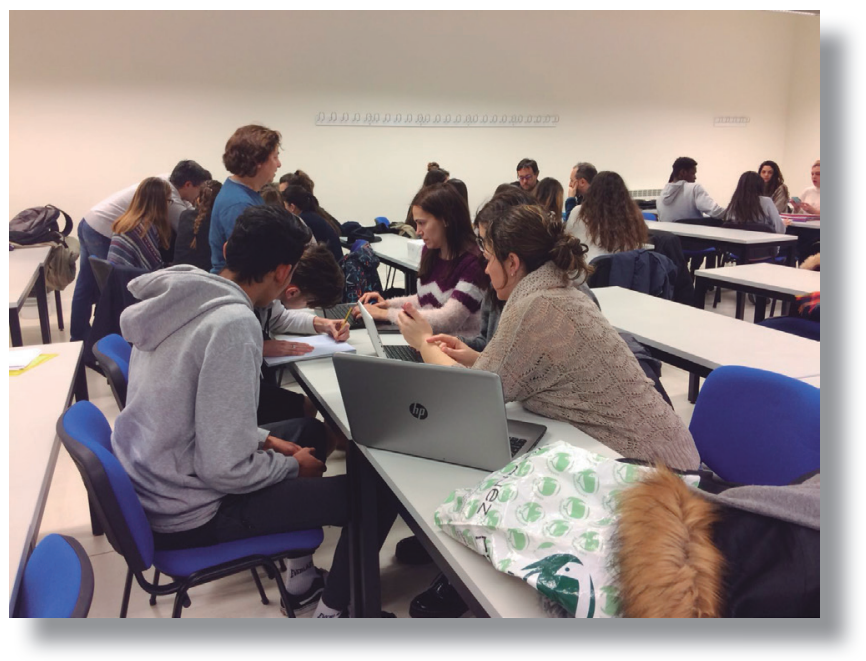




\subsection{Formación en Tecnologías de la Información y la Comunicación}

El alumnado de primer curso del Grado de Maestro en Educación Primaria, aplicó los conocimientos y destrezas adquiridos en la asignatura de Educación en la Sociedad del Conocimiento, impartiendo distintos talleres de formación a alumnado y profesorado de distintos Centros Sociolaborales. En este caso los CSLs actuaron también como receptores del servicio.

Los alumnos y alumnas de la Facultad de Educación prepararon distintos talleres sobre aplicaciones informáticas, entre ellos uno de Realidad Aumentada. Además de aprender el funcionamiento y características de estas aplicaciones, debían preparase para explicarlas ejerciendo el rol de docentes. Para ello, en primer lugar se informaron sobre qué es un CSL, cómo se organizan y cómo es el alumnado de estos centros.

Desde el CSL, se les solicitó también la búsqueda de aplicaciones con las que pudieran trabajarse algunos contenidos específicos de los Programas de cualificación inicial, como fontanería o carpintería. EL alumnado tuvo que investigar y encontrar la herramienta adecuada para trabajar los contenidos solicitados.

El alumnado universitario además de conocer los contenidos propios de la asignatura, tuvo que desarrollar competencias orales y personales para realizar las exposiciones delante de docentes y alumnado.

Imagen 6. Alumnado universitario impartiendo taller de Realidad Aumentada

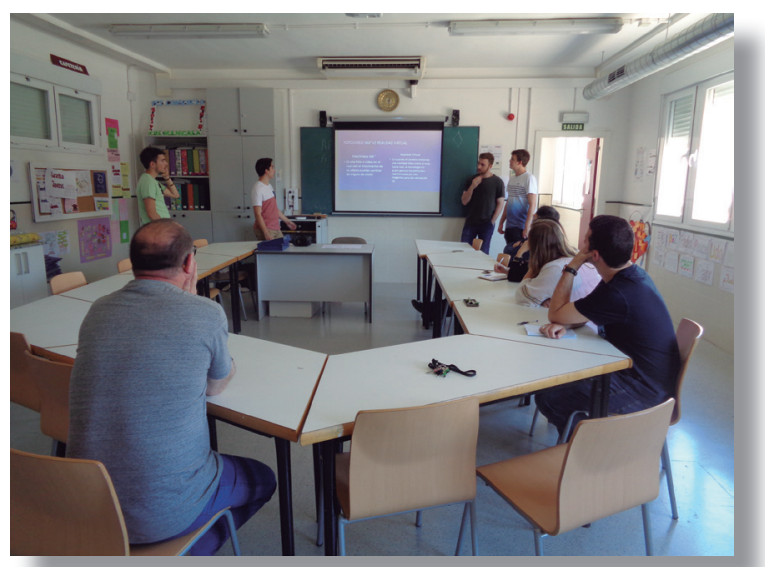


Imagen 7. Reflexiones en el taller de Realidad Aumentada

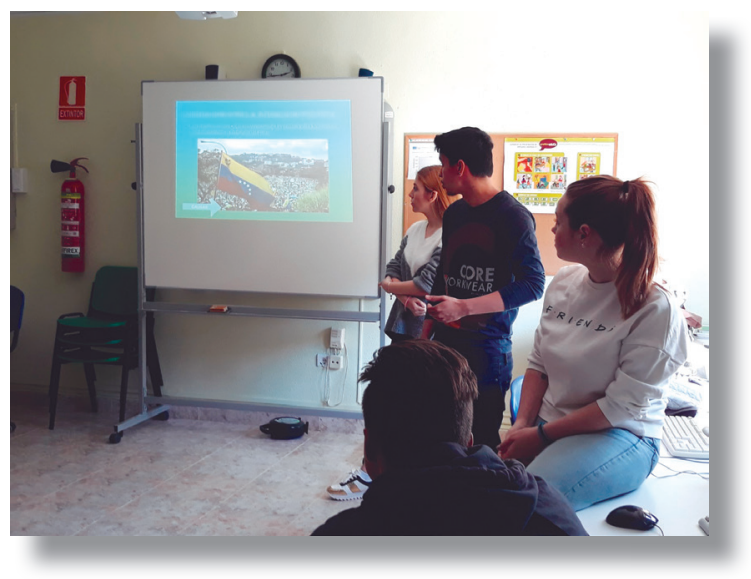

\subsection{Taller de repostería}

Este proyecto lo realizaron alumnado de un Programa de Cualificación Inicial en Repostería y una asociación de su entorno. Esta actividad fue asesorada y guiada por docentes de la Universidad de Zaragoza. En este proyecto se insistió mucho en la participación del alumnado del PCI. Se le involucró en planificar, organizar y llevar a cabo la actividad. También fue importante el contacto del alumnado con las personas de la asociación, en este caso mujeres y amas de casa en su mayoría.

Los alumnos y alumnas, además de desarrollar las competencias propias de su programa de repostería, pudieron trabajar otros aspectos curriculares, como la expresión oral y escrita, ya que tuvieron que preparar folletos explicativos sobre cómo hacer repostería sana y transmitir toda esta información a las integrantes de la asociación.

Hubo dos encuentros: uno de conocimiento mutuo, en el que las mujeres les explicaron su asociación y les pidieron qué querían aprender. En el segundo encuentro ya se hizo la formación.

La formación incluyó un folleto informativo, una exposición y un taller donde las mujeres de la asociación hicieron su propia repostería. 
Imagen 8. Realización del taller de repostería.

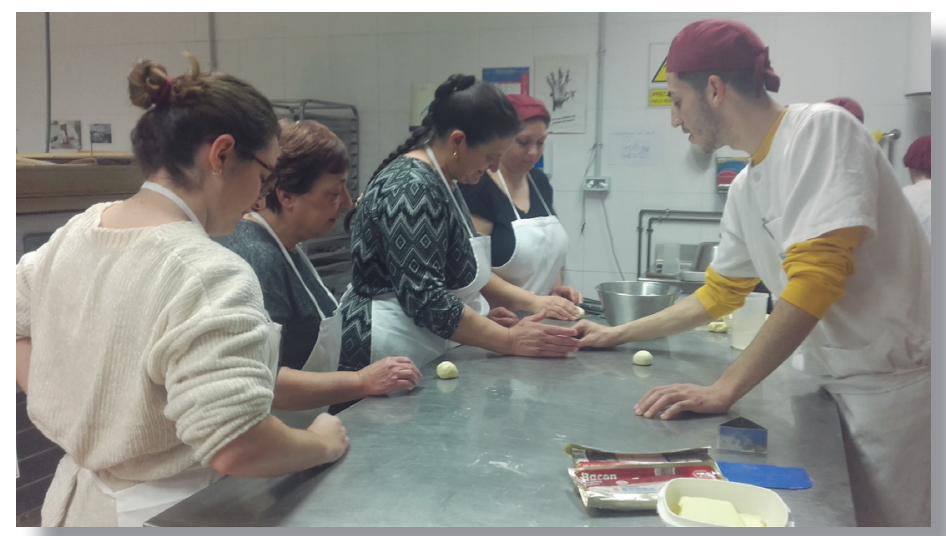

Imagen 9. Otro momento del taller de repostería.

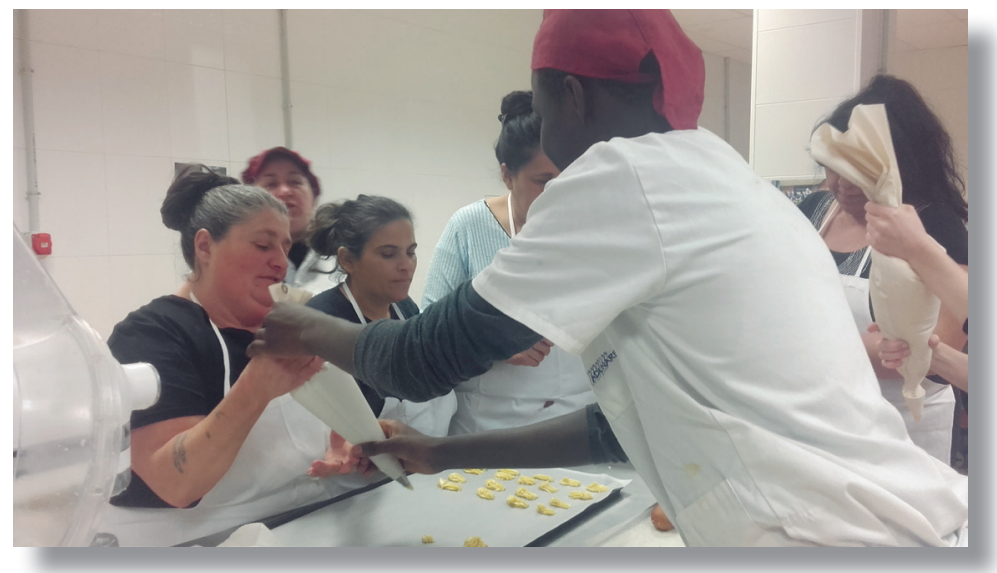


Imagen 10. Alumnado y mujeres de la Asociación tras el taller de repostería.

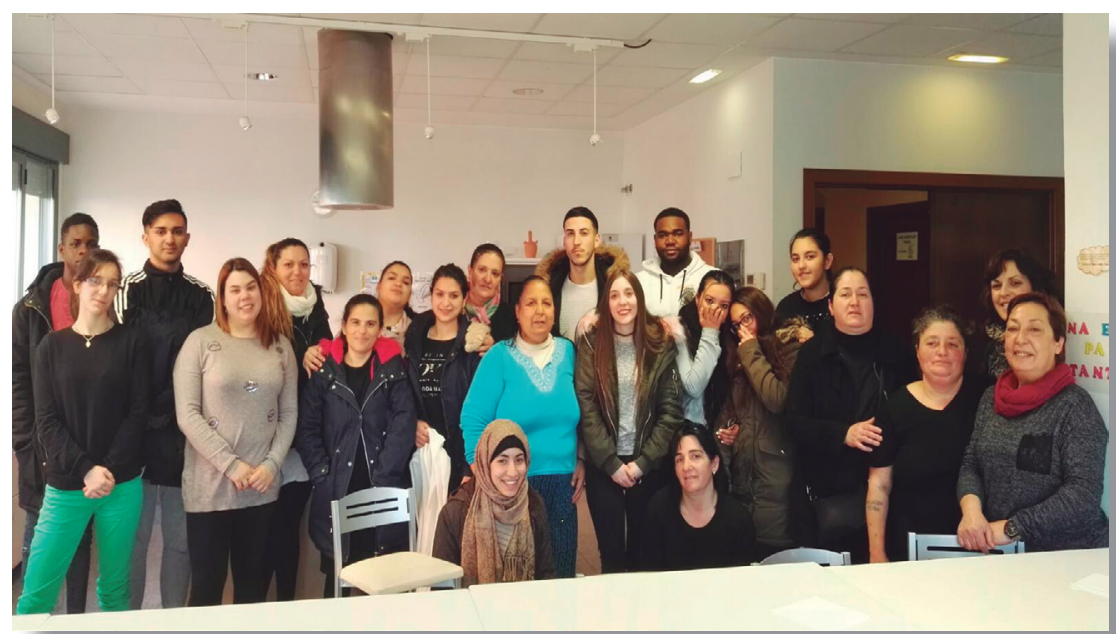





\subsection{REPORTAJES DE TV PARA VISIBILIZAR A LOS PROTAGONISTAS DE LOS CENTROS SOCIOLABORALES}

Elena Bandrés (profesora en el Grado de Periodismo, Universidad de Zaragoza).

El alumnado de $2^{\circ}$ del Grado de Periodismo y Comunicación Audiovisual de la Universidad de Zaragoza ha realizado cuatro reportajes de unos cinco minutos de duración cada uno, con el objetivo de visibilizar al alumnado de los Centros Sociolaborales, a su profesorado y a la labor que se lleva a cabo, así como aprender a realizar esta técnica televisiva.

La asignatura Producción de Informativos de TV, que se imparte en el segundo curso del Grado de Periodismo de la Universidad de Zaragoza ha colaborado con el proyecto Innovación y éxito educativo en los Centros Sociolaborales (\#innovaCSL), con la realización de cuatro reportajes con los que se ha retratado el trabajo realizado en estos centros, desde cuatro puntos de vista diferentes. La experiencia ha sido altamente positiva para ambas partes ya que, desde el punto de vista educativo para el alumnado de Periodismo, no sólo han tomado contacto con este tipo de práctica periodística, sino que también han establecido un puente de conexión con jóvenes que llevan trayectorias académicas diferentes. Al poner al servicio de estas chicas y chicos toda la infraestructura televisiva, ha servido también para poner en valor a los propios estudiantes de los CSL's, al convertirlos en protagonistas televisivos, algo a lo que ellos no estaban acostumbrados/as.

Durante toda la realización del reportaje, cada estudiante de Periodismo ha tenido presente el servicio público del trabajo periodístico.

Para tal fin se han realizado cuatro reportajes con cuatro temáticas diferenciadas:

a. El primero ha recogido la información genérica sobre los Centros Sociolaborales. Se han respondido a las preguntas, qué son los CSL; cuándo se forman y por qué; cuánto alumnado tienen; cuáles son los perfiles mayoritarios del alumnado; qué tipos de enseñanzas reciben y qué se aprende.

b. El segundo reportaje ha consistido en reflejar la aplicación de una actividad de aprendizaje servicio (ApS) en el Centro Sociolaboral. Este reportaje ha recogido el trabajo que varios colegios de educación infantil y primaria de Zaragoza han encargado al alumnado de segundo curso del Grado de Educación Infantil, dentro de la asignatura "Materiales y recursos didácticos 
en Educación Infantil". El alumnado de los Centros Sociolaborales de Las Fuentes y San José, entre otros, han colaborado en la elaboración de estos materiales didácticos.

c. El tercer reportaje ha recogido el éxito en la vida, tras haber sido alumna o alumnos de un centro sociolaboral. Se ha retratado el éxito de una chica como cocinera, tras haber cursado estudios en un CSL.

d. Por último, se ha realizado un reportaje sobre la multiculturalidad de los Centros Sociolaborales, en donde se ha puesto en valor la riqueza de la diversidad cultural que hay en sus aulas.

Imagen 11 y 12 Estudiantes dentro del aula.
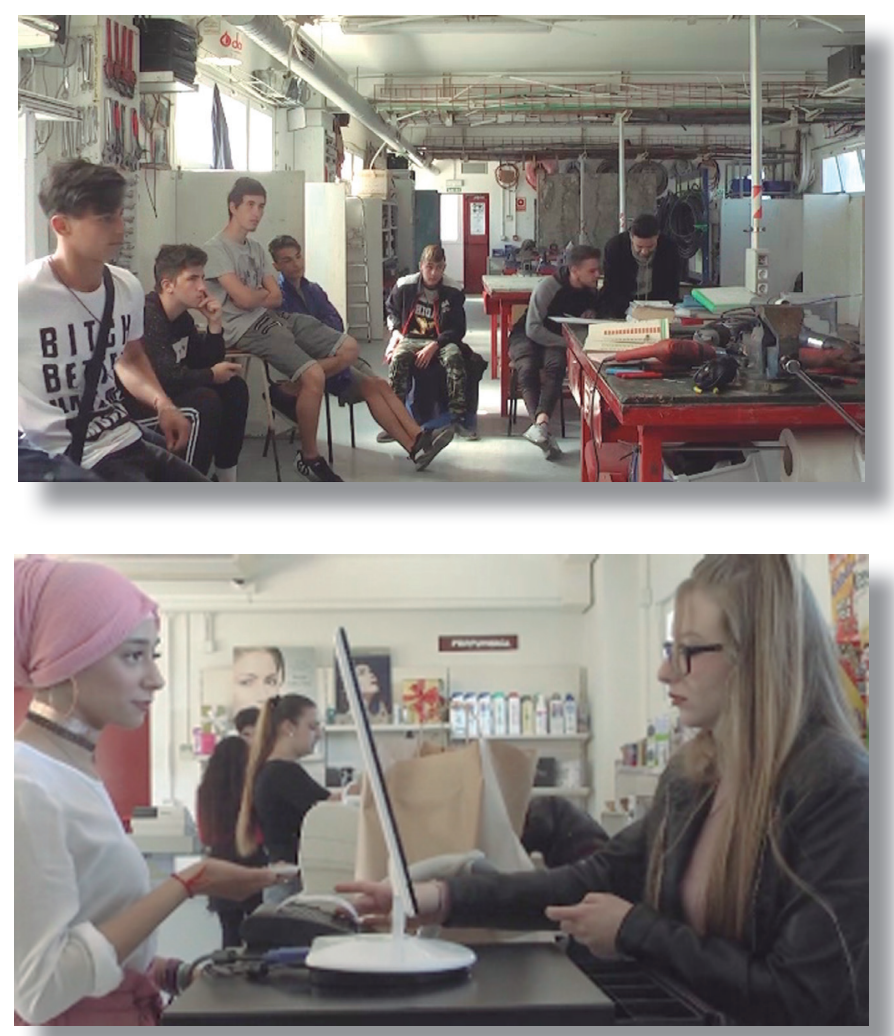


\section{CONCLUSIONES}

A través de los proyectos de aprendizaje-servicio, desde distintas materias y titulaciones, se pretende aportar mayor significado y aplicación a los aprendizajes del alumnado universitario, permitiendo, con dichas prácticas, desarrollar contenidos curriculares y consolidar aprendizajes, de modo que se dinamice la adquisición de las competencias académicas específicas, y también las denominadas transversales (práctica de la planificación, esfuerzo, iniciativa, facilidad para trabajar en equipo, etc.) y las relacionadas con la responsabilidad social tanto en la vida personal como en la profesional (Arranz, Vázquez y Abán, 2013)

Con estas experiencias, se pretende dar muestra de la necesidad de que la Universidad abra sus puertas y ventanas hacia la realidad social en la que se enmarca y que ha depositado su confianza en esta institución pública que es la Universidad de Zaragoza (Vázquez, Liesa y Revilla, 2015). En este sentido, el trabajar con los CSL permite al alumnado universitario conocer otra realidad educativa y social.

En esta relación de distintas entidades y realidades educativas cuyo eje motor ha sido la metodología Aprendizaje-Servicio, podemos extraer las siguientes conclusiones como aspectos relevantes a tener en cuenta en futuros proyectos:

a. Es imprescindible contar con una buena coordinación entre todas las partes implicadas.

b. Deben conocerse y ajustar bien las expectativas de partida de actores y receptores.

c. Se debe formare informar bien a las partes implicadas.

d. Debemos pensar y planificar bien otros aspectos formales: seguros estudiantiles, desplazamientos, ...

e. Se deben plantear los aprendizajes relacionados con el currículo que el alumnado está trabajando.

f. El servicio que se da a la comunidad debe ser de calidad.

g. Debe existir un destacado protagonismo del alumnado en todas las fases del proyecto.

Para finalizar, deseamos poner de manifiesto que, habiendo diferentes motivos por los que las profesoras firmantes de este capítulo estemos satisfechas con nuestro 
trabajo en la Universidad de Zaragoza (es una fuente de ingresos, tenemos la oportunidad de investigar, nos gusta ser profesoras, etc., etc.), pero hay uno común que estimamos pertinente resaltar, y es que el aprendizaje servicio contribuye a nuestro interés de mejorar cada curso la docencia que nos adjudican y a sentirnos más responsables de los posibles logros que puedan alcanzar nuestros estudiantes y todos los estudiantes de la comunidad próxima. También nosotras aprendemos a través de los proyectos de aprendizaje-servicio y de los estudiantes que los llevan a cabo.

\section{REFERENCIAS BIBLIOGRÁFICAS}

Arranz, P. (2015). El aprendizaje-Servicio en la formación de docentes. En S. Vázquez, M. Liesa y A. Revilla, (coords.) El aprendizaje-servicio: diálogo universidad y sociedad (pp.7-21). Zaragoza, España: Facultad de Ciencias Humanas y de la Educación. Recuperado de https://zaguan.unizar.es/record/31885? ln=es

Arranz, P.; Vázquez, S. y Abán, A. (2013). El proyecto de Aprendizaje-servicio en la Universidad de Zaragoza: un análisis DAFO. En L. Rubio, E. Prats y L. Gómez (coords.). Universidad y sociedad. Experiencias de aprendizaje servicio en la universidad (pp.299-214). Barcelona: Universitat de Barcelona (Institut de Ciències de l'Educació). Obra disponible en https://www.uv.es/aps/doc/Biblioteca $\% 20$ Blog/Univerdidad $\% 20 y \% 20$ sociedad.pdf

Dieste, B.; Arranz, P.; Aristizábal, D.; García, C.; Gayán, T. y Vázquez, S. (2013). Aprendizaje-Servicio. Creación de materiales y recursos didácticos de educación infantil en contextos educativos reales. En L. Rubio, E. Prats y L. Gómez (Coords.). Universidad y sociedad. Experiencias de aprendizaje servicio en la universidad (pp. 41-44). Barcelona, España: Universitat de Barcelona (Institut de Ciències de l'Educació). Obra disponible en https://www.uv.es/aps/doc/Biblioteca\%20Blog/ Univerdidad $\% 20 \mathrm{y} \% 20$ sociedad.pdf 


\title{
INTERVENCIÓN CON FAMILIARES DE ALUMNADO DE LA RED MUNICIPAL DE CENTROS SOCIOLABORALES (ZARAGOZA).
}

\author{
Chabier Gimeno Monterde \\ Universidad de Zaragoza
}

\section{FAMILIAS Y EDUCACIÓN: UNA RELACIÓN COMPLEJA}

La familia es un grupo social primario, que desempeña funciones clave para la socialización de los miembros y la cobertura de sus necesidades básicas. Por lo que también juega un papel determinante en la educación de los miembros. Y lo hace no desde una posición aislada, sino permeable a las transformaciones de la sociedad, por los cambios económicos, sociales y políticos. Así como siendo agente generador de cambios (Fernández, 2015). En este último sentido, entendemos que su rol ante el fracaso escolar, como agente preventivo y, cuando es necesario, de promoción, también resulta clave.

Con todo, en relación a la familia y su intervención en el contexto escolar, hay dos visiones contrapuestas cuando hablamos de fracaso escolar: esto es, cuando el alumnado no es capaz de alcanzar el nivel de rendimiento medio esperado para su edad y nivel pedagógico (Mateo, 2010: 2). Por un lado, se propone un análisis según el cual este fracaso está causado por el nivel de estudios de la familia, su clase social, sus recursos, etc (Rahona y Morales, 2013; Fernández, 2011; Gastañaga, 2007; Roselló, 1998; Sanz, 2007). Mientras que, por otro lado, otros análisis del origen del fracaso escolar señalan a la metodología del centro educativo como clave para superarlo, independientemente del origen social o cultural de las familias y el alumnado (Girbés, Macías y Álvarez, 2015; Garcia, Morlà y Ionescu, 2018).

El primero de los enfoques plantea una relación positiva entre el nivel económico y educativo de los progenitores y el éxito escolar del alumnado (Fernández, Mena y Riviere, 2010a y 2010b). De forma que la probabilidad de acceder a la educación superior es mucho mayor para el alumnado que proviene de la clase media, que para el que proviene de la clase trabajadora. Llegando a vincular la estructura familiar (familia no nuclear, etc) y el resultado académico (Díaz, Rodríguez y Sánchez, 2011). 
Según esto, el alumnado que forma parte de familias en situación de exclusión social, a las que se atribuye un menor nivel académico y menor autonomía económica, tendría más posibilidades fracasar en su itinerario formativo (Meil, 2006). No por una inferior capacidad intelectual o por poseer menos habilidades, sino por condicionantes sociales, laborales o culturales de su familia (Blanco, 2006).

En clara contraposición a estos análisis, existen otros equipos de investigación que señalan que el origen del fracaso escolar no está en la familia, sino en diversos puntos débiles del sistema educativo: como los contenidos excesivos en el currículo escolar, la formación inadecuada del profesorado, los recursos técnicos y físicos que tiene la escuela, la falta de democracia en los centros, etc (Mateo, 2010). Según esto, no existe una relación directa entre el fracaso escolar y el nivel académico o económico de los progenitores. Sino que la clave está en las estrategias educativas que se dan en los diversos contextos donde el alumnado desarrolla su vida escolar (Valls, Prados y Aguilera, 2014). Entre otras, una buena comunicación y uso del lenguaje académico con la familia, unas expectativas de futuro positivas hacia el alumnado, una actividad cultural sostenida en el centro, etc. De forma que, aunque la familia provenga de una trayectoria educativa con resultados inferiores, ésta pueda compensarse, mediante un mayor compromiso y apoyo por parte de la familia a la actividad académica del alumnado (Lozano, 2003).

Como señalan los resultados del proyecto europeo INCLUD-ED ${ }^{1}$, si las familias participan en actividades formativas, pueden superar la barrera que supone tener un bajo nivel de estudios. Aprendiendo los familiares a la vez que sus hijos nuevos conocimientos. Lo que produce cambios en la dinámica del funcionamiento del hogar y en la relación con la experiencia escolar (Valls, Prados y Aguilera, 2014).

De acuerdo a esto, el proyecto \#innovaCSL plantea que el rendimiento escolar no depende del nivel de estudios de la familia, ni de los recursos económicos que esta posea. Siendo la clave para superarlo que tanto los centros educativos, como las familias trabajen juntas, no culpabilizándose mutuamente. Cuando ambos entornos permanecen ajenos entre sí, incluso irreconciliables, es muy difícil abordar el abandono escolar prematuro y el absentismo del alumnado.

1 Dentro del VI Programa Marco de la Comisión Europea (2006 y 2011), con catorce estados participantes. 
Desde este equipo de investigación apostamos por experiencias de implicación de las familias en el contexto educativo, basadas en la generación de espacios y tiempos para la participación (Martínez y Niemelä, 2010; Amador y Girbés, 2016). Entre ellas:

a. La oferta de formación para familiares, como los programas de alfabetización. Estas actividades mejoran la participación de las familias en los centros y facilitan la colaboración con los deberes, así como en la estimulación de hábitos de estudio en los menores. Generando, además, un aumento de las expectativas de futuro en relación a los hijos.

b. La participación en los procesos de toma de decisión de los centros educativos junto al profesorado. Estos espacios contribuyen a la caída del absentismo y facilitan acuerdos entre profesores y familias en relación al tipo de formación que se quiere impartir al alumnado. Mejorando igualmente la convivencia en los centros.

c. La participación en el desarrollo del currículo y en la evaluación de las actividades del centro educativo (Lastikka y García-Carrión, 2012).

d. Y la participación de las familias y de otras personas de la comunidad dentro del aula: a través, por ejemplo, de los grupos interactivos. Que reúnen al alumnado de manera heterogénea en la misma aula, con el profesorado y otra persona adulta (que facilita la cooperación y el diálogo), mejorando tanto la convivencia, como el rendimiento escolar.

De ahí que se haya presentado como innovación la implementación de estrategias para implicar positivamente a las familias en los Centros Sociolaborales, mejorando su relación con sus profesionales. Yendo más allá de lo educativo, pues la participación de familiares y otros miembros de la comunidad local influye de manera positiva en las habilidades sociales, la autoestima o los hábitos de estudio del alumnado (Martínez y Álvarez, 2005). Y contribuye a una mejora, igualmente, en la motivación hacia el logro entre los docentes (García y Macías, 2013), que deben implicarse en mejorar los vínculos con alumnado y familias a través de proyectos concretos (Domínguez, 2010).

Como veremos después, para que esta intervención tenga lugar, hay que tener en cuenta la disponibilidad o la implicación de los familiares, muy heterogénea. Ya que todos no tienen las mismas motivaciones para participar socialmente $\mathrm{y}$, por tanto, también en los centros educativos. Aunque ese sea un paso ineludible en el itinerario hacia el éxito educativo (Amaya, 2016). 


\subsection{Familias, diversidad cultural y educación.}

Dadas las características sociodemográficas del alumnado de los CSL y sus familias, debemos analizar también los debates en torno al riesgo o la oportunidad que supone la diversidad cultural en sus aulas. Al igual que en el resto de los entornos educativos. Analizando la relación entre la escuela y las familias procedentes de culturas diferentes de la mayoritaria, las perspectivas críticas (Macías y Redondo, 2012) señalan que los elevados índices de exclusión social existentes en nuestra sociedad indican un déficit de igualdad de oportunidades. Lo que cuestiona las garantías democráticas de la actual ordenación de lo escolar, al no existir un derecho universal a la educación.

Desde este punto de vista, la implantación de la LOGSE y otras leyes posteriores ha incidido negativamente sobre la igualdad. Estos modelos legislativos diversifican curricularmente, con un resultado final segregador (FSG, 2013). Para ejemplificarlo, se plantea como paradigma la exclusión educativa del pueblo gitano. Que a día de hoy no ha conseguido superar su marginación histórica, fruto de factores de segregación, racismo y estereotipos sobre su cultura (Macías y Redondo, 2012).

Precisamente en esta comunidad la familia tiene un papel clave como articuladora, también a la hora de transmitir los valores y la educación a sus descendientes. Por lo que es necesario que brinde el apoyo a estos en el acceso al sistema educativo (Arbex, Chamorro, de Silva, Hernández y Sánchez, 2013). La ausencia de estrategias educativas que tengan en cuenta este factor, ha provocado un desfase, una brecha entre la mejora del perfil académico del pueblo gitano y del resto de la población.

En la misma situación se encuentran las familias de origen extranjero que, desde inicios de siglo, concurren en los centros educativos aragoneses. Y que protagonizan un nuevo desencuentro entre familias de grupos culturales minoritarios y un sistema educativo que no ha conseguido plantearles una colaboración positiva (Prados, Gomáriz, Parra y García, 2016). Las carencias técnicas del profesorado en cuanto a educación intercultural, llevan a las organizaciones educativas a incidir en la diversidad como una "necesidad" o "dificultad", contra las evidencias que la postulan como un factor propiciatorio del éxito educativo (Campani y Serradell, 2010).

En este caso, las investigaciones también muestran divergencias. Aunque la evaluación internacional de los cambios favorables que propician las metodologías 
participativas (Flecha y Soler, 2013) está arrinconando progresivamente los discursos culturalistas ${ }^{2}$ de algunos referentes académicos (Fernández, 1999: 26) y de una parte del Tercer Sector.

\section{Las Familias en \#innovaCSL.}

Para aproximarnos al conocimiento de la relación entre las familias y la educación del alumnado de los CSL hemos optado por una metodología cualitativa. Pues lo que pretendemos analizar es la implicación de las familias, la opinión de los profesionales, etc. Y lo cualitativo nos permite, además, acceder a la subjetividad de los participantes en el proceso estudiado, de forma que puedan ser sujetos activos de la investigación (Gómez, Elboj y Capllonch, 2013).

Entre febrero y junio de 2017, dos alumnas del Grado de Trabajo Social y el equipo investigador hemos llevado a cabo: un taller formativo con la Fundación Pioneros (durante las I Jornadas del proyecto, noviembre 2016), observación participante en cuatro CSL y en dos grupos de trabajo del proyecto de innovación (Familias y Diversidad), un grupo focal con profesionales y entrevistas semiestructuradas a cuatro coordinadoras de centros. Mientras que, por su parte, el grupo de trabajo sobre familias ha realizado tres entrevistas a familiares de alumnos y un cuestionario a los doce centros de la Red sobre su metodología de intervención con familias y la diversidad en el aula.

Con la información recabada, se organizó una sesión de retorno al conjunto de los profesionales de la Red, dentro de las II Jornadas "Herramientas para la innovación y el éxito educativo" (junio 2017). Concluyendo las mismas con un taller de formación, a cargo de un experto en intervención familiar.

En este capítulo se analiza la información surgida en este trabajo de campo, dentro de la primera fase del proyecto de investigación (curso 2016-2017). 


\section{LA INTERVENCIÓN SOCIOEDUCATIVA CON FAMILIAS EN LOS CSL.}

A partir de la información recogida durante el trabajo de campo, además del perfil del alumnado, también nos hemos acercado al de sus familias. Así como a su implicación en las actividades socioeducativas de los centros y la imagen que tienen de estos. Como veremos, las dificultades, que las investigaciones citadas anteriormente nos muestran, también están presentes en este contexto formativo. De forma que entre los profesionales de los CSL se valora positivamente la participación de familiares, pero se percibe como un reto de gran dificultad, que exigiría objetivos asequibles a corto plazo.

\subsection{Perfiles de las familias.}

En primer lugar, hemos concluido que el perfil de las familias del alumnado de los CSL es muy diverso, no existiendo uno prototípico. En cuanto a la tipología para perfilar a las familias, existe una gran variedad, pero se puede afirmar que según su extensión existen dos tipos de familias principales (Elboj y Íñiguez, 2012):

a. La familia nuclear, que suele estar compuesta por dos personas adultas que viven juntas en un hogar, con hijos propios o adoptados. Dentro de ella también existen familias monoparentales y monomarentales, que pueden incluir a un padre o una madre solos (solteros, viudos, divorciados, separados) con uno o más hijos.

b. Y la familia extensa, en la que convive la pareja casada, los hijos y otros familiares, ya sea en el mismo hogar o en contacto continuo.

Además de por su estructura, las familias del alumnado pueden clasificarse por otras variables. De forma que puede plantearse la siguiente tabla:

Tabla 1.Características de las familias

\begin{tabular}{|c|c|c|}
\hline \multirow{2}{*}{$\begin{array}{l}\text { Diversidad } \\
\text { cultural }\end{array}$} & Origen extranjero & $39,44 \%$ \\
\hline & Pueblo gitano & $38,53 \%$ \\
\hline \multirow{2}{*}{ Intervención } & Servicio de Protección de Menores & $19,26 \%$ \\
\hline & $\begin{array}{c}\text { Con apoyo económico o socioeducativo } \\
\text { por recursos sociales }\end{array}$ & $50,45 \%$ \\
\hline
\end{tabular}

Fuente: elaboración propia, datos del Ayuntamiento de Zaragoza (2017-18). 
Por tanto, el $77,97 \%$ de las familias pertenecen a grupos culturales minoritarios (de origen extranjero y etnia gitana), sobrerrepresentados respecto a la Educación Secundaria. Y para un quinto del alumnado actúan como referentes para el ámbito escolar los profesionales de la intervención social (educadores, trabajadores sociales y psicólogos).

Así mismo, percibimos una situación dual. La situación económica de las familias, donde la mitad no necesita apoyo económico, parece evidenciar que, en esta franja de edad, no hay un vínculo directo y universal entre renta familiar y "fracaso escolar", al contrario de lo que plantean algunas investigaciones (Fernández, Mena y Riviére, 2010a). Aunque, observando el volumen de las familias más vulnerables, estas también están sobrerrepresentadas respecto a la Educación Secundaria. Señalando los datos a quienes están sufriendo no sólo la actual crisis económica, sino a quienes ya estaban excluidos en generaciones anteriores, como ya reseñábamos en la introducción del libro (Macías y Flecha, 2013).

\subsection{Relación e implicación del Centro con la familia.}

Con estos perfiles familiares de trasfondo, nuestro análisis observa que tanto la implicación, como la relación del Centro con la familia tienen una condición previa, pues en la práctica dependen de la edad del alumnado. Esto es, cuando los alumnos son mayores de edad, la relación del centro con la familia suele ser mínima. Dado que, si uno de estos alumnos falta, se le suele llamar a él y no a su familia. Pero cuando los alumnos todavía son menores, la relación que existe con la familia es mayor, ya que se les comunica a estos todo lo relacionado con sus hijos.

En ambos casos, hay también una fuerte influencia de otra circunstancia ajena a los CSL, como es la relación previa de la familia con el Instituto de Educación Secundaria de procedencia. Y en especial con los orientadores de los mismos. El factor que determina esta relación es el mayor o menor conocimiento del adolescente por parte del orientador del IES. El discurso mayoritario recogido en los CSL indica que "muchos orientadores apenas conocen a los chicos e incluso carecen de información suficiente sobre ellos" (grupo focal). Por lo que, según ese mismo argumento, la posterior relación de la familia con los tutores y los orientadores de los CSL, viene ya marcada por malas experiencias previas. Esto es más grave en los casos 
de externalizaciones a las Aulas Taller, cuando la familia desconoce qué itinerario escolar permite esta modalidad educativa: “ ¿Va aprobar la secundaria aquí? ¿Que va a obtener mi bijo? Se les dice que el aula taller no equipara a la secundaria y hay que sentarse a bablar con ellos y explicárselo" (grupo focal).

Una vez tenidas en cuenta estas consideraciones previas, de acuerdo a la tabla 2, cuando las familias tienen una relación con el centro a demanda de éste, suele circunscribirse a trámites formales en tanto que menores de edad: firma de notas y documentos que después irán al expediente. Así como firmas relacionadas con el protocolo inicial, documentos de matrícula, protección de datos y notificaciones puntuales, etc. Siendo el resto de encuentros con el tutor del Centro en función del proceso de cada alumno.

Analizando en grupo esta primera categoría de relaciones, los profesionales afirman que existe un problema fundamental en cuanto a la relación familia-centro. En concreto, en los itinerarios de Aulas Taller, que suelen abarcar sólo un año lectivo, y ocasionalmente dos, según la edad del menor: 15 y 14 años, respectivamente. Con aquellos que permanecen dos años en el Centro se puede intentar establecer una relación con las familias. Pero aquellos que llegan con 15 años, la relación es muy difícil, dadas las experiencias previas en los Institutos de Educación Secundaria y el plazo que se precisa para establecer un nuevo vínculo. Con todo, como señalan las entrevistas y el focus group, dado que más de la mitad del alumnado continua dentro de la Red de Centros tras su primer año, la relación con la familia se puede seguir implementando. Resultando clave para ello el trabajo en red, más allá de cada centro. En cuanto a las relaciones basadas en demandas al propio Centro, estas se centran en el requerimiento por parte de las familias de orientación, atención de necesidades básicas, contacto con trabajadoras sociales del entorno, ayudas puntuales en tramitaciones administrativas y derivaciones a especialidades sanitarias, entre otras gestiones. Y en ocasiones, las demandas pueden abarcar también la orientación sobre la gestión adecuada del ocio y el tiempo libre.

En lo que se refiere a los jóvenes tutelados por los Servicios de Protección de Menores, la demanda proviene de estos últimos, sin necesidad de que sea el centro quien solicite el contacto. Pues entra dentro de las funciones de los profesionales de la protección la coordinación con agentes educativos y sanitarios. 
Por último, los educadores de los CSL añaden que, aunque las familias no acuden, mayoritariamente, por iniciativa propia, una vez que se contacta con ellos, suelen tener disposición para acudir al Centro. En ocasiones, esto es facilitado por vínculos previos. Por conocerse mutuamente por el arraigo del centro en el barrio o porque hay experiencia familiar de alumnado perteneciente a otras generaciones (progenitores, tíos, primos, etc). Este aspecto, señalado como positivo, podemos analizarlo también como un indicador negativo, que remite a una cronicidad generacional en la exclusión escolar.

Finalmente, en una posición opuesta, también es frecuente que las familias lleguen derivadas de institutos y que desconozcan el centro. Lo que conforma una amplia diversidad de perfiles familiares. Todos ellos tienen en común que, siempre que hay presencia de la familia de referencia o los tutores legales en el Centro, aunque sea puntual, la asistencia del alumnado mejora.

Tabla 2. Relación familia y centro

\begin{tabular}{|c|c|}
\hline CATEGORÍA & CARACTERÍSTICAS \\
\hline Sin relación con el centro & Alumnado mayor de edad: relación mínima. \\
\hline Relación a demanda del centro & $\begin{array}{l}\text { Para trámites formales: firma de notas y documentos } \\
\text { que después irán al expediente; firma del protocolo } \\
\text { inicial; documentos de matrícula; protección de datos; } \\
\text { notificaciones puntuales; tutorias trimestrales, etc. }\end{array}$ \\
\hline $\begin{array}{l}\text { Relación por demandas } \\
\text { sociales al centro }\end{array}$ & $\begin{array}{l}\text { Orientación para cobertura de necesidades básicas. } \\
\text { Contacto con las trabajadoras sociales de zona. } \\
\text { Apoyos puntuales para tramitaciones. } \\
\text { Derivaciones a especialistas: salud, psicología, etc. }\end{array}$ \\
\hline $\begin{array}{l}\text { Relación por demandas educativas y } \\
\text { laborales al centro }\end{array}$ & Sobre ocio y tiempo libre. \\
\hline $\begin{array}{c}\text { Tutelados por Servicio de Protección } \\
\text { de Menores }\end{array}$ & A demanda de los servicios de protección o viceversa. \\
\hline $\begin{array}{c}\text { Familias o tutores legales que } \\
\text { participan en actividades del centro }\end{array}$ & Escasa y a demanda de los profesionales del centro. \\
\hline
\end{tabular}

Fuente: elaboración propia. 


\subsection{Imagen de los familiares sobre el Centro}

Para poder estructurar propuestas de mejora en la relación entre centros y familias, también es preciso aproximarnos a la imagen que estas tienen de aquellos. Para lo que hemos recurrido a la información extraída del grupo focal, la observación en los Centros y las entrevistas a familiares ${ }^{3}$.

Tabla 3. Aportaciones de las familias entrevistadas (resumen)

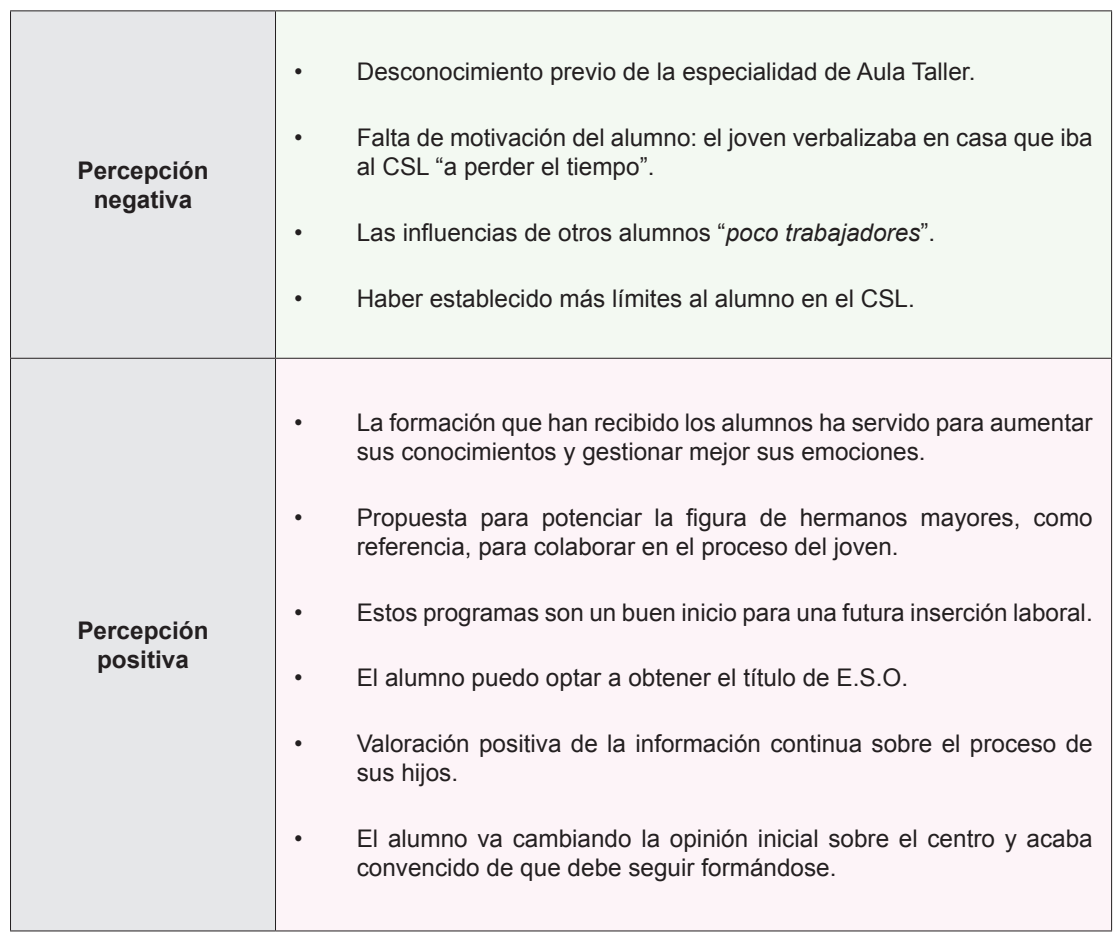

Fuente: elaboración propia

En primer lugar, esta imagen varía según los perfiles socioeconómicos de las familias. Para las de nivel económico medio, la imagen es positiva. Pues perciben los centros como un último recurso, una última oportunidad que tiene su hijo para continuar formándose. Por el contrario, entre las familias con un nivel económico elevado existe

3 Se contactaron de acuerdo a cuatro perfiles: familia gitana, familia de origen migrante, familia colaboradora y familia no colaboradora con el centro. La última no acudió a la cita. 
cierta reticencia de que su hijo asista a los CSL, pues perciben que es una sanción o derivación vinculada al fracaso del menor en dispositivos educativos anteriores: " $m i$ bijo no tendría que está aqui'. Esta imagen negativa se da sobre todo en las Aulas Taller. $\mathrm{Y}$ se fundamenta en la imagen que los institutos transmiten a las familias sobre los CSL. Por lo que una de las primeras tareas para establecer algún vínculo entre centro y familia es deconstruir esta imagen previa.

En segundo lugar, la escena urbana que rodea los CSL, así como su imagen interior también influyen positiva o negativamente en las familias y en los adolescentes, según señala la observación. Dándose extremos muy opuestos, entre centros instalados en edificios exentos, con estética escolar, y centros que ocupan locales de edificios, sin apenas iluminación natural y con una baja inversión en la decoración de los interiores. De la misma forma que algunos centros aparecen vinculados a zonas con otros equipamientos educativos, sanitarios, etc; mientras que algunos otros son desconocidos por la población del entorno, dada su escasa visibilidad como centros educativos (cuadernos de campo).

$\mathrm{Y}$, en tercer lugar, tras la visita al CEIP Ramiro Solans, se ha debatido con los profesionales de los CSL si los centros se acercan o se alejan del concepto de "aulas felices" (Arguís, Bolsas, Hernández y Salvador, 2012): si existe una programación dirigida a potenciar el desarrollo personal y social del alumnado, a través de la atención plena y la educación de las fortalezas personales (creatividad, curiosidad, apertura mental, etc). Con ese referente de experiencias educativas ya desarrolladas, se ha debatido si la acción tutorial puede ir orientada a conseguir que el alumno sea feliz acudiendo al centro y, por tanto, aumente su motivación por asistir, creando así un buen ambiente, tanto en su clase, como en el centro. Concluyendo que este aspecto es un reto de innovación pendiente.

A esos retos dedicamos el último apartado.

\section{PROPUESTAS Y RETOS PENDIENTES.}

Durante el curso 2016-2017 se realizó, por tanto, un primer diagnóstico y se emitieron unas primeras propuestas de innovación.

En esta fase del proyecto, las propuestas tenían como objetivo revertir la percepción actual en los equipos educativos y convertir a las familias en referente positivo 
hacia la educación. Estableciendo cauces para construir relaciones con las familias. Marcando para ello objetivos operativos asequibles y a corto plazo, que comiencen con un acogimiento a las familias, diferente al actual, que se percibe como rígido y poco eficaz. Y apoyándose en las familias con relaciones más positivas con cada centro, para iniciar el proceso de innovación.

Al demandar a los profesionales y a las familias nuevas propuestas, tenemos en cuenta la situación de partida:

a) Actualmente sólo se realizan tutorías, actividades de inicio del curso, atención a demanda u otras actividades marcadas por la relación administrativa de lo escolar.

b) Las familias proceden de entornos escolares, de Educación Secundaria, donde los centros educativos suelen tener muy poca relación con ellas.

c) El alumnado se concentra en edades próximas a la adolescencia, con la complejidad de su evolución madurativa.

d) Y, además, también aquí el mercado de trabajo, marcado por la precariedad y la ausencia de vías para conciliar la vida laboral y la familiar, impone un ritmo que impide atender a las necesidades educativas de los hijos e hijas (Marchesi, 2000).

Contando, también, con la oportunidad de participar en una Red Municipal de centros, que permite multiplicar los recursos y las capacidades de intervención.

A partir de ahí, familiares, profesionales y participantes en el grupo de trabajo señalaron unas primeras innovaciones a implementar en los centros, las aulas y la Red Municipal. En cuanto a los centros, el objetivo sería incrementar los espacios de relación entre familiares, alumnado y profesionales. Comenzando también a trabajar hacia la corresponsabilidad familiar, con hermanos mayores, abuelos y otros referentes familiares que puedan ser positivos. Para ello, se propuso trabajar hacia:

a. La creación de una Asociación de Madres y Padres de Alumnado de la Red Municipal.

b. La puesta en marcha de una Escuela de Madres y Padres en la Red Municipal.

c. La participación en procesos de toma de decisión, donde familiares y profesorado desarrollen, por ejemplo, la creación de las normas del centro. Y, 
en la misma línea, la participación de familiares en el desarrollo del currículo y la evaluación de las actividades del centro.

d. Ofertar como Red Municipal actividades de formación para familiares, relacionadas con la educación de adultos, mejorando su nivel educativo e implicándolas así en el centro.

e. Sistematizar en toda la Red actividades de visibilización y socialización con la comunidad educativa (especialmente las familias) y el entorno: Jornadas de Puertas Abiertas (en primavera), Jornadas de Inauguración del Curso Académico y de Clausura, así como temáticas (por oficios, interculturales, etc).

f. Y, en relación con la necesidad de visibilizar y mejorar la imagen de la Red, incorporar las nuevas tecnologías a la relación con las familias (seguimiento, refuerzo positivo, etc) y el entorno, especialmente los equipos de orientación de los centros de Secundaria, a través de webs, redes sociales y otros social media.

En torno a las aulas, el objetivo es potenciar la participación de familiares en ellas. Recogiéndose como propuestas:

a. Promover la participación de las familias dentro del aula, en la línea de los grupos interactivos. Así como tertulias educativas (como el World Café4), donde familiares, alumnado y profesionales compartan inquietudes comunes sobre la educación y el empleo.

b. Ofertar la libre asistencia al aula de familiares, para conocer la metodología de enseñanza, las relaciones entre alumnado y profesionales, etc.

c. Incorporar a actividades formativas puntuales a familiares que puedan tener habilidades profesionales o culturales de interés para cualquier centro de la Red Municipal, creando la figura del Colaborador.

Y, finalmente, potenciar la Red Municipal como espacio de coordinación en el ámbito integrador de las familias y el alumnado. Para ello se propuso:

a. Abordar un modelo de Centros que permita acceder a programas estables y con itinerarios más prolongados, que incluyan el acompañamiento (mentoring, befriend, etc).

b. Y colaborar en la implementación de un protocolo de relación técnica con los Institutos de Educación Secundaria. 


\section{REFERENCIAS BIBLIOGRÁFICAS}

Amador, J. y Girbés, S. (2016). Formación y participación decisiva de las familias en los centros educativos. Revista Padres y Maestros, 367, 27-31.

Amaya, R. (2016). Cooperación entre las familias y los centros escolares como medida preventiva del fracaso y del riesgo de abandono escolar en adolescentes. Revista Latinoamericana de Educacion Inclusiva, 10, 175-192.

Arbex, C., Chamorro, M., de Silva, A., Hernández, M., \& Sánchez, B. (2013). Guía para trabajar con familias gitanas el éxito escolar de sus hijos. Madrid: Fundación Secretariado Gitano.

Arguís, R., Bolsas, A. P., Hernández, S. y Salvador, M. D. (2011). Aulas felices. Revista Amazônica, 6 (1), 62-87.

Blanco, L. A. (2006). Familia y abandono escolar. Importancia de la implicación familiar en el proceso educativo. Madrid: Ediciones Cinca.

Campani, G. y Serradell, O. (2010). Grupos culturales: migrantes y minorías culturales en educación. Revista Educación y Pedagogía, 22(56), 57-66.

Choi, A. y Calero, J. (2013). Determinantes del riesgo de fracaso escolar en España en PISA-2009 y propuestas de reforma. Revista de educación, 362, 562-593.

Cutanda, M. T. (2014). De los Programas de Cualificación Profesional Inicial a la Formación Profesional Básica: algunas consideraciones. Revista educativa Hekademos, 16, 69-79.

Domínguez, S. (2010). La Educación cosa de dos: La escuela y la familia. Revista digital para profesionales de la enseñanza, 8, 1-15.

Elboj, C. e Íñiguez, T. (2012). Capital cultural, familia y centros educativos. En A. Trinidad y F. J. Gómez (eds), Sociedad, familia, educación: una introducción a la Sociología de la Educación. Madrid: Tecnos. Pp. 134-146

Fernández, D. (2011). El Trabajo Social en el Sistema educativo. Madrid: Consejo General del Trabajo Social.

Fernández, J. (2015). Document de bases per la intervenció amb les famílies des del treball social. Universitat de Barcelona. Grup de recerca i innovació en Treball Social. 
Fernández, M. (1999). Alumnos gitanos en la escuela paya: Un estudio sobre las relaciones étnicas en el sistema educativo. Madrid: Ariel Practicum.

Fernández, M., Mena, L. y Riviere, J. (2010a). Desenganchados de la educación. Factores, procesos y dimensiones del fracaso y el abandono escolar en España. Revista de educación, no Extra 1, 119-145.

Fernández, M., Mena, L. y Riviere, J. (2010b). Fracaso y abandono escolar en España. Col. Estudios Sociales, n 29. Barcelona: Fundación La Caixa.

Flecha, R. y Soler, M. (2013). Turning difficulties into possibilities: engaging Roma families and students in school through dialogic learning. Cambridge Journal of Education, 43 (4), 451-465.

García, R. y Macías, F. (2013). Gestionar los centros educativos con la participación de la comunidad. Revista del Fórum Europeo de Administradores de la educación, 21 (5), 22-25.

Garcia, C., Morlà, T., \& Ionescu, V. (2018). Dreams of Higher Education in the Mediterrani School Through Family Education. Frontiers in Education, 3(79).

Gastañaga, J.L. (2007). Trabajo social, familia y escuela. Cuadernos de Trabajo Social, $17,255-271$.

Girbés, S., Macías, F., \& Álvarez, P. (2015). De la Escuela Gueto a una Comunidad de Aprendizaje: Un Estudio de Caso sobre la Superación de la Pobreza a través de una Educación de Éxito. International and Multidisciplinary Journal of Social Sciences, 4(1), 88-116.

Gómez, A., Elboj, C., \& Capllonch, M. (2013). Beyond Action Research. The communicative Methodology of research. International Review of Qualitative Research, 6(2), 183-197.

INCLUD-ED (2006-2011). Strategies for Inclusion and Social Cohesion in Europe from Education. Bruselas: European Commission.

Lastikka, A. y García-Carrión, R. (2012). Participación de las famílias en el currículo y la evaluación. Cuadernos de Pedagogía, 429, 61-63.

Lozano, A. (2003). Factores personales, familiares y académicos que afectan al fracaso escolar en la Educación Secundaria. Revista Electrónica de Investigación Psicoeducativa y Psicopedagógica, 1, 43-66.

Macías, F. y Flecha, R. (2013). Hacia una formación del profesorado para la igualdad del pueblo gitano. Revista de la Asociación de Enseñantes Gitanos, 30, 75-83. 
Macías, F. y Redondo, G. (2012). Pueblo gitano, género y educación: investigar para excluir o investigar para transformar. RISE- International Journal of Sociology of Education, 1 (1), 71-92.

Marchesi, Á. (2000). Controversia en la educación española. Madrid: Alianza Editorial.

Martinez, B., \& Niemelä, R. (2010). Formas de implicación de las familias y de la comunidad hacia el éxito educativo. Revista de Educación y Pedagogía, 22, 69-77.

Martinez, R. A. y Álvarez, L. (2005). Fracaso y abandono escolar en Educación Secundaria Obligatoria: implicación de la familia y los centros escolares. Revista Aula Abierta, 85, 127-146.

Mateo, L. (2010). Temas para la educación. Revista digital para profesionales de la enseñanza, 8, 1-12.

Meil, G. (2006). Padres e hijos en la España actual. Barcelona: Fundación La Caixa.

Prados, M. Á., Gomariz, M. Á., Parra, J. y García, M. P. (2016). Familia, inmigración y comunicación con el centro escolar: Un estudio comparativo. Educación XXI, 19 (2), 127-151.

Rahona, M. y Morales, S. (2013). Diferencias en el rendimiento educativo de nativos e inmigrantes en España. Revista de la Asociación de Sociología de la Educación, Vol. 6 (1), 72-90.

Roselló, E. (1998). Reflexiones sobre la intervención del trabajador social en el contexto educativo. Alternativas. Cuadernos de Trabajo Social, 6, 233-258.

Sanz, M.E. (2007). El trabajador social en el ámbito educativo. Experiencia de intervención con menores en desventaja social desde la inclusión. Trabajo social hoy, $\mathrm{N}^{\circ}$. Extra 1, 105-118.

Valls, R., Prados, M. D., y Aguilera, A. (2014). El proyecto INCLUD-ED: estrategias para la inclusión y la cohesión social en Europa desde la educación. Investigación en la escuela, $82,31-44$ 


\title{
PROPUESTA DE TRABAJO CON LAS FAMILIAS
}

\author{
Luis Manuel Vilas Buendia ${ }^{I}$ \\ ${ }^{I}$ Departamento de Psicología y Sociología. Universidad de Zaragoza
}

\section{INTRODUCCIÓN}

El ser humano es un ser social. Como ser social se encuentra en constante interacción (sumativa o sustractiva) con otros seres humanos y con el entorno que le rodea. En esas sumas y restas los seres humanos nos agrupamos, entre otras, en grupos más o menos estables, asociaciones e instituciones, con o sin vocación, o fin, de permanencia en el tiempo. También estas agrupaciones, más o menos amplias, interaccionan con otras instituciones, asociaciones o grupos, con los mismos comportamientos, fines e intereses, para sumar o para restar, o si se quiere decir de otra manera con la vocación de competir, obstaculizar, cooperar, asimilar, etc. Estamos hablando de la complejidad de los procesos sociales

En esta complejidad la institución familiar y la institución escolar son una de las que innegablemente están en constante interacción, muchas veces para oponerse, obstaculizarse... y por qué no: colisionar, en parte porque ambas cumplen, al menos, con la función de socialización de sus miembros, en primer lugar, más jóvenes.

Pero estas fuerzas entrelazadas están condenadas a entenderse porque, al menos, son determinantes para la construcción de los valores, los estilos de vida y comportamiento para las personas que pasan por ellas. Los integrantes de las mismas, especialmente los miembros adultos son los modelos, los actores, de los procesos que las generaciones jóvenes tienen en el escenario para ir conformándose como seres humanos y seres sociales.

Las colisiones pueden ser positivas o negativas para una o para ambas instituciones. En algunas ocasiones parecen encadenarse una serie de circunstancias para que una de ellas, la institución familiar, se encuentre en un estado de permanente alerta ante cualquier acontecimiento que el adolescente o joven de dicha institución realice en el ámbito y el espacio de la otra (la escolar). Debemos recordar que no podemos 
vivir en una independencia total del resto de la humanidad, que necesitamos de la mutua colaboración, que va conformándonos a lo largo de nuestra existencia.

Muchas veces la institución familiar es definida por las dificultades que tiene en la función de contención y limitación que pueden propiciar carencias de regulación afectiva y conductual de sus miembros jóvenes o adolescentes. Dicha definición y dificultades quedan, en algunas ocasiones, enmarcadas (cosificadas) en la relación que ambas instituciones mantienen, lo que va a provocar a la larga un clima no amistoso que, a su vez, generará malos entendidos en la relación durante el transcurso del paso del adolescente o joven por la institución escolar. Y al final una simple llamada telefónica de uno de los miembros de la comunidad educativa puede prender una llama que encadena una serie de emociones que pueden desbordarse en cualquier momento.

Todos estos malos entendidos ${ }^{1}$ a la larga, van creando las condiciones de sensación de pérdida de confianza y a su vez de fracaso, generando una retroalimentación cada vez más negativas, con descalificaciones en uno u otro bando. Nos olvidamos, en muchas ocasiones, que la convivencia está relacionada con la idea y el ejercicio de que como individuos todos aportamos algo a nuestros conciudadanos y al entorno que nos rodea y que tenemos una serie de capacidades que necesitamos poner en juego y que nos permiten aportar un algo a todos los sistemas ${ }^{2}$ que nos rodean.

Ocurre que en ocasiones es en este momento álgido de variadas emociones, es cuando se produce el encuentro de las familias con los Centros Sociolaborales. Encuentro que, a su vez, viene marcado por una explicación confusa de las causas

1 Esto malos entendidos no son solo del orden comunicacional, sino que devienen también de las características de la población atendida en los Centro Sociolaborales, que presenta un creciente número de conductas externalizantes (violencia, consumos e interrupciones de la relación de ayuda) que provienen de dificultades del ejercicio de las competencias familiares, especialmente en la que tiene que ver con la de contención en el entorno familiar.

2 Recordemos que en la teoría ecológica de Bronfenbrenner (1991), todos los contextos y ambientes que rodean a la familia y con los que se relaciona tienen una gran influencia sobre el desarrollo de todos, y cada uno de los miembros del sistema familiar.

Establece cuatro sistemas interrelacionados:

a. Macrosistema: valores culturales, creencias e historia que definen el lugar donde vive.

b. Exosistema: familia extensa, condiciones laborales de la familia, las amistades, los vecinos,

c. Mesosistema: en donde se dan las relaciones entre los microsistemas en los que los sujetos participan.

d. Microsistema: sistemas más próximos y en los que se desenvuelve el sujeto (familia, escuela, Centros Sociolaborales, etc.). 
de los problemas que les han llevado a ese lugar educativo, a ese nuevo recurso. Explicaciones no muy clarificadoras que han puesto en centro del problema al mismo joven ${ }^{3}$.

Todo ello enmarcado por el hecho que habitualmente se ha realizado un recorrido por distintos dispositivos del sistema que no han cumplido con la función de encontrar, o desarrollar, cambios o soluciones en el adolescente o en el joven y/o en la familia.

Una de las consecuencias de este recorrido es que se haya generado, en este tipo familias, una falta de confianza en los profesionales que les rodean ${ }^{4}$, al mismo tiempo que habrá ido creciendo en ellos un sentimiento de ser constantemente evaluados y juzgados por todos los miembros del sistema, al menos del escolar, y en muchos casos de fracaso e imposibilidad de cambio.

En estas circunstancias vitales las acciones que se emprenden desde los Centros Sociolaborales para la acogida y recibimiento de las familias es, en muchas ocasiones, complejo. Lo mismo ocurre con el trabajo conjunto que se puede desplegar durante el tiempo en que los participantes de los Centros se encuentran en sus diversas aulas. Durante los cursos 2016/17 y 2017/18 un grupo de educadores y de profesionales de los Centros Sociolaborales de la ciudad de Zaragoza que mantienen el contacto significativo y frecuente con las familias se reunieron para reflexionar y para encontrar cauces de mejora en las tareas cotidianas que se pueden emprender para unir sinergias en la interacción e integración de las familias y de los Centros Sociolaborales.

El objetivo último era reforzar aquellas prácticas de éxito que puedan permitir unas adecuadas correlaciones y concordancias (de la familia y del Centro) que a su vez ayuden a los adolescentes y jóvenes a reintegrarse al sistema formativo reglado o iniciar o continuar un itinerario laboral.

Fruto de esas reflexiones se plantearon algunas cuestiones para el trabajo conjunto de Familia y Centro y que serían tenidas en cuenta a la hora de desarrollar acciones que favorecieran una mejor coordinación: Familia y Centro Sociolaboral:

3 A veces el mensaje es que el joven es el centro y la raíz del problema. Todo esto puede llevar al resto del sistema familiar a no tener conciencia de todas las causas y la amplitud del problema. 4 No sólo los profesionales. 
a. Integrar, en mayor medida, a las familias en el funcionamiento de los Proyectos y de los Programas.

b. Potenciar la Red de los Centros Sociolaborales como elemento integrador de las familias, independientemente del Centro Sociolaboral en el que esté matriculado el joven.

c. Iniciar los pasos para crear la Asociación de Madres y Padres de Alumnos de los Centros Sociolaborales.

d. Impartir Programas estables y más amplios que permitan ofrecer itinerarios de inserción consolidados a alumnos y familias.

\section{PROPUESTA DE TRABAJO CON LAS FAMILIAS}

Bajo estas premisas se fueron diseñando y/o redescubriendo algunas acciones que se podían poner en práctica a lo largo del curso presente.

Después de un periodo de lluvia de ideas se tomó como objetivo relanzar la posibilidad de una "Jornada de Puertas Abiertas en todos los Centros de la Red".

La Jornada de Puertas Abiertas como tal no representa una acción nueva en sí misma, en tanto que ha sido una realizada en el tiempo por algunos Centros. Pero o bien ha caído en desuso, o realizada de forma esporádica y discontinua.

Lo novedoso de esta acción radicaría en el planteamiento de su realización como Red y en todos los centros. También la temporalización de la misma dentro de un proyecto más amplio de trabajo con las familias.

\subsection{Primer paso: acogimiento empático}

Tal como hemos comentado anteriormente esta Jornada se plantea como un punto final de varios pasos que se inician con la recepción de las familias en cada uno de los Centros, para ello se plantea un nuevo estilo de acogimiento.

Es crear un espacio de relación con la familia que tenga las características de un vínculo seguro que permita la confianza.

Por ello las personas encargadas del acogimiento deberían tener:

- Habilidades empáticas, en tanto que desafiasen los prejuicios, apostando por lo que une y dejando de lado lo que divide. Con capacidad de 
escucha activa que permita al otro (la familia) poder reconstruir su relato ${ }^{5}$ desde una óptica positiva.

- Construir una explicación consensuada del problema y de sus causas, analizando el motivo de entrada en el recurso.

- Ayudar a formular una demanda conjunta entre los miembros de la familia y los profesionales del recurso que tenga relación con el motivo de entrada. Puede reformularse en momentos posteriores de la relación. Construir una relación de confianza que permita una progresiva apertura del sistema familia y la consolidación de la alianza.

Con el objetivo último, que se mantendrá a lo largo de todo el proceso de trabajo con la familia, que está conformado por:

\section{INFORMAR - ORIENTAR - PARTICIPAR - COLABORAR.}

Es necesario, también, que estas personas pudiesen tener una visión mucho más amplia de toda la Red, y no solo de las características propias de su Centro (o dispositivo), en tanto en cuanto pudieran derivar a la familia (a cualquiera de los otros miembros de la unidad familiar) a otros Centros que pudiesen dar una mejor respuesta a otras de las necesidades que pudieran presentarse.

Así mismo mientras se construye, o cuando se haya construido, el compromiso mutuo y llegan los efectos positivos de dicho compromiso, estas personas de acogimiento tendrán que tener habilidades en el manejo de las emociones experimentadas por las partes que asisten a dicho encuentro (recordemos que pueden estar marcadas por la desconfianza, el resentimiento y la cadena de fracasos que pueden haber llevado al punto en el que nos encontramos).

Este manejo de las emociones podrá permitir transformarlas positivamente y generaran una influencia beneficiosa sobre la percepción mutua de las partes, así se pueden desarrollar otro tipo de relaciones, reales o potenciales, generando una retroalimentación positiva.

5 Ya hemos comentado con anterioridad que a veces las familias llegan con una gran carga emocional y confusional. 
Debemos recordar que nuestro fin es conocer o clarificar la demanda y que la demanda se construye abriéndonos a entender y comprender qué necesitan, aunque inicialmente no esté relacionado con el carácter formativo del dispositivo y concretando la forma de colaboración para atenderlo ${ }^{6}$, incluso, si pudiera ser, temporalizándolo.

Una vez generada una nueva relación, esta se puede mantener con el uso de instrumentos que mantengan la retroalimentación positiva.

\subsection{Segundo paso: construcciones de itinerarios}

Una vez recogida toda la información y habiendo entendido el contexto y la demanda de la familia es recomendable que cada equipo pueda construir unas herramientas que les permitan dotar o sostener a los miembros adultos en sus competencias parentales? ${ }^{7}$.

En este sentido sería importante conocer el abordaje que las familias han ido realizando de las conductas externalizantes de los miembros jóvenes y adultos para poder, desde sus peculiares formas de intervención, potenciar o construir límites y normas que permitan una aplicación eficiente y eficaz.

Este análisis puede requerir tiempo significativo para que la familia no se sienta juzgada y evaluada como se hizo en el pasado, y ahondar en las posibilidades de aplicación o no de esas nuevas (o viejas reformuladas) normas de actuación. La incorporación del entorno y/o el uso de personas de referencia de la familia, del adolescente y joven, y de otros significativos será una herramienta más a utilizar en este paso ${ }^{8}$.

6 Escuchar cómo han vivido o cómo han sido las experiencias anteriores, es muy importante. Por un lado, definen el problema, adelantan las expectativas que se tienen con la intervención y nos dan información sobre como colocan al profesional y al dispositivo en "su mundo".

$7 \quad \mathrm{Al}$ hablar de competencias parentales no nos estamos refiriendo exclusivamente a los padres biológicos, sino que extendemos el desarrollo de las mismas a los miembros adultos de una unidad familiar, independientemente de la tipología familiar concreta.

8 Es justo reivindicar en estos momentos la herramienta del Ecomapa: "El ecomapa no es otra cosa que una representación gráfica de las diversas uniones de una familia, personas y estructuras sociales del entorno en el que habita, podríamos decir que es un dibujo de su "sistema ecológico". Identifica los patrones organizacionales de la familia y la naturaleza de las sus relaciones con el medio, mostrándonos el equilibrio entre las necesidades y los recursos de la familia". 
El acompañamiento a nivel familiar y el apoyo social ${ }^{9}$ son la parte fundamental para retomar y restaurar aquellas interacciones que generaron distancia y conflicto. Algunas de las acciones que se pueden implementar en este segundo paso pueden ser algunas que ya han tenido éxito en el pasado, como, por ejemplo:

a. Introducir en las aulas a los padres para que puedan compartir aquellas competencias y habilidades que posean y que puedan ser un ejemplo práctico para lo que se está desarrollando en las mismas. Su incorporación como voluntarios también puede ser un itinerario de participación.

b. Utilizar talleres:

- Para realizar pequeñas reparaciones en los electrodomésticos que permitan interacciones entre los padres y los educadores que fomenten el conocimiento mutuo y aumento de las competencias.

- De intercambio de conocimientos culinarios para reforzar la inclusión y el multiculturalismo que existe en los centros.

- Para tratar algún tema de interés, dirigido a las familias, teniendo en cuenta sus intereses, que previamente se habrán detectado con el estilo de acompañamiento emprendido en los primeros encuentros Centro-Familia.

c. Otro tipo de acciones que puedan plantearse de la interacción entre Familia y Centro desde una actitud de escucha activa y participación dialogada, atendiendo a Paulo Freire: "Enseñar exige saber escuchar".

En definitiva, mantener el objetivo planteado desde el principio.

$9 \quad$ Estamos hablando de un verdadero trabajo en red: "el trabajo en red es el trabajo sistemático de colaboración y complementación entre los recursos locales de un ámbito territorial. Es más que la coordinación (intercambio de información), es una articulación comunitaria: colaborar de forma estable y sistemática, por evitar duplicidades, competencia entre recursos, descoordinación y potenciar el trabajo en conjunto.” (Ballester, Orte, Oliver,\& March, 2004) 


\subsection{Tercer paso: Jornada de puertas abiertas}

Todo el trabajo planteado va a desembocar en una Jornada de Puertas abiertas que tenga las siguientes características.

a. Que sea una Jornada en la que estén implicados todos y cada uno de los Centros de la Red.

Para ello el primer paso será encontrar una semana en el mes que se decida (probablemente mayo) y en la que todos los centros puedan organizarse para estar abiertos un día de esa semana.

Si el reparto está bien organizado permitiría que las personas que lo deseasen, en esa semana, pudiesen conocer aquellos dispositivos que le pudiesen dar visibilidad a los objetivos o intereses que pudiese tener para planificar su futuro escolar o laboral.

Podrían realizarse en horario de mañana en todos los centros y con el fin de facilitar a las familias se ve conveniente la apertura por las tardes durante unas horas $^{10}$.

b. Es conveniente la difusión previa y con gran alcance mediático de dicha jornada a través de los medios de comunicación (mupis, cartelería, flyer, presencia en programas de radio y tv...)

Se podría realizar un vídeo de la Red Municipal, previo a la semana de puertas abiertas, para difundir la actividad. Para ello se valoró en su momento por el grupo de profesionales y educadores la posibilidad de encargar esta tarea, siempre y cuando fuese posible a la Facultad de Periodismo de la Universidad de Zaragoza, integrándose dentro de algún prácticum o Trabajo Fin de Grado.

Este encargo entroncaría con la difusión más amplia de la Jornada a la que se debería invitar, a parte de las familias, a las personas y grupos de interés de los territorios en los que están insertos los Centros Sociolaborales.

Para ello, y con la antelación suficiente se debería contactar, al menos con las Administraciones Municipales y Autonómicas, los IES, la Universidad de Zaragoza (con especial referencia a las Facultades de Educación y Facultad de Ciencias

10 Entendemos que este aspecto pertenece a la organización interna de los dispositivos y habría que ver si existe la posibilidad real de llevarlo a cabo. 
Sociales y del Trabajo), UNED, empresas, entidades y tejido asociativo del barrio, juntas de distrito, etc.

\subsection{Desarrollo de la Jornada}

El encargo de la Jornada estará realizado por los protagonistas primeros que son los propios participantes del Centro, comenzando por los alumnos que serán los encargados principales de presentar cada uno de los proyectos, acompañados por uno de los Educadores o profesionales del mismo.

a. Sería conveniente el que hubiese un Equipo encargado de la Jornada, que estaría compuesto por Educadores y participantes de los proyectos, elegidos todos ellos mediante un proceso participativo. Dicho proceso se atendría a la idiosincrasia de cada uno de los dispositivos.

Para crear la imagen de Red sería conveniente que mediante algún elemento tangible se pudiera visibilizar el trabajo desarrollado en los otros Centros Sociolaborales, por ejemplo:

a. Hostelería y Repostería que se "encargarán de prepararpara los 12 centros y para dicha Jornadas de puertas abiertas una serie de productos para que los/as visitantes pudieran probar las elaboraciones que realizan los/as alumnos/as de dichos proyectos".

b. Un video sobre las actividades que se realizan en uno o varios Centros Sociolaborales.

\subsection{Evaluación de la Jornada}

El Equipo encargado de la Jornada desarrollará aquellos instrumentos cualitativos y cuantitativos que permitan evaluar la Jornada.

Se tendrá en cuenta en estos instrumentos la valoración positiva de lo realizado, como ya indicamos anteriormente que lo que mueve el planteamiento de esta Jornada es crear una acción positiva y enriquecedora para todos los participantes en la misma. Evitamos, al menos por una vez la sensación de fracaso que viene acompañando a los participantes de los dispositivos y de las familias. Creándose sinergias positivas en el itinerario vital de todos y cada uno de los participantes. 


\section{REFERENCIAS BIBLIOGRÁFICAS}

Agostinho, M. (Mayo de 2007). Ecomapa. Revista Portuguesa de Medicina Geral e Familiar, 23(3), 327-330.

Ballester, L., Orte, C., Oliver, J. L., \& March, M. X. (2004). Metodología para el trabajo socioeducativo en red. IV CONGRESO ESTATAL DEL/A EDUCADOR/A SOCLAL. Santiago de Compostela.

Bronfenbrener, U. (1991). La Ecología del Desarrollo Humano. Barcelona: Paidos.

Navarro, M., García, A., \& Rodríguez, R. (2010). Redes de apoyo en el anciano por medio del genograma y el ecomapa. Atención Familiar, 17(1), 19-21. 


\title{
EL ESPACIO EDUCATIVO NO ESCOLAR Y LOS ESTUDIANTES DEL PUEBLO GITANO
}

\author{
Chabier Gimeno \\ Universidad de Zaragoza
}

\section{INTRODUCCIÓN.}

Puesto que su actividad económica es con frecuencia parasitaria y su ethos económico consiste en engañar, aunque sea moderadamente, al payo (en el precio pagado o exigido, en la calidad de lo vendido, en la elegibilidad para las prestaciones sociales,...), al menos entre los grupos más apegados al modo de vida tradicional... (Fernández, 1999: 26).

Este texto, publicado por un profesor universitario, que ya citamos en el capítulo dedicado a las familias, es un buen ejemplo de la convergencia de dos ideologías. Por un lado, la académica que culpabiliza al grupo cultural, étnico, nacional del estudiante y de su familia por su abandono escolar temprano. Por otro, la que se desinteresa por los orígenes de la desigualdad y la exclusión educativa, y la aborda desde el management, como un producto más, en el mercado de lo social surgido con la privatización del Estado del Bienestar mediterráneo.

En una dirección contraria, alejándonos de las bajas expectativas a partir de las cuales comienza una parte de la investigación sobre la educación, como también decíamos anteriormente, presentamos aquí un resumen operativo ${ }^{1}$ de la investigación aplicada desarrollada con el Grupo de Trabajo de Diversidad en \#innovaCSL. Cuyo objetivo era abordar la presencia de alumnado gitano en la Red Municipal de Centros Sociolaborales. Un colectivo, como también hemos advertido ya, sobrerrepresentado en estos dispositivos no escolares, con respecto a sus iguales edatarios en la Educación Secundaria y postobligatoria (ver anexo 1 de este capítulo).

1 Estos resultados se presentaron parcialmente en el Colloque International Evascol: «École, migration, itinérance: regards croisés », el día 5 de abril de 2018 en el l’INSHEA (París, Francia). Así como en las III Jornadas de este proyecto, en junio de 2018. 
Gráfico 1. Alumnado gitano en la Red (2017-2018)

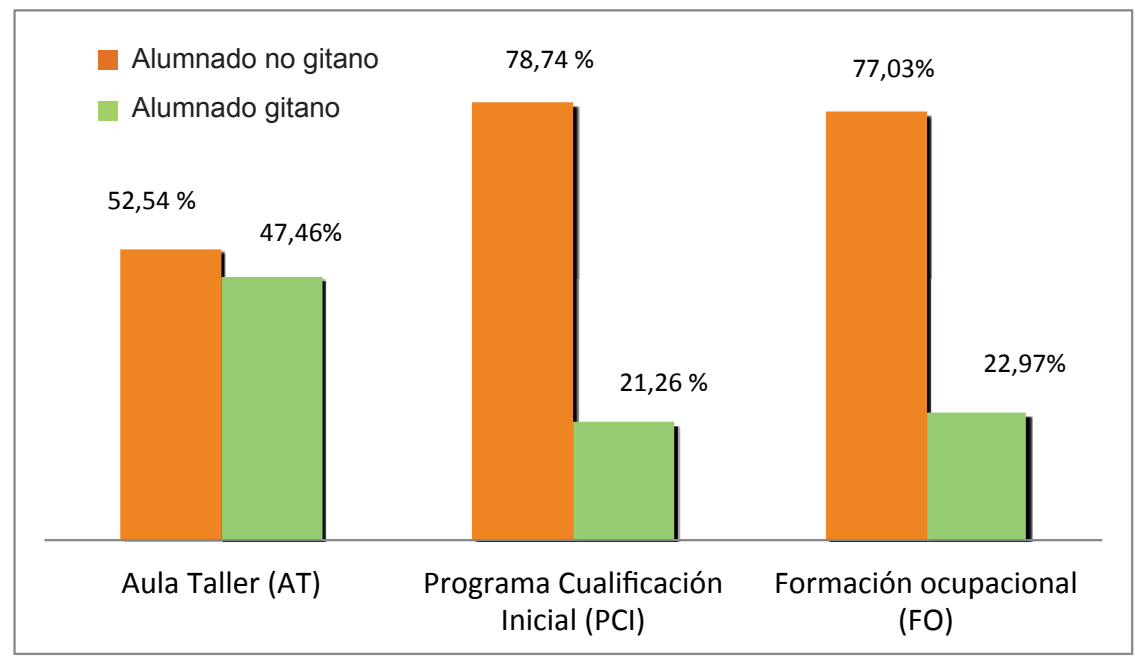

Como también aclarábamos anteriormente, el proyecto asume la necesidad de implementar medidas que eviten, que prevengan el abandono escolar temprano (Carabaña, 2010). Pero, para aquellas jóvenes que no han titulado en Secundaria, es necesario abrir y mejorar itinerarios formativos que les lleven más allá de las vías académicas muertas, que no implican retorno a lo escolar, ni éxito educativo, ni inserción laboral (García et al., 2013). Con ese enfoque, apostamos desde el inicio del proyecto por atender a la necesidad explicitada por los profesionales: es necesario un cambio en las estrategias educativas y sociales dirigidas al alumnado gitano.

\section{LA DIVERSIDAD EN \#INNOVACSL.}

En la primera actividad formativa del proyecto, las I Jornadas (noviembre 2016), introdujimos dos talleres sobre el pueblo gitano ${ }^{2}$, impartidos por Fernando Macías (Campus Rom y Universitat de Barcelona): "Participación decisiva y educación del pueblo gitano" y "Hacia una formación del profesorado para la igualdad del Pueblo Gitano". A partir de ambos, y de su eco en los profesionales de la Red, con la constitución del Grupo de Trabajo sobre Diversidad, en febrero de 2017, nos marcamos varios objetivos.

2 https://www.heraldo.es/noticias/aragon/2016/12/02/los-gitanos-que-llegamosuniversidad-somos-extraterrestres-1145815-300.html 
Uno de ellos, era elaborar un diagnóstico sobre la diversidad (cultural, afectivosexual, funcional, etc) en la Red, además de ofrecer formación a las profesionales y recurrir a expertos del territorio. Tras esa primera fase, durante el curso 20172018 se elaborarían propuestas y, en la medida de lo posible, se implementarían experiencias piloto.

Durante la primera fase, tras cinco reuniones previas, el diagnóstico concluía que se detectaban dos necesidades no cubiertas con los recursos de la Red en ese momento:

a. La necesidad de una mediación intercultural profesional.

b. Y la formación en competencias profesionales interculturales.

Sumando esfuerzos con compañeras y compañeros voluntarios, en las II Jornadas (junio 2017), se ofreció a la Red un taller sobre "Educación y Pueblo gitano". Carmen Jiménez (educadora del Ayuntamiento de Zaragoza), Carmelo Giménez (mediador), Tamara Clavería (licenciada en Educación y trabajadora de la Fundación Secretariado Gitano) y José Antonio Jiménez (Graduado en Trabajo Social y policía nacional ${ }^{3}$ ) prepararon una sesión de historia del Pueblo Gitano, estereotipos, cultura gitana y, para terminar, un caso práctico, que se trabajó en grupos. A partir del esfuerzo colectivo que hicieron para preparar ese taller, crearon meses después lo que hoy es la delegación aragonesa de Campus Rom4. Organización orientada a favorecer el acceso a la universidad de estudiantes gitanos.

3 https://www.heraldo.es/noticias/aragon/zaragoza-provincia/zaragoza/2017/09/28/ estoy-muy-orgulloso-ser-gitano-policia-nacional-1198830-301.html 
Imagen 1. Taller sobre Pueblo Gitano en las II Jornadas.

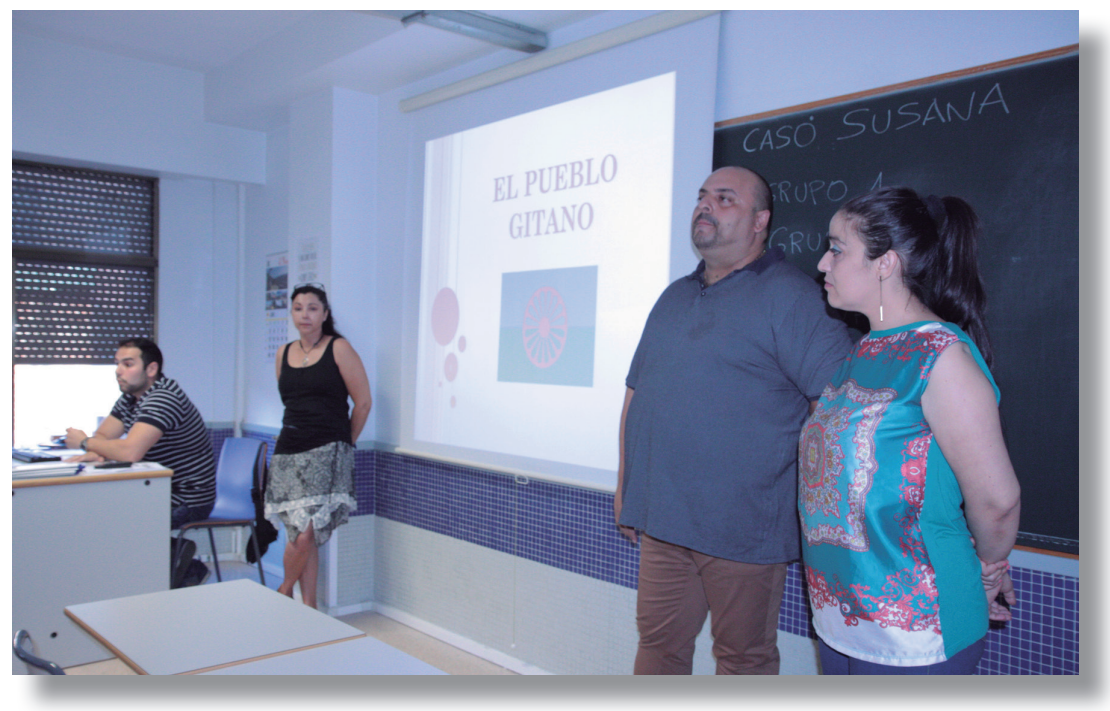

Durante el curso 2017-2018, el Grupo de Trabajo abordó las necesidades detectadas a partir de dos tipos de acciones:

a. Formación para profesionales.

b. Y mediación con alumnado gitano: elaborando un diagnóstico específico y redactando un proyecto de intervención.

En cuanto a las acciones formativas, se impartieron tres sesiones de formación:

a. Introducción a las competencias profesionales interculturales, impartida por Chabier Gimeno (Universidad de Zaragoza), con la colaboración de Joaquín Moso (profesor jubilado de Educación Secundaria y voluntario).

b. Introducción a la mediación con alumnado de origen magrebí y subsahariano, impartida por dos mediadoras del CAREI (Consejería de Educación, Gobierno de Aragón).

c. Y estrategias para atender la diversidad funcional, impartida por Luis Vilas (Universidad de Zaragoza).

De cara a diagnosticar las necesidades y fortalezas de la Red, en cuanto al Pueblo Gitano, se contó con la colaboración de las profesionales participantes en el Grupo de Trabajo, así como voluntariado y alumnado en prácticas extracurriculares 5 de 
los Grados de Educación y Trabajo Social (Universidad de Zaragoza). Entre todas, se desarrolló el siguiente trabajo de campo:

a. Sistematizar lo recogido en las actas de reuniones, así como en el cuaderno de campo de los investigadores.

b. Se consultó a los doce centros (once respondieron) a través de un cuestionario, donde debían reflejar las características sociodemográficas del alumnado, su asistencia, experiencia escolar previa, etc (ver Anexo 1).

c. Se visitaron los once centros participantes, entrevistando a las profesionales de referencia (coordinadoras, orientadoras, etc) y recogiendo sus aportaciones de forma escrita.

d. Y, finalmente, con la colaboración de Campus Rom Aragón se realizó un grupo focal, con familiares y exalumnas gitanas de la Red, que fue registrado mediante notas, para presevar su anonimato.

Como complemento a este diagnóstico, y con el fin de facilitar información al Grupo de Trabajo sobre las competencias profesionales interculturales de los equipos de la Red Municipal, se realizó una encuesta6.

\section{CAMBIOS EN LA RELACIÓN ENTRE EDUCACIÓN Y PUEBLO GITANO.}

Los resultados de este diagnóstico, nos remiten a lo que ya hemos advertido en el capítulo introductorio. Los dispositivos no escolares orientados a los jóvenes que no titulan en Secundaria encaran un reto evidente. El escenario es muy diferente al previo a la Gran Recesión. Dado que el desempleo juvenil es ya estructural en el sur de Europa y, además, el denominado "mercado de trabajo" no muestra signos de absorver y mejorar las condiciones laborales de los jóvenes con itinerarios formativos como los que aquí estudiamos (Eurofound, 2012). Lo que ha introducido, como ya decíamos, nuevos debates sobre la adecuación de estos dispositivos educativos no escolares, en todas las Comunidades Autónomas, también entre los vinculados a la nueva filantropia (Collet y Tarabini, 2017). En suma, mantener modelos formativos que priorizan "lo social", en tanto asistencial, por encima de lo académico, en tanto capacitador, es una orientación del ciclo económico anterior. Que se plasma en un muy débil acceso al mercado laboral: un 3,72 \% durante su participación en los

6 Con la colaboración de la alumna Jéssica Gracia Llorente (Grado de Trabajo Social), se envió a los equipos educativos la encuesta "Recognising intercultural competence" del Consejo de Europa. 
Programas de Cualificación Inicial de la Red, más un 6,91 \% al finalizar los mismos, dentro de la misma especialidad estudiada (curso 2017-2018).

Gráfico 2. Cambios en las tendencias educativas.

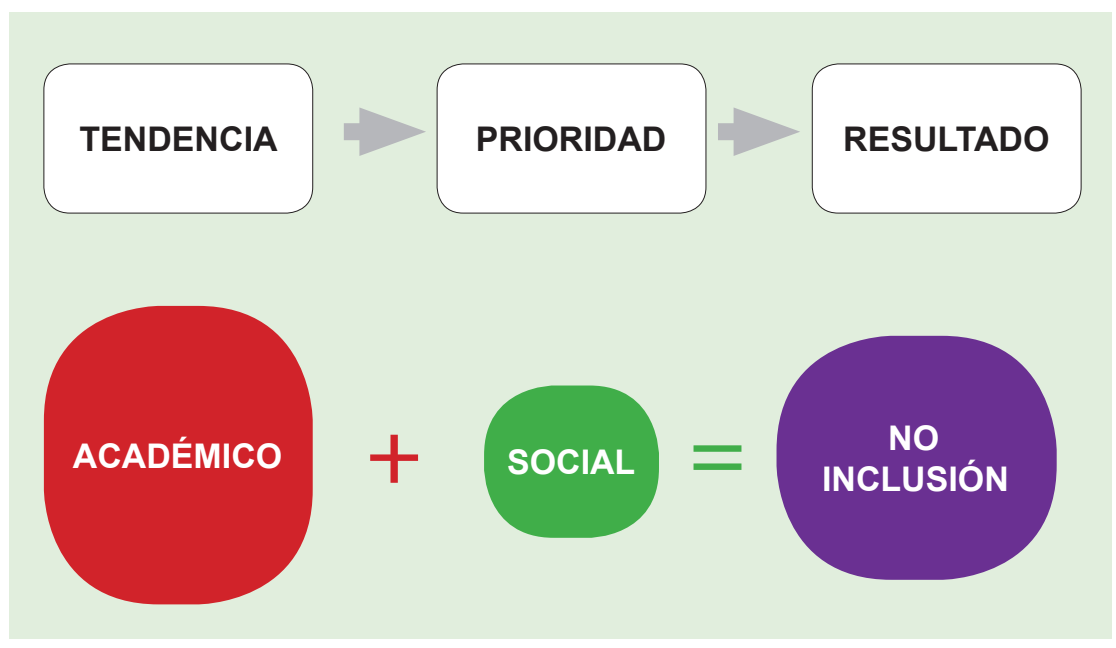

Si esta percepción de que la formación es un "refugio", ante un mercado laboral hostil (Termes, 2012), es generalizada para el alumnado de la Red, según nuestro trabajo de campo, en el caso del alumnado gitano los discursos cambian notablemente. El origen de esta diferenciación en la relación con la formación, entre el alumnado gitano y no gitano (con especial referencia por parte de las educadoras al alumnado migrante), se sitúa en la Educación Secundaria. Como características comunes a esa etapa, los profesionales señalan:

"A gran parte de las familias gitanas no les importa que aprendan, sino la inserción laboral' (educadora).

"Cuando están en Secundaria empiezan a ir al rastro e influye mucho en menor asistencia $y$ desenganche” (educadora).

“... algunas características comunes del colectivo gitano: absentismo, temprano abandono del Programa, poca motivación (en ocasiones les obligan desde el Centro Municipal de Servicios Sociales), ..." (Grupo de Trabajo de Diversidad).

Por tanto, no sólo hay una clara diferencia cuantitativa por su presencia, respecto 
a la Secundaria. Si no que también se percibe una mayor dificultad para lograr el éxito educativo postobligatorio. Para sistematizar la información que desarrollaría este argumento y permitir una análisis que nos conduzca a propuestas de mejora, decidimos establecer tres categorías de retos y oportunidades: las competencias interculturales de las profesionales de la Red, el rol de la familia y el de la comunidad en relación a la educación de los estudiantes gitanos. En todos estos niveles, hemos recogido fortalezas y necesidades, manifestadas por profesionales, familiares y ex-estudiantes.

\section{COMPETENCIAS PROFESIONALES INTERCULTURALES.}

Ante una sociedad aragonesa que era multicultural (multilingüe, multiétnica, etc) y que, con el nuevo siglo, ha devenido pluricultural (con las migraciones internacionales), es habitual, en esta temprana etapa de esa mutación, la presencia de estereotipos entre las profesionales de la Educación o la intervención social, mayoritariamente de origen "nativo / payo". Esto nos remite a sus competencias profesionales interculturales.

Estas competencias son la combinación de actitudes, conocimientos y habilidades aplicadas a través de la acción, que permiten, ya sea individualmente o colectivamente:

a. Comprender y respetar a las personas que percibimos que tienen diferentes afiliaciones culturales de las nuestras.

b. Responder de manera apropiada, efectiva y respetuosa al interactuar y comunicarnos con estas personas.

c. Establecer relaciones positivas y constructivas con estas personas.

d. Y comprenderse a una misma y sus propias múltiples afiliaciones culturales a través de encuentros con otros grupos culturales.

Como nos indican los resultados de la encuesta, en el caso de la Red Municipal, las competencias declaradas, en tanto actitudes y habilidades, se posicionan dentro de un nivel adecuado al marco de la intervención. Siendo necesaria, de forma general, abordar una adquisición de conocimientos sobre las culturas de origen de muchas de las alumnas y alumnos, principal carencia manifestada. Desde esta constatación, el trabajo de campo realizado sobre alumnado gitano, nos remite a estereotipos que son superables y que hemos examinado durante las diferentes Jornadas de 
formación realizadas. Ponemos como ejemplo de partida una afirmación muy alejada de este objetivo y poco representativa de las actitudes comunes en la Red, según la encuesta:

"En este Centro no hay gitanos, porque nuestra especialidad [oficio] es muy dificil y no se apuntan" (educadora).

Por el contrario, familiares y exalumnas parten siempre de una valoración positiva de los programas, apuntando a posteriori las necesarias mejoras en cuanto a las expectativas hacia el pueblo gitano:

"Los CSL hacen una rápida acogida a los alumnos y hacen que se sientan cómodos" (grupo focal).

"Se adaptan más a nuestras necesidades" (grupo focal).

"[Padre] Me senti avergonzado, cuando me llamaron para mostrarme que mi hijo habia pintado un metro cuadrado de pared.... Como si mi hijo no pudiese hacer algo mejor que eso..." (grupo focal).

"Exalumnas: sienten que tienen expectativas minimas sobre ellos"

(cuaderno de campo).

"En ocasiones se sienten discriminados, estigmatizados por ser gitanos: "nos tratan como si fuéramos tontos" " (cuaderno de campo).

"Ex-alumno: se ha sentido discriminado cuando ve que a los demás les explican más paso a paso las cosas o que se les dedica más tiempo a otros compañero que a él, como si él no tuviese interés" (cuaderno de campo).

Esta construcción desde abajo de un discurso que demanda más altas expectativas educativas, implica un cambio generacional y permite alianzas con las familias. Cuando estas diferencian entre las ofertas formativas, según su capacidad de facilitar el acceso al empleo:

"Estudiantes: coinciden en que no recomendarian a ningún conocido que se apuntase a los centros, porque luego "no van a encontrar trabajo" (cuaderno de campo).

Y cuando examinan las demandas del mercado laboral, para valorar el rol de la Red: 
"Creen que debería haber oferta de cursos "modernizada", "cosas que motiven a los jóvenes de boy en día", puesto que la realidad social ba cambiado y la oferta "sigue siendo la misma que hace 30 años" (cuaderno de campo).

\section{FAMILIA.}

Con la perspectiva biográfica que nos aporta Campus Rom Aragón, el rol de la familia para apoyar a los equipos educativos en la mejora de los resultados formativos es clave. Esto, como demuestran las trayectorias de estos estudiantes y profesionales gitanos, no depende del nivel educativo de los padres, si no de su valoración favorable del itinerario formativo que se ofrece a sus hijas e hijos (Anexo 2).

Luis Miguel contaba su propia experiencia, que tomamos como ejemplo y evidencia. Según recoge la periodista ${ }^{7}$ :

"Su madre ha trabajado en la limpieza y la venta ambulante. Su padre ha trabajado haciendo reformas y recogiendo chatarra"

"Sus padres no tienen el Graduado Escolar pero siempre le han apoyado mucho para que estudiara".

"Repetí $3^{\circ}$ de la ESO, estaba en una época rebelde y quería dejar los estudios. En casa me dijeron que al menos terminara la ESO".

Los datos recogidos nos permiten establecer cuatro bloques de análisis, para abordar la participación positiva de las familias gitanas en la Red Municipal. En primer lugar, como con otras estudiantes de los Centros, la relación con la Educación Secundaria ha sido muy negativa. El contacto y proximidad con las familias "desaparece", en tanto apoyo, y se centra en las llamadas por hechos negativos (sanciones, castigos, etc). No se ofrece, según las familias, otra solución que no sea inscribirse en un Centro Sociolaboral. Lo que, según las entrevistas, es percibido como un intento de los institutos para "quitarse un peso de encima" (cuaderno de campo). De forma que alumnado y familias llegan a los Centros "poco motivados y frustrados; van porque saben que es lo que les toca, no porque realmente quieran hacer eso" (cuaderno de campo).

7 https://www.heraldo.es/noticias/aragon/2018/04/25/soy-gitano-100-futuroabogado-1236636-300.html 
Del trabajo de campo previo al proyecto (Gimeno, 2016), extraemos algunas resistencias a esta derivación, percibida como expulsión más allá de los límites de la empleabilidad.

"Yo no quería que mi bijo viniera aqui. Quiero que lo lleven al instituto [...]. Alli también lo tenían en una clase solo para gitanos [...]. Nosotros vendemos, tenemos una tienda, mis hijos mayores tampoco estudiaron, pero saben ganarse la vida vendiendo. Aqui solo les enseñan a trabajar con las manos. Yo no quiero que mi bijo sea albañil o esas cosas para los que no estudian" (madre de alumno).

'No quiero copiar. Copiar es para tontos. Yo soy vago. No trabajo en clase porque no quiero. Me da pereza. Pero yo no soy tonto. En el instituto nos trataban igual. Te llevaban a la clase de los tontos, a compensatoria. Solo habia gitanos, todos los gitanos alli, y payos que no quieren estudiar. Te sacaban de clase y a copiar a la clase de los tontos" (alumno).

"Mi madre me ha dicho que venga. Que si no le quitan el IAI [renta mínima]. Pero después de Navidad dejaré de venir. Que ya no hace falta que venga tanto” (alumno).

En segundo lugar, las familias plantean que esta dinámica puede reproducirse en algunos contextos de la Red, aunque no es universal en la misma. En el capítulo sobre familias ya se ha señalado la importancia de implementar innovaciones en esa línea de comunicación positiva.

“Te llaman por burlas, amonestaciones, porque se porta mal..., pero no es habitual que te llamen para nada bueno" (grupo focal).

En tercer lugar, el conocimiento de la cultura gitana, como ámbito de las competencias interculturales, permitirá a los profesionales incorporar los cambios en los paradigmas generacionales que la academia, al menos la más alejada de la perspectiva transformadora, tampoco está atendiendo. Estos cambios tienden a una mayor valoración de la formación, especialmente la cualificante para el empleo.

"Los gitanos de mi edad, damos mucha importancia a que nuestros hijos estudien, aunque en nuestro caso nosotros no hayamos podido estudiar" (grupo focal).

En cuarto lugar, las familias y alumnado gitano nos señalan las estrategias que, como profesionales de la educación, pueden desplegarse para revertir esa desconfianza 
anclada en la Secundaria. La fundamental es el establecimiento de un vínculo de acompañamiento, como prestación técnica, no como seguimiento o control (COTSM, 2003).

Padre: "No hay relación entre iguales", "los propios educadores giran la cara si me ven por la calle y no me saludan" (grupo focal).

"Nunca me han dicho de quedar fuera, tomar algo o vernos fuera de lo que es el centro"; "No se han interesado por nada, más que los estudios" (grupo focal).

"Aunque las relaciones con los profesionales del CSL son mucho mejores que en el IES, 1@s alumn@sno sienten que les motiven para seguir estudiando,ni que les orienten para saber a qué otros recursos educativos pueden acceder. Su principal objetivo es que no falten a clase, el absentismo" (cuaderno de campo).

Familiares: hay poca flexibilidad porparte de los profesionales a la hora de comunicarse y trabajar con la familia (cuaderno de campo).

\section{COMUNIDAD}

Por último, un tercer bloque de información se refiere a la importancia del enfoque comunitario en la intervención educativa y social. No sólo con el pueblo gitano, aunque aquí nos centremos en este. La primera de las claves, adoptando esta perspectiva, es la necesidad de vincular la Red Municipal a las expectativas de movilidad social del alumnado y, sobre todo, de las familias y el entorno próximo al alumnado. Un indicio viene dado por la renovación de los patrones de inscripción, también del alumnado gitano. Existe, tal y como recogimos en las reuniones del Grupo de Trabajo, una resistencia a la movilidad geográfica, más allá del espacio donde la familia desarrolla su vida comunitaria. Aunque las entrevistas recogen que, si la actividad formativa permite una superación de las desigualdades, las familias "no tienen problema en apuntarse a otros CSL, aunque estén lejos de su barrio" (cuaderno de campo).

Con la dificultad que supone invertir el enfoque instalado actualmente en los servicios sociales y educativos, una lectura en clave de construcción de ciudadanía (igualdad en acceso a los derechos) nos sitúa ante demandas explícitas de mayor empleabilidad e inserción laboral, según los discursos recogidos (cuaderno de campo y grupo focal): 
"No recomendarían el centro a amigos, porque saben que con eso no van a conseguir un trabajo o aprender realmente un oficio".

"No hay expectativas de progresar por parte de los alumnos después de salir de los CSL".

¿Cuáles son las herramientas y estrategias para incorporar a la comunidad a la intervención educativa de la Red Municipal? En primer lugar, las entrevistas y el Grupo de Trabajo subrayan el rol de los espacios profesionales estables o espacios técnicos de relación (Marchioni, 2002). En los territorios donde esto se da, hay mayor coordinación con los profesionales de otros recursos que intervienen con la familia.

En segundo lugar, enfocarse al territorio, más allá de los límites del distrito, permite acceder a recursos que el pueblo gitano ya ha desarrollado, como el asociacionismo. Su papel, más allá de la mediación, ha sido subrayado por las familias, sobre todo. ¿Qué presencia tienen estas asociaciones dentro del calendario escolar de los centros? ¿Cuáles son los programas desarrollados por estas en los que participa la Red, ofreciéndolos también a las familias gitanas? ¿Cómo se introduce el liderazgo positivo como recurso al servicio de las educadoras y educadores? ¿Hay un acceso reconocido a estos liderazgos? La intervención de algunas personas de Campus Rom en varios centros nos da pautas para establecer puentes estables a estas personas y entidades, reforzando los ya existentes.

Precisamente ese era el objetivo de la exploración de la viabilidad de un proyecto de mentoría, que también tiene un capítulo en este libro. A pesar de las dificultades para acceder al trabajo de campo (ajenas a este equipo), que han influido notablemente en sus resultados, esa colaboración con el proyecto de innovación concluye que hay experiencias que pueden ser replicables en la Red Municipal, a partir de referentes de éxito educativo en el pueblo gitano.

Para ello, tengamos en cuenta el impacto de las actividades de Campus Rom Aragón, en las que hemos colaborado como proyecto desde su inicio. La presencia de algunos de sus participantes en entornos educativos de Primaria y Secundaria, prensa escrita y televisión, ha provocado el propio crecimiento del grupo, facilitando la preparación de pruebas de acceso a la Universidad por adultos. Así como una amplia repercusión 
en familias gitanas, muchas de ellas que han pasado o que están presentes en los Centros Sociolaborales. En este caso, con expectativas educativas altas.

Imagen 2. Carta de agradecimiento.

Querido Carmelo y José Ant onio.

Somos los alumnos de $6^{\circ}$ de Educ. Primaria del colegio "Ramiro Soláns".

En primer lugar, queremos darles las GRACIAS por su visita e interés que han demostrado hacia nosotros, nuestra educación y habernos aconsejado y animado a seguir estudiando para tener un mejor futuro y no depender de nadie y no sentirnos avergonzados por ser git anos.

Nos encantaron mucho sus palabras, mientras hablaba nos imaginábamos con un buen trabajo, nos hicist éis sentir bien, felices, orgullosos de lo que somos y que podemos llegar a ser lo que nos propongamos con mucho trabajo, volunt ad, iniciativa y constancia porque cualquier meta requiere un esfuerzo. Tenemos que luchar por hacer de nuestros sueños y metas una realidad.

Nos despedimos con gran esperanza e ilusión y esperamos verles por aquí de nuevo.

Un gran abrazo de todos los alumnos de $6^{\circ}$ de Primaria.

Imagen 3. Mensaje de adolescente a referente.

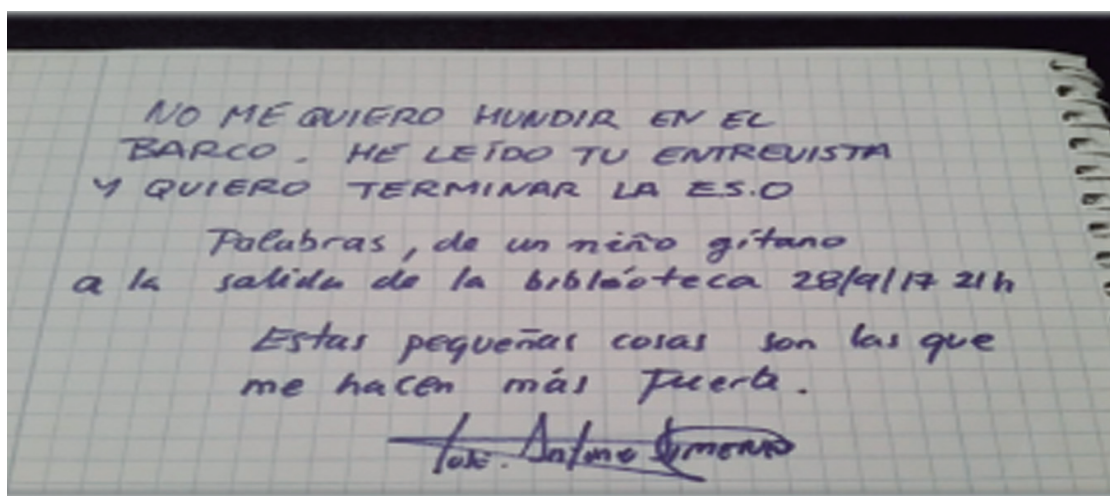

Es evidente que, ante las mismas familias que demandan este enfoque, el reto actual de la Red Municipal es mantener la asistencia del alumnado gitano, motivarlo y acompañarlo, aprovechando los dos años de media en los que se interviene como estructura pública (ver capítulos sobre familias). Es viable, como lo fue para Campus Rom desbordar un centro cívico con alumnado y familias, prensa y asociaciones, para expresarles que "los obstáculos no nos tienen que arrebatar nuestras ilusiones" (25 abril 2018). 


\section{PROPUESTA DE PROTOCOLO}

Gracias al Grupo de Trabajo, en el que agradecemos especialmente la colaboración de Carmelo Giménez y José Antonio Jiménez (ambos de Campus Rom), se redactó un protocolo para lograr ese objetivo: lograr una participación más exitosa del alumnado y las familias gitanas en la Red Municipal. La figura principal es una o un profesional de la mediación, que dé soporte a los centros durante el proceso de incorporación al programa educativo correspondiente ${ }^{8}$.

5. Preinscripción de alumno o alumna: el mediador podría participar en la reunión.

6. Si no lo hace: desde orientación del centro se le transmitirá la información de los alumnos seleccionados, para que pueda establecer un primer contacto, si se considera necesario.

7. En ambos casos, el mediador realizará una visita a la familia en la vivienda, para presentarse, ir creando vínculo y también poder obtener información sobre condiciones de vida, etc.

8. Presencia del mediador en una segunda entrevista, con la orientadora en el centro. Por ejemplo, en la de matrícula, para favorecer que lo identifiquen como referente dentro del proceso educativo.

9. Visitas periódicas a la familia (para mantener el vínculo, seguimiento del proceso, detección de necesidades, etc).

10. Otras intervenciones del mediador: charlas para abordar contenidos concretos, en pequeños grupos de alumnos gitanos. Con dos posibilidades: que estén previamente planificadas, con el objetivo de favorecer su participación (sentimiento "cuentan conmigo") y el empoderamiento del alumno; y a demanda de los educadores, por necesidades detectadas (información, sensibilización, etc). 


\section{CONCLUSIONES}

Como hemos reseñado ya en la introducción, los puntos fuertes de estos centros públicos, para encarar una mejor intervención educativa con el alumnado gitano, son la propia existencia del Grupo de Trabajo, que tiene por delante el reto de continuar la formación permanente de los profesionales, atendiendo a los resultados de la encuesta y a sus propias demandas. Así como el giro que se plantea hacia la comunidad (el barrio y los recursos asociativos de la ciudad) y hacia el éxito educativo (basado en evidencias). Desbordando, de esta forma, las resistencias existentes en el ámbito educativo, en general: como los discursos sobre las bajas expectativas y el fracaso vinculado al origen étnico del alumnado gitano; o las tensiones ya reseñadas sobre el enfoque neoliberal de esta y otras políticas públicas (privatización de servicios y aceptación de la secesión social).

El Grupo de Trabajo y el propio proyecto de investigación eran más ambiciosos, queriendo haber abordado todas las diversidades que la Red Municipal acoge. Pero la evaluación que hacemos del esfuerzo y las metas conseguidas es muy favorable. Por los medios con los que contábamos, que han partido siempre de la generosidad de las profesionales, las voluntarias y colaboradoras, del personal de IMEFEZ y del equipo investigador. Y por la relevancia de la meta: una política educativa que revierta las desigualdades, con un enfoque intercultural, de relación positiva con toda la diversidad del alumnado y sus familias.

Muchas gracias a todas.

\section{REFERENCIAS BIBLIOGRÁFICAS.}

Clavé, A. (2018). Les contours mouvants de la "famille » dans une politique d'intégration de migrants roms : une étude de cas. Ethnologie française, 172,(4), 645-656.

Colegio Oficial de Trabajadores Sociales de Madrid. (2003). Manual para el trabajo social de acompañamiento en los itinerarios de inserción. Madrid: Colegio Oficial de Trabajadores Social de Madrid.

Fernández, M. (1999). Alumnos gitanos en la escuela paya : un estudio sobre las relaciones étnicas en el sistema educativo. Barcelona : Ariel. 
Fundación Secretariado Gitano (2010). Evaluación de la normalización educativa de las alumnas y alumnos gitanos en Educación Primaria.

Madrid: Instituto de la Mujer.

Gimeno, C. (2016). Estos chicos no van a trabajar nunca. De las resistencias juveniles frente a la exclusión laboral y académica. En J. Gracia y D. Jiménez (coords.) Tristes tópicos. Representaciones Sociales desenfocadas. Zaragoza: Laboratorio de Sociología Jurídica. Universidad de Zaragoza.

Macías, F. y Flecha, R. (2013). Hacia una formación del profesorado para la igualdad del pueblo gitano. Revista de la Asociación de Enseñantes Gitanos, 30, 75-83.

Macías, F. y Redondo, G. (2012). Pueblo gitano, género y educación: investigar para excluir o investigar para transformar. RISE- International Journal of Sociology of Education, 1 (1), 71-92.

Marchioni, M., (2002). Organización y desarrollo de la comunidad. La intervención comunitaria en las nuevas condiciones sociales. M.L. Sarrate (coord.), Programas de animación sociocultural, pp. 455-479. Madrid: UNED.

Szalai, J. (ed.) (2011). Contested Issues of Social Inclusion through Education in Multiethnic Communities across Europe (Budapest: Edumigrom) 


\section{ANEXO 1}

\section{Alumnado gitano en la Red Municipal de CSL.}

Elaborado por Marisa Alcaraz Gavín y Carla Sainz Viartola (trabajadoras sociales).

Gráfico 3. Alumnado gitano que comienza el programa por sexo (2017/2018).

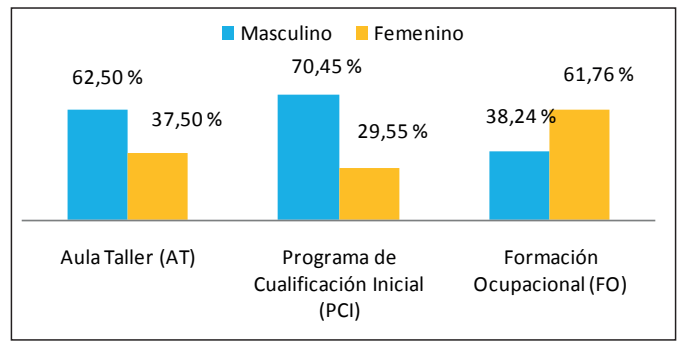

Gráfico 4. Alumnado gitano que finaliza el programa por sexo (2016/2017).

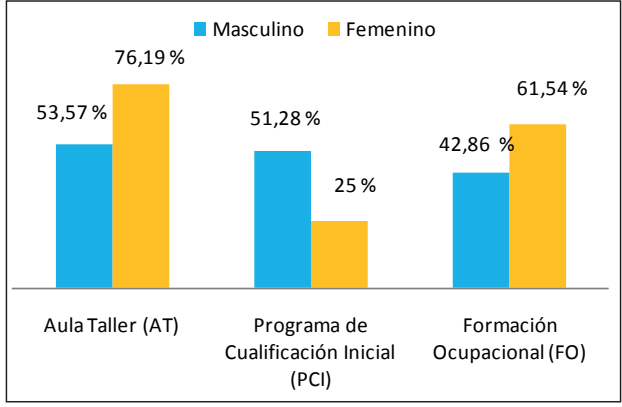

Gráfico 5. Alumnado gitano que finaliza el programa (2016/2017) .

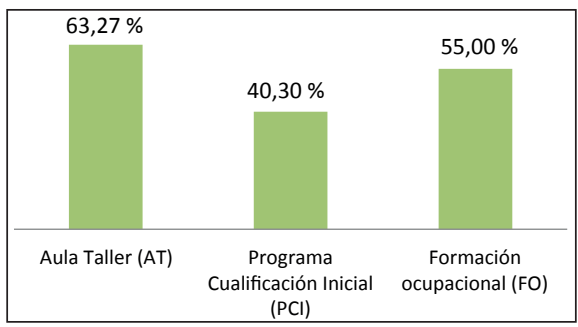


Gráfico 6. Escolarización previa (último curso realizado) .

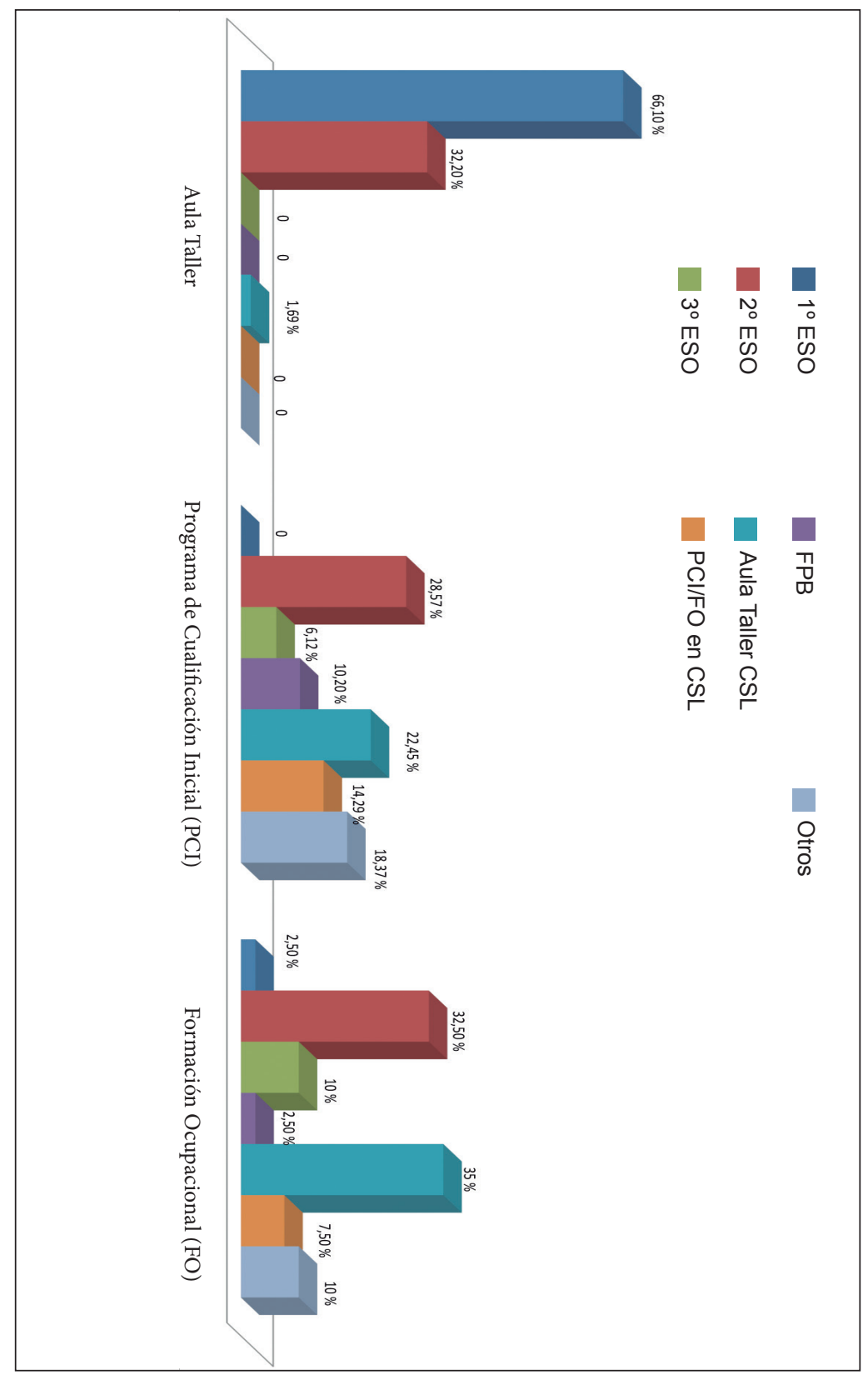




\section{ANEXO 2 \\ Entrevista a Carmen Jiménez Dual (Campus Rom). \\ Enseñanza y comunidad gitana, ¿qué tipo de dificultades hay en este ámbito? ¿Puedes hablarnos de tu experiencia personal?}

Hay un muchos estudios que nos hablan de factores que pueden incidir en el ámbito educativo. Algunos de estos factores parece que tienen que ver con la falta de adecuación de las políticas educativas, la falta de preparación intercultural del profesorado, la poca presencia de la cultura en la escuela, la lejanía socioafectiva del mismo hacia el alumnado gitano etc. Otros apuntan a que tienen que ver con la familia, su débil valoración de los estudios como parte fundamental para el futuro de sus hijos/as, sus carencias socieconómicas, su escasa relación con el centro educativo etc. Por último algunos ponen el acento en el propio alumnado: el desfase curricular, la falta de motivación del alumnado, las dificultades vitales, la sensación de rechazo que puedan sentir, etc.

La imagen social de la realidad de la comunidad gitana en la educación está llena de estereotipos negativos y de falta de expectativas.

Pero esto, como siempre, depende del caso en concreto. Ni todos los alumnos/ as gitanos/as tienen la misma preparación y rendimiento en la larga trayectoria educativa; ni en todos los coles son tratados igual; ni todas las familias tienen la misma visión respecto a la educación de sus hijos/as.

No existen soluciones únicas, estos factores influyen los unos en los otros. Es necesario hacer cambios en positivo incidiendo en éstos factores para que éstos influyan revirtiendo resultado. Sería más adecuado hablar de la educación de tal forma que, aunque tengamos en cuenta las dificultades podamos hablar de fortalezas o factores de éxito. Ver qué hace que un niño/a acabe sus estudios con normalidad.

Mi experiencia personal ha sido buena en general. Estudié en un colegio público femenino del barrio de la Magdalena.

Hasta los 14 años que acabé mis estudios de Graduado Escolar no tuve académicamente problema alguno. Sacaba buenas notas y las relaciones con mis 
profesoras y compañeras eran buenas. Tengo un recuerdo muy especial de la mayoría de mis profesoras y también de la directora de mi colegio. Muchas veces, estudiaba para agradarlas a ellas intentando compensar el cariño y la consideración que mostraban hacia mí. Sentía que la escuela era mi segunda casa.

Las monitoras del comedor escolar creaban un buen ambiente. Las alumnas mayores les ayudábamos a recoger las mesas después de comer y luego ellas se ponían de juerga a cantar y bailar con nosotras haciendo un gran corro. La mayoría de veces flamenco y rumbas para todas. Otras veces las compañeras payas nos enseñaban a bailar jota. Nadie se quedaba sin participar.

En algunas de mis compañeras gitanas y también payas, veía ciertas dificultades para superar los cursos con éxito y por ello tenían que repetir. Acababan en un aula de recuperación donde iban todas aquellas alumnas que habían repetido curso con la idea de volver a su curso correspondiente una vez alcanzado el nivel. Ellas me contaban que la profe era muy rígida y que no aprendían nada. En todos los años que estuve en el cole sólo tengo conciencia de una de ellas que sí consiguió recuperar: mi hermana mayor. Ella era dos años mayor que yo y tuvimos la suerte de estar juntas en clase con un buen rendimiento desde quinto hasta séptimo de EGB.

Ella se había ocupado de cuidar de mis hermanas pequeñas cuando estaban enfermas y tenía que faltar a clase por ello. Mis padres iban a trabajar en la venta ambulante y su relación con la escuela era buena pero escasa. Cuando mi hermana todavía no había acabado, con 14 años, ya tenía edad para trabajar y así lo tuvo que hacer porque hacía falta un apoyo económico en casa.

Así que, tengo que agradecerle a mi hermana el hecho de haber estudiado. Si yo hubiera sido la mayor, lo hubiera tenido mucho más difícil para estudiar. Somos cinco hermanas y nos educaron para cuidarnos las unas de las otras. El único hermano que tengo nació cuando las chicas ya éramos mayores.

Mis padres tenían miedo de que fuera al instituto con chicos payos pero yo les demostré que tenía la intención de estudiar y ellos se fueron convenciendo y dándose cuenta de lo importante que era para mí. Se enorgullecían y valoraban mis esfuerzos.

La época de bachiller la recuerdo con cambios, cambio de domicilio, cambio de colegio, de amigos, cambio personal porque entraba en la adolescencia, acontecimentos vitales 
estresantes, costaba adaptarse a todo. Ya no era tan brillante y con alguna dificultad, sacaba adelante los cursos.

Cuando llegué a COU (Curso de Orientación Universitaria), mis notas bajaron y me fuí del instituto para trabajar en un restaurante haciendo la limpieza por la mañana y a continuación entraba a la cocina. Trabajaba un montón de horas y me pagaban una miseria.

Al curso siguiente volví con fuerzas renovadas y lo aprobé todo. Así pude hacer la selectividad para estudiar la carrera de Trabajo Social. Los fines de semana y vacaciones ayudaba a mi familia en la venta ambulante.

Hablamos de Campus Rom, de acceso a enseñanza superior. ¿Cuál es el origen de Campus ROM en Cataluña? A partir de vuestra visita a Barcelona: ¿Qué dificultades, aprendizajes, presente y futuro tienen?

Campus Rom tiene su origen en Cataluña, a través de un proyecto europeo llamado INCLUD-ED que fomenta la participación de las familias gitanas en la escuela con el apoyo del Plan Integral de Desarrollo del Pueblo Gitano de Cataluña. Nace como una actuación de éxito educativo donde las familias tienen capacidad de decisión en los asuntos escolares de sus hijos. Las familias tienen un espacio y un lugar en la propia escuela para aprender lo que ellos decidan al mismo tiempo que acompañan a sus hijos en el proceso educativo.

Una de las cosas que las familias decidieron estudiar fue un curso de preparación para superar las pruebas oficiales de acceso a la Universidad para mayores de 25 años. Son en su mayoría padres y madres jóvenes que tuvieron que abandonar sus estudios por diferentes motivos y que tienen la oportunidad de retomarlos.

Tuvieron muchas dificultades y al principio, pocos accedían a la universidad. Pero después de superarlas ayudándose entre ellos el número de personas que lo consiguen sigue en aumento.

En junio de este año pudimos visitar a nuestros primos y primas de Barcelona para que nos contaran su proyecto. Vimos que las necesidades y los objetivos eran compartidos y quisimos sumarnos a esta iniciativa creando una delegación de Campus Rom en Aragón. 
Nuestros objetivos son:

a. Crear mayor conciencia en las familias de la importancia de la educación para el futuro de sus miembros y de la comunidad gitana.

b. Trabajar de forma coordinada con otras iniciativas, recursos, asociaciones e instituciones que desempeñen su labor en la defensa de los derechos sociales y educativos para favorecer el éxito del alumnado.

c. Impulsar políticas y medidas socioeducativas que palien las desventajas favoreciendo la igualdad de oportunidades.

d. Favorecer la superación de estereotipos negativos y prejuicios sobre los gitanos y la educación militando en la visibilización de diferentes perfiles de jóvenes (y no tan jóvenes) estudiantes y profesionales que estén implicados en procesos formativos y laborales de éxito.

e. Dar soporte, acompañar y ayudar a estudiantes gitanos/as mayores de 16 años que quieran iniciar o estén en algún proceso formativo.

f. Fomentar la participación y el liderazgo de personas que hayan finalizado, estén cursando o vayan a iniciar la educación media y superior para que sirvan de referentes a otras que quieran seguir su camino.

Las personas referentes gitanas, tienen mucho que decir. ¿Qué mensaje lanzarías a las y los jóvenes gitanos que estudian en los Centros Sociolaborales del Ayuntamiento de Zaragoza?

La educación nos convierte en personas autónomas, nos da herramientas para adaptarnos a cualquier circunstancia que incida en nuestras vidas. Nos da los medios para que nuestras familias puedan avanzar en otros campos, abriéndonos las puertas del desarrollo cultural y la participación en la sociedad.

La educación nos permite una reflexión y una acción en términos positivos, cargados de esperanza. En definitiva, nos hace más libres para decidir nuestro destino.

Mi mensaje: "A las chicas gitanas y a los chicos gitanos, que van a los centros educativos con sus mochilas cargadas de ilusiones. Con el deseo de compartir y ayudar a cumplir un sueño: el de estudiar. Con la esperanza de que ello contribuya a ampliar sus opciones vitales".

Mas información en: www.campusrom.org 


\title{
ALIANZAS COMUNITARIAS POR EL EMPLEO JUVENIL EN ZARAGOZA
}

\author{
Jose María Regalado López \\ Trabajador Social, Docente del Grado de Trabajo Social en la Universidad Pontificia \\ de Comillas y en la Universidad de La Salle de Madrid
}

\section{INTRODUCCIÓN}

El Grupo de Trabajo de Empleabilidad, compuesto por integrantes de 9 de los 12 centros sociolaborales de Zaragoza, el referente municipal de los mismos y un consultor del equipo científico del proyecto, desarrolló las propuestas que describimos a continuación a partir de siete sesiones de trabajo comprendidas entre octubre de 2017 y junio de 2018 .

Las expectativas expresadas por los profesionales participantes, de las que partimos en 2017 para encauzar el trabajo fueron:

a. Reflexionar sobre la adecuación de las especialidades que se imparten.

b. La baja salida profesional, acceso a puesto de trabajo, de los y las participantes en las formaciones de los centros.

c. La dificultad del contacto con las empresas del territorio, de forma independiente cada centro y, a su vez, cada maestro de taller.

d. La falta de cobertura de las necesidades de los y las jóvenes.

e. La necesidad de estudiar el mercado laboral de Zaragoza, y adecuarse a la demanda.

Desde las primeras sesiones, cobró especial relevancia la necesidad de construir una estrategia de Red, desde la lógica de la colaboración frente a la competitividad entre centros y proyectos educativos. El debate ponía en valor las posibles ventajas de diseñar una estrategia basada en la unión de fuerzas de trabajo entre las diferentes organizaciones que gestionan los centros, de la mano de la administración pública, en particular con el Ayuntamiento de Zaragoza como impulsor de la Red. Y la misión de establecer alianzas con el tejido empresarial del territorio como potenciales empleadores. 
Para poder construir estar relaciones, se requiere levantar pilares fundamentales que se convierten en las líneas de trabajo del grupo de empleabilidad. La necesidad de cultivar una identidad de Red Municipal, para alinear acciones y recursos. Una identidad, que permita diseñar acciones globales en el territorio de los centros, actuaciones encaminadas a construir alianzas con empresas, administraciones públicas, y otras entidades para favorecer mayores oportunidades de empleo para los y las jóvenes.

Así, el tejer esta identidad de Red entre los Centros Sociolaborales, pasó a ser el elemento vertebral del grupo, que desembocó en los productos que describimos a continuación.

\section{PRODUCTOS DESARROLLADOS DURANTE EL PROYECTO ARGUMENTARIO COMÚN DE LA RED}

Uno de los primeros consensos del grupo fue la necesidad de desarrollar un discurso común, que unificase los argumentos de los centros de la Red de cara a las empresas colaboradoras en la fase de prácticas curriculares de las especialidades. Se acordó alinear las diferentes fórmulas y discursos existentes, con el objetivo de construir la mencionada identidad de Red de centros, que permita una mayor repercusión en el territorio.

Para ello, se elaboró un cuestionario que contempló 6 preguntas abiertas orientadas a recoger la información relevante en cuanto a:

a. Objetivos de los centros sociolaborales.

b. Acciones del centro en cuanto a la orientación laboral.

c. Valor añadido aportado a las empresas colaboradoras.

d. Protocolo de prácticas.

e. Aspectos de valor que puede aportar la identidad de red en la empleabilidad de los y las jóvenes, frente a las acciones individuales o aisladas.

f. Aspectos de valor que puede aportar el modelo de prácticas de red a una empresa del territorio.

De esta forma, se obtuvo la información relevante para elaborar el producto clave, hito en el proceso de trabajo colaborativo de la Red, el Modelo común de Prácticas de la Red de CSL. Y su transferencia mediante un díptico común orientado a un target específico, las empresas colaboradoras de prácticas, presentes y futuras. 
Cabe reseñar, que hasta la actualidad cada centro y/o entidad gestora disponía de documentación diferenciada, no conectada con la identidad de la Red.

Imagen 1. Díptico unificado para empresas de Prácticas de la Red de Centros Sociolaborales

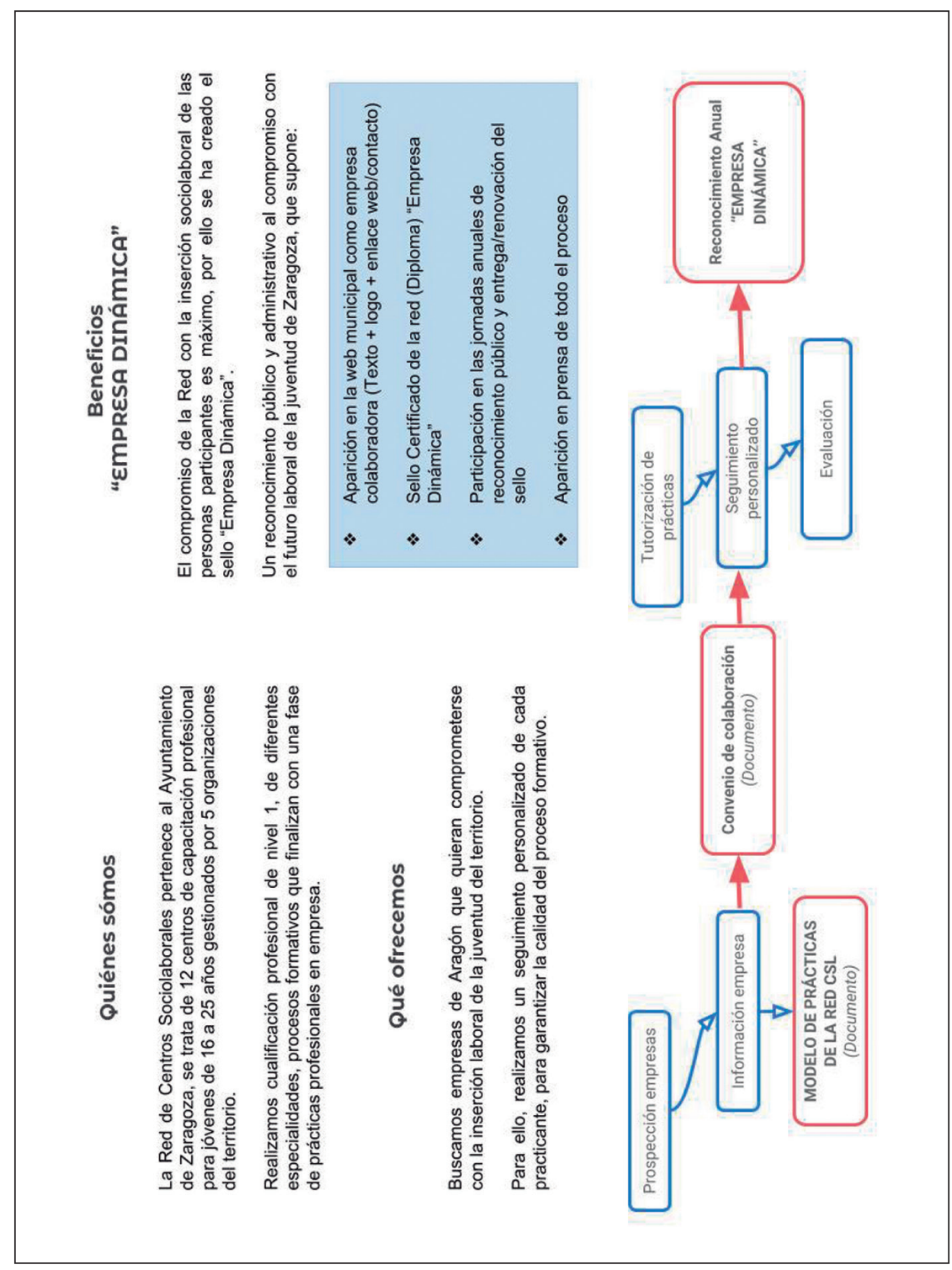



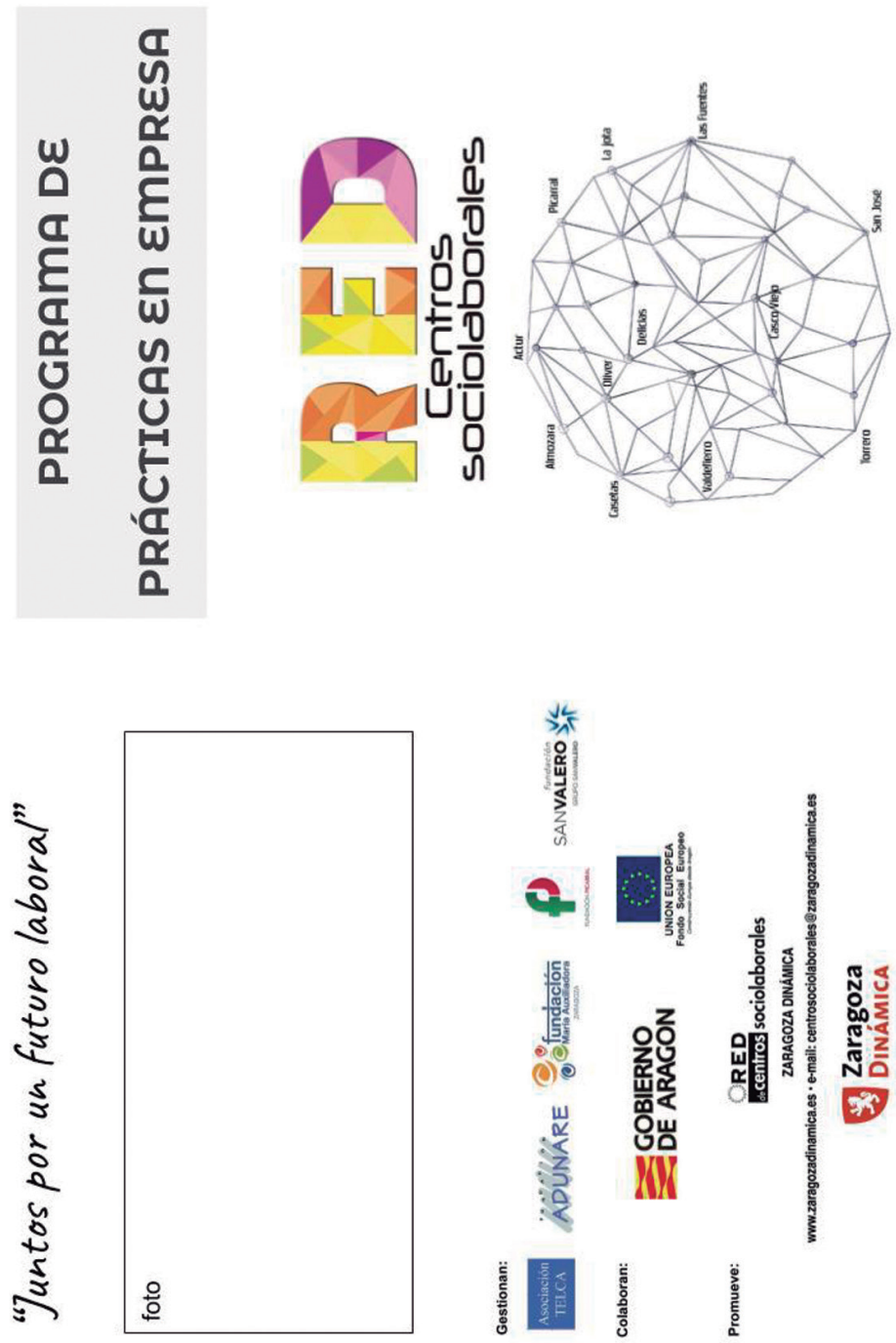

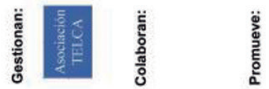




\section{MODELO DE PRÁCTICAS DE LA RED DE CENTROS SOCIOLABORALES}

La elaboración del argumentario común, orientado a la construcción de un Modelo de Prácticas de la Red, marcó un hito en el proceso de trabajo del grupo de Empleabilidad. La puesta en común de los procedimientos de desarrollo habituales de cada centro, y el posterior consenso en la identificación de sus puntos clave. Así como, el interés mutuo en unificar estos elementos centrales, bajo un paraguas de Red Municipal de Centros Sociolaborales, aprovechando la fuerza de la agrupación y la alianza público-privada.

Los hitos que componen el Modelo de Prácticas de Red propuesto son: la prospección, la información a la empresa del Modelo de Prácticas, el convenio de colaboración, la tutorización de las prácticas, su seguimiento y evaluación y el cierre del proceso con la entrega de reconocimientos a las empresas colaboradoras en un acto público.

Imagen 2. Fases consensuadas del Modelo de Prácticas de la Red de Centros Sociolaborales

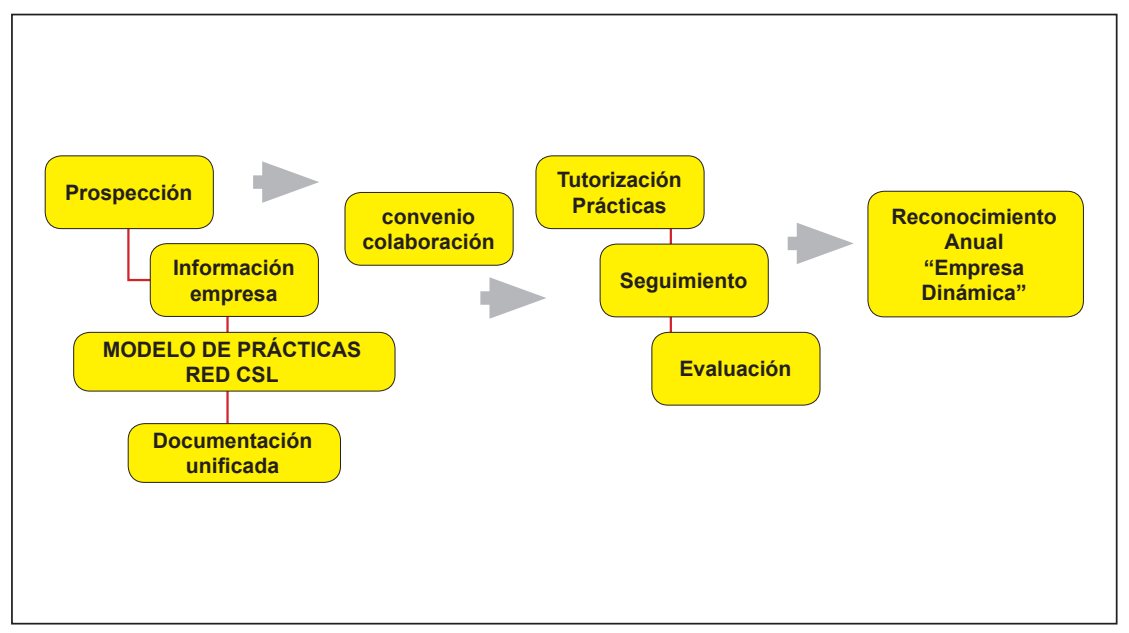

Prospección, todos los centros desarrollan de forma anual un acercamiento a nuevas empresas, o un ciclo de contactos con empresarios colaboradores de años anteriores, esta fase denominada prospección es determinante para identificar las plazas disponibles para prácticas (FCT). Este proceso de acercamiento a nuevas 
empresas colaboradoras se unifica de forma documental mediante la elaboración del díptico mencionado con anterioridad (ver imagen 1).

Modelo de prácticas unificado. En este acercamiento inicial a la empresa, se ha unificado el criterio informacional aplicado, no sólo mediante el díptico informativo, sino también mediante el consenso y desarrollo de una identidad gráfica en la documentación de las prácticas, que contemple los 3 pilares de la Red, la marca CSL, el Ayuntamiento y las entidades que gestionan cada uno de los centros. Entre la documentación unificada se encuentra el convenio de colaboración con la entidad gestora del Centro Sociolaboral.

Tutorización, seguimiento y evaluación de las prácticas, dentro del argumentario se expone como valor añadido, el seguimiento individualizado del alumnado con el tutor/a identificado por la empresa colaboradora como referente en el puesto de trabajo. Esto promueva una relación de confianza que permite un clima de enseñanza-aprendizaje más adecuado, y a medida de la empresa. No es una cuestión baladí, ya que esta relación de confianza entre profesionales, puede favorecer el contexto adecuado para dar el salto a la inserción laboral del/la participante, poniendo en evidencia las principales competencias y habilidades de cada uno de nuestros alumnos y alumnas.

Acto público de reconocimiento, como cierre unificado del proceso anual, que otorgue una puesta en escena pública de la repercusión de la Red Municipal. Y aporte un valor estandarizado a toda empresa colaboradora de la Red en su conjunto.

De esta forma se llega a una homogeneización del proceso, y a su vez a una necesidad de consenso para su transformación que sienta las bases para el trabajo en red.

Varios de los retos de la Red Municipal de CSL para alcanzar una conexión con la comunidad a partir del establecimiento de alianzas estratégicas son:

- El continuo trabajo conjunto como Red para unir fuerzas y recursos ganando autoridad y repercusión de cara al sector empresarial.

- Atención a estructuras de segundo nivel del territorio (asociaciones de comerciantes, cámara de comercio, agrupaciones empresariales o de servicios, etc.) 
- Identificar los principales actores comunitarios a integrar al proyecto (empresas, administración, entidades, agrupaciones, vecinos/as, jóvenes, etc)

- Incorporar estrategias de "marketing" para ganar visibilidad.

- Analizar nuevas estrategias de relación con las empresas de prácticas, buscando establecer relaciones win-win.

El Modelo de Prácticas consensuado, permitió iniciar el debate en torno al desarrollo de una actividad de Red para ganar visibilidad y repercusión ante las empresas del territorio, que derivó en la propuesta de Jornadas y reconocimiento "Empresa Dinámica".

\section{JORNADAS Y RECONOCIMIENTO "EMPRESA DINÁMICA”}

En las últimas sesiones del grupo de Empleabilidad, tomó forma el desarrollo de una acción global de la red orientada a establecer y fortalecer alianzas con empresas colaboradoras en las prácticas laborales, que son la principal fuente de empleabilidad para los y las jóvenes de los centros.

Este evento empezó a dibujarse con dos objetivos. La Presentación del Modelo de prácticas de la Red. Y establecer un reconocimiento para las empresas colaboradoras, de la mano del Ayuntamiento, con una proyección municipal a través de un acto público, la aparición en la web municipal y el consecuente impacto en medios de comunicación de las empresas reconocidas de la Red Municipal de Centros Sociolaborales, poniendo en cabeza la valía de los y las jóvenes participantes, que suelen ser víctimas de estereotipos constantes.

Así se promueve una línea de trabajo orientada a tejer alianzas comunitarias con el tejido empresarial del entorno, desde una perspectiva de beneficio mutuo, en alianza por el bienestar de la juventud más vulnerable de Zaragoza.

Para ello, se propone desarrollar el reconocimiento a las empresas colaboradoras de la Red, favoreciendo este clima de colaboración. Las empresas obtienen una distinción municipal, que se ha propuesto vincular a la marca municipal Zaragoza Dinámica. De este modo, se plantea el desarrollo del Sello "Empresa Dinámica", que implicaría: 
- Diploma firmado por el Ayuntamiento hacía las empresas locales colaboradoras

- Aparición en un site de la web municipal como empresas comprometidas con el empleo joven del territorio

- Acto de reconocimiento anual, con la asistencia de responsables públicos y privados, y estudiantes de los centros.

- Impacto en medios de comunicación del acto público, notas de prensa, medios digitales, vídeos del evento, etc.

Con este contexto de crecimiento mutuo buscamos implicar a más empresas con el "compromiso de contribuir al futuro de Zaragoza, garantizando el futuro de laboral de sus jóvenes".

En una segunda fase se plantea reforzar el proceso desarrollando el I Premio del Ayuntamiento de Zaragoza al Compromiso Empresarial con el Empleo Juvenil.

Con estas medidas la Red busca incrementar el conjunto de tejido empresarial implicado con los Centros Sociolaborales, conectando con nuevas empresas y con organizaciones empresariales de segundo nivel.

\section{PROPUESTA DE ACTUACIÓN COMUNITARIA EN EL TERRITORIO}

Como posibles líneas a dibujar en un futuro, tras dar los primeros pasos hacia la lógica de trabajo en Red entre los Centros Sociolaborales, se ha planteado buscar el beneficio común de todos los actores a partir de proyectos globales de carácter comunitario, más allá del contexto de prácticas profesionales.

Poner al servicio de la comunidad las acciones de formación. Para contribuir a proyectos de dinamización comercial y vecinal, con el compromiso a su vez por parte de las empresas de implicarse en la formación de las participantes.

Hablamos de una propuesta que supera la colaboración, hacia un marco de cocreación, de comunidad de aprendizaje, donde los Centros Sociolaborales se pongan al servicio de la comunidad, no sólo como espacios de formación profesional, sino como espacios de aprendizaje significativo y desarrollo comunitario. 
Para ello, se plantea que el conjunto de centros y especialidades trabajen por proyectos de impacto local que puedan resolver problemáticas identificadas en el territorio, desde los diferentes prismas profesionales en desarrollo (especialidades). Sería necesario para ello la construcción de un grupo motor que realice un acompañamiento para acometer un análisis de necesidades, junto a recursos sociales, comunitarios y vecinales. E integrar actores en el proceso, ciudadanía, recursos profesionales y un apoyo institucional de las administraciones locales, para posicionar las acciones del alumnado de los Centros Sociolaborales como motor de transformación local, rompiendo estigmas y construyendo futuro.

Esta propuesta de continuidad a largo plazo puede ser garante de un impacto global en el territorio desde la lógica del desarrollo comunitario.

\section{TAREAS PENDIENTES}

Otro aspecto trabajado en este tiempo por el grupo, pero que no ha llegado a finalizarse, es el análisis de las especialidades de los Centros Sociolaborales. En primer lugar, estudiando aquellas familias profesionales que, en su catálogo de nivel 1 (Catálogo Nacional de la Cualificación Profesional), no se están desarrollando en los centros, y podrían tener una salida profesional relevante. $\mathrm{Y}$, en segundo lugar, analizar los contenidos o metodologías transversales de valor para incorporar en las especialidades existentes, que puedan integrarse en colaboración con otros actores del territorio. Esto permitiría el establecimiento de nuevas alianzas públicoprivadas, y la orientación al impacto social local.

Para ello se han identificado diferentes experiencias a nivel nacional que pueden orientar los siguientes pasos del proyecto en cuestiones de empleabilidad. 



\title{
METODOLOGÍAS ACTIVAS PARA EL APRENDIZAJE. APRENDIZAJE DIALÓGICO Y APRENDIZAJE BASADO EN PROBLEMAS (ABP)
}

\author{
Ana Cristina Blasco Serrano ${ }^{1}$, Belén Dieste Gracia ${ }^{2}$, \\ 1, 2 Dpto. CC. de la Educación/Facultad de Educación/Universidad de Zaragoza.
}

\section{INTRODUCCIÓN}

Actualmente, nos encontramos en la sociedad del conocimiento, en la que los jóvenes disponen de acceso a una gran cantidad de información. Los educadores nos enfrentamos así a la difícil situación de provocar curiosidad en el alumnado, a pesar de que puedan disponer de gran cantidad de información en las redes o en los medios de comunicación.

Por ello, los docentes hemos de incluir en el aula metodologías activas, motivadoras, contextualizadas y basadas en la experiencia, con el fin de establecer puentes entre la realidad y los intereses del alumnado.

\section{EL APRENDIZAJE DIALÓGICO}

El aprendizaje dialógico es clave en la mayoría de las metodologías activas, dado que actúa como catalizador de las operaciones mentales internas, y por tanto, de los procesos de aprendizaje (Vygostki, 1996).

Las personas comienzan a ser conscientes de su aprendizaje y conocimiento cuando se esfuerzan en argumentar para convencer sobre su propio punto de vista. En la interacción con otras personas, emergen situaciones de reflexión y de activación de la comprensión y del análisis. Esto ocurre al tener en cuenta las opiniones, conocimientos y creencias de los demás, con de fin de nutrirse, en una actitud de apertura hacia el otro/a (Frith, 2012).

La interacción abre las puertas al aprendizaje y permite dar la oportunidad al otro 
de guiar o colaborar para resolver un problema o ampliar el conocimiento previo. En este contexto, los estudiantes son capaces de explicar a sus iguales, consiguiendo en ocasiones, alcanzar logros que el profesorado no ha sido capaz.

En consecuencia, el alumnado aprende a través de sus propias preguntas, diálogos y reflexiones. El diálogo pasa a ser una herramienta clave para el aprendizaje, a partir de las interacciones verbales y no verbales con las personas del entorno (Wells, 2001). Para que se pueda llevar a cabo un aprendizaje dialógico, son necesarios una serie de principios (Aubert, García y Racionero, 2009):

a. Diálogo igualitario. Todas las intervenciones son importantes, todas han de ser consideradas, sin recriminaciones ni desprecios.

b. Inteligencia cultural. Incluye los saberes académicos, su aplicación práctica y las habilidades comunicativas para transmitirlos.

c. Transformación. Búsqueda de la mejora de la persona y del grupo. El individuo se considera como parte de un colectivo.

d. Dimensión instrumental. Desarrollo de habilidades instrumentales: técnicas y profesionales, indispensables para trabajar e integrarse en la sociedad de manera plena.

e. Creación de sentido. Los grupos interactivos pueden favorecer la contextualización y significación del aprendizaje y la convivencia entre sus participantes.

f. Solidaridad. Para trabajar en equipo, mediante interacción, los estudiantes han de apoyarse unos en otros, de manera que la diversidad aporte valor añadido al grupo.

g. Igualdad de diferencias. La diferencia es una aportación de riqueza, un valor añadido.

El aprendizaje dialógico constituye para Morin (1996) uno de los principios para la construcción de un conocimiento profundo, complejo y transdisciplinar. Para este autor, el aprendizaje dialógico permite relacionar dos ideas que son antagónicas entre sí, pero que a su vez son complementarias. Sumando ambas ideas en una misma realidad o situación se consigue estructurar y organizar el conocimiento.

Los educadores pueden presentar casos contrarios, antagónicos de la misma 
realidad, para que el alumnado pueda reflexionar perspectivas opuestas sobre un mismo fenómeno (Gómez, Hernández, y Ramos, 2017).

\subsection{El aprendizaje dialógico como estrategia educativa en el aula.}

Las aulas funcionan y se organizan según unas reglas y una estructura social determinada, por las que cada uno de los participantes, alumnado y profesorado, tiene un rol establecido (Wells, 2001). Esto adquiere especial relevancia en las aulas de los centros sociolaborales, en las que se dan unas interacciones y relaciones entre alumando y profesorado, así como entre el propio alumnado.

Los procesos de enseñanza-aprendizaje de estos centros destacan por su caracter experiencial y pragmático, muy orientados a la inserción social y laboral de su alumnado.

En este contexto, tras recibir una sesión de formación sobre aprendizaje dialógico, dos educadoras del Centro Sociolaboral La Jota, decidieron conjuntamente poner en marcha grupos interactivos ${ }^{1}$ para trabajar contenidos específicos de la especialidad y contenidos de formación básica (lenguaje y matemáticas). Cada grupo interactivo estaba formado por 3 o 4 alumnas, tal y como recomiendan los expertos (Álvarez y Puigdellívol, 2014).

Tras la autorización por parte de la coordinación de centro, se contactó con varias personas conocidas del entorno para que fueran voluntarias y dinamizaran los grupos interactivos. Pero y .... ¿Cuáles son las funciones de las personas

\section{voluntarias?}

Las principales funciones de las personas voluntarias son (Álvarez y Puigdellívol, 2014):

a. Estimular la participación de todos/as.

b. Favorecer las habilidades de colaboración y resolución de problemas.

c. Propiciar la ayuda entre iguales, evitando proporcionar ayuda directa.

d. Potenciar el consenso.

En el Centro Sociolaboral (CSL) se consiguió la participación de la comunidad

1 Los grupos interactivos son agrupaciones de estudiantes heterogéneas en los que el aprendizaje se desarrolla a partir de las interacciones.

Los estudiantes se apoyan y ayudan unos a otros. Además, una persona voluntaria dinamizará el grupo y facilitará las interacciones entre el alumnado para incentivar el aprendizaje. 
educativa a través de dos voluntarias y un voluntario, que recibieron una sesión de formación antes de iniciar los grupos interactivos.

Además, antes de comenzar cada una de las sesiones, las educadoras se reunían con los voluntarios para informar del desarrollo de la sesión y de las actividades.

Imagen 1.Información de las educadoras a los voluntarios en los momentos previos a la sesión

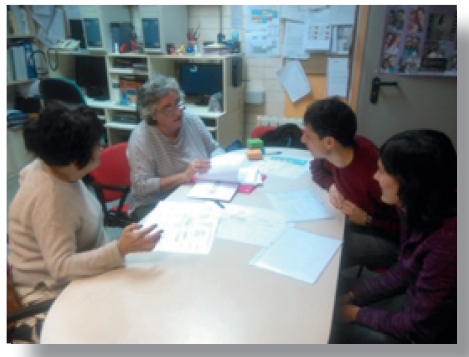

Una de las voluntarias era ex-alumna, actualmente en activo laboralmente. El hecho de que se hubiera formado en el centro, favoreció especialmente el principio de inteligencia cultural, ya que había pasado por la misma realidad. Esta voluntaria conectó muy bien con las alumnas, las comprendía, se ponía en su lugar. Además, probablemente, sirvió como referente, puesto que tras su paso por el centro, había retomado el itinerario académico y actualmente estaba trabajando. Era por tanto, un modelo a seguir para las actuales alumnas que componían el grupo.

Otra de las voluntarias fue la madre de una de las educadoras, que no conocía el contenido técnico de la materia que se trabajaba. Por esta misma razón, se dedicó a dinamizar las interacciones, favoreciendo el aprendizaje colaborativo, el apoyo entre unas y otras, potenciando el principio de solidaridad.

Finalmente, participó como voluntario un educador del Centro de Tiempo Libre El Cuco, aportando así un perfil diferente al de las alumnas, pero que forma parte de la comunidad educativa, favoreciendo el principio de transformación de la comunidad educativa.

En total se realizaron cuatro sesiones: dos en las que se trabajaron contenidos específicos y dos en las que se trabajó formación básica.

Imagen 2. Sesión de grupos interactivos 


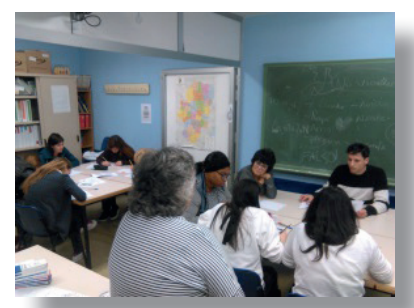

La evaluación por parte de las educadoras ha sido positiva. Los grupos interactivos favorecieron que las alumnas colaboraran entre sí para lograr resolver las tareas propuestas, potenciando el aprendizaje y el apoyo entre ellas.

Imagen 3.Colaboración entre las alumnas en la sesión de grupos interactivos

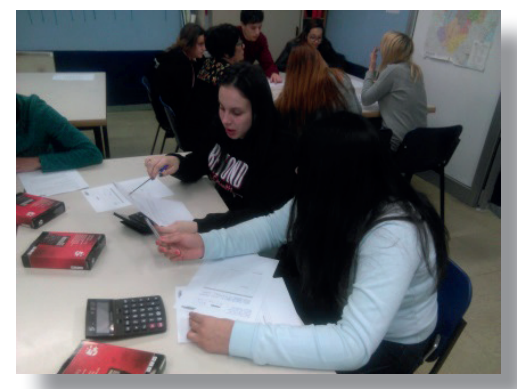

Disminuyó la demanda de las alumnas a los adultos a la hora de resolver las tareas, así como el intervencionismo por parte de las educadoras. Asimismo, se observó que se reforzó el sentimiento de grupo, la cohesión entre las alumnas.

Figura 1 Grupos interactivos

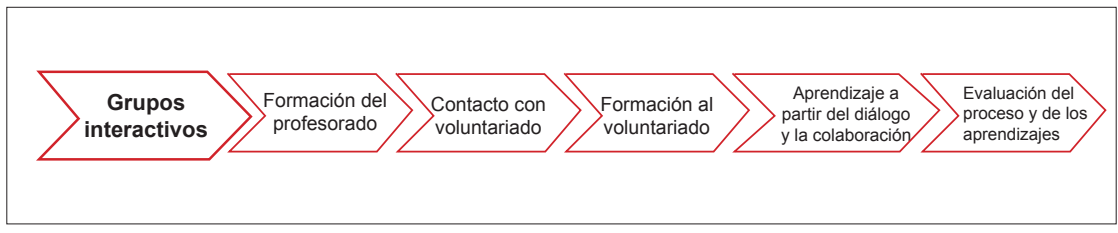

Los voluntarios realizaron valoraciones al finalizar cada una de las sesiones. En estas evaluaciones destacan valores, actitudes y habilidades en las alumnas tales como: 
complicidad, ayuda, fluidez, buen comportamiento, mayor expresividad, mejoría en la resolución de problemas, respeto, compañerismo, escucha e interacción.

Imagen 4.Valoración de las sesiones por parte de dos voluntarias

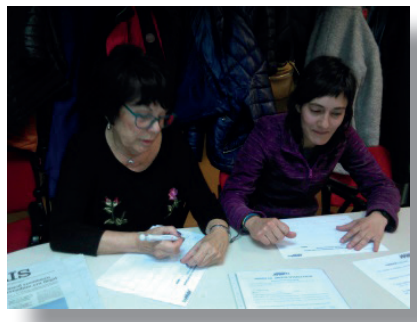

Las propias alumnas valoraron positivamente los grupos interactivos, les gustó que hubiera personas adultas ajenas al centro, como un cambio en la dinámica diaria. Esta misma percepción es confirmada por las educadoras que ven cómo la presencia de personas externas hace situarse a las alumnas de otra manera.

Como dificultades, se podría decir que, al ser grupos de clase poco numerosos, se depende de la asistencia de las alumnas. Por otro lado, sería conveniente una mayor formación de las educadoras en grupos interactivos y aprendizaje dialógico.

\section{APRENDIZAJE BASADO EN PROBLEMAS (ABP) EN LOS CENTROS SOCIOLABORALES}

El aprendizaje basado en problemas (ABP) es también una metodología didáctica centrada en el alumnado, que conlleva una determinada manera de elaborar y organizar los procesos de enseñanza-aprendizaje.

El proceso de enseñanza-aprendizaje se inicia con un problema que permite activar los conocimientos del alumnado para resolverlo en un contexto determinado. Para ello, los estudiantes, guiados por educadores, observan, investigan, analizan, reflexionan y evalúan (Egido et al., 2006).

Dado su carácter experimental, varios educadores de los CSL se han iniciado en la práctica de esta metodología.

En el CSL Actur ,el grupo-clase se organizó en equipos para analizar y diseñar 
"Desayunos Saludables".

Imagen 5.Desayunos saludables.

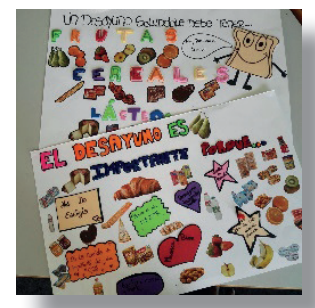

En el CSL Oliver se trabajó "El periódico", para el desarrollo de competencias lingüísticas de expresión y redacción.

En el CSL Valdefierro, el ABP adquirió protagonismo en la materia de la especialidad profesional, donde se organizó al alumnado en dos grupos de cinco jóvenes cada uno. El problema que se planteó consistió en conocer y distinguir los símbolos de soldadura para la lectura de planos, mediante la búsqueda de diferencias entre las normas UNE y AWS.

Para ello se otorgó una serie de responsabilidades a cada uno de los miembros del grupo: director, portavoz, periodista y redactor.

Una vez repartidos los roles de trabajo, se realizó la investigación, recogida y análisis de la información.

Figura 2 Metodología ABP.

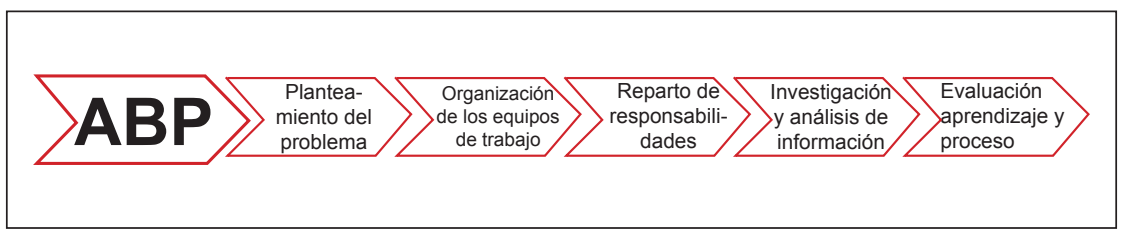

Finalmente, cabe destacar la valoración por parte de este último centro, según la cual, se han favorecido en el alumnado las habilidades y actitudes de compromiso, autonomía y capacidad de organización. Asimismo, se ha facilitado el aprendizaje 
de los símbolos de soldadura como competencia técnica.

Se ha considerado también, que se debe mejorar el reparto de funciones considerando las características del alumnado, los criterios de evaluación y la presentación de la información antes de comenzar el trabajo.

\section{Notas}

La redacción de este capítulo ha sido posible gracias a la implicación y colaboración de los docentes Pilar Acosta Fillat, $\mathrm{M}^{\mathrm{a}}$ Teresa Flores García, Santiago Dolz y la alumna de la Facultad de Educación Sara Marco, además de todos los educadores y educadoras de los CSLs que han facilitado el desarrollo de metodologías activas.

\section{REFERENCIAS BIBLIOGRÁFICAS}

Álvarez, C., y Puigdellívol, I. (2014). Cuando la comunidad entra en la escuela: un estudio de casos sobre los grupos interactivos, valorados por sus protagonistas. Profesorado. Revista de Curriculum y Formación de Profesorado, 18(3), 239-253.

Aubert, A., García, C., y Racionero, S. (2009). El aprendizaje dialógico. Cultura y educación, 21(2), 129-139.

Frith, C.D. (2012). El papel de la metacognición en las interacciones sociales humanas. Fil. Trans. R. Soc. B, 367(1599), 2213-2223.

Egido, I., Aranda, R., Cerrillo, R., Herrán, A., de Miguel, S., Gómez, M., Hernández, R. Izuzquiza, D., Murillo, F.J. y Serrano, M. (2006). Aprendizaje basado en problemas $(\mathrm{ABP})$. Estrategia metodológica y organizativa del currículum para la calidad de la enseñanza en los estudios de Magisterio. Revista interuniversitaria de formación del profesorado(57), 137-150.

Gómez, C.E., Hernández, M.W., y Ramos, R.E. (2017). Principios epistemológicos para el proceso de la enseñanza-aprendizaje, según el pensamiento complejo de Edgar Morin. Pueblo Continente, 27(2), 471-479.

Morin, E. (2015). Por una reforma del pensamiento. Correo UNESCO.

Vygostki, L.S. (1996). El desarrollo de los procesos psicológicos superiores. Barcelona: Crítica.

Wells, G. (2001). Indagación dialógica. Barcelona: Paidós 


\section{ANÁLISIS DE LAS PERCEPCIONES DEL ALUMNADO EN LA RED MUNICIPAL DE CENTROS SOCIOLABORALES. EVOLUCIÓN EDUCATIVA Y PERSONAL.}

Almansa Laheras, B., Fernández Lafaja, B., Martín Asenjo, A., Pros del O, S., Sierra Justes, M., Torres Burillo, A.

DIRECCIÓN: ANA CRISTINA TESÁN TESÁN

Dpto de Psicología y Sociología

Facultad de Ciencias Sociales y del Trabajo. Universidad de Zaragoza.

\section{INTRODUCCIÓN}

Esta investigación tiene como objetivo identificar aquellos aspectos con los que el alumnado siente que se ha beneficiado con su paso por el Centro Sociolaboral. Se trata de analizar, no solamente los conocimientos adquiridos y su utilidad para el futuro profesional, sino también la incidencia que este programa municipal ha tenido en su evolución personal.

Para ello, es necesario indagar acerca de la historia de los centros, la definición de este mismo término, la red de Centros en la ciudad de Zaragoza, así como conocer brevemente las fundaciones que colaboran con cada Centro. Además, conocer las diferentes áreas de intervención, los destinatarios a los que van dirigidos los Centros Sociolaborales y también las características comunes de cada uno de ellos, sin olvidarnos de conocer la legislación en la que se encuentran enmarcados. De esta manera, trabajaremos con una muestra, investigando la percepción del alumnado de los Centros Sociolaborales.

Nuestro prácticum de investigación se enmarca en un proyecto que trata de conocer la percepción del alumnado sobre su evolución, tanto educativa como personal, en la Red Municipal de Centros Sociolaborales . Es importante porque la inserción sociolaboral de jóvenes forma parte del campo de actuación del Trabajo Social, y además nos ayuda a ganar práctica a la hora de enfrentarnos a la realidad como profesionales. Bajo el título "Análisis de las percepciones del alumnado en la Red Municipal de Centros Sociolaborales: Evolución educativa y personal" comenzó un proyecto 
de investigación aplicada en el ámbito socioeducativo, impulsado por profesorado de la Universidad de Zaragoza y el Ayuntamiento de la ciudad de Zaragoza, con el objetivo de implementar mejoras en la inclusión social, educativa y laboral de los jóvenes que participan en estos Centros Municipales.

\section{METODOLOGÍA}

Como trabajamos con variables independientes asociadas a los sujetos, el diseño elegido para realizar nuestra investigación, es el diseño ex post facto. Es decir, los alumnos son seleccionados tras haber trascurrido la variable independiente. La característica principal en ese tipo de diseño, es que investigador no puede manipular de manera intencionada la variable. Los sujetos se han sido seleccionados por pertenecer al sistema educativo de los Centros Sociolaborales, por lo cual, la variable independiente es ajena al organismo.

Consideramos esta investigación como un estudio retrospectivo, ya que el proceso causal ya ha ocurrido, es decir, son alumnos que han comenzado el curso. La respuesta de nuestras encuestas viene dada por las variables independientes. Los objetivos son estimar la percepción de los alumnos en relación a los cambios tras el periodo transcurrido en los centros. Por consiguiente, se va a desarrollar los métodos utilizados para la investigación de la percepción del alumnado en los Centros Sociolaborales en los aspectos personales y educativos, partiendo de la hipótesis de eficacia, en ambas dimensiones, de estos centros, concebidos como favorecedores del desarrollo personal y social, y compensadores de orientación profesional en los colectivos más desfavorecidos. Contribución social hacia el logro de una mayor justicia tanto en el sistema educativo como en el sistema productivo. En este estudio se configuran de nuestro interés los aspectos relacionales de los alumnos/as, su estilo de vida saludable (hábitos, cuidado personal, ocio y tiempo libre,...), su conocimiento de la actualidad y participación ciudadana, su desarrollo vital académico y sus expectativas de futuro.

\section{MUESTRA}

La muestra seleccionada bajo el criterio de muestreo de juicio probabilístico, aparece configurada por el alumnado perteneciente a seis de los doce Centros Sociolaborales 
dependientes del municipio, Casco Viejo, Picarral, Oliver, Valdefierro, Las Fuentes y La Jota.

Del total de alumnos (41) del Centro Sociolaboral Casco Viejo participaron 25; de Valdefierro 20 encuestados de un total de 27 alumnos; en el Centro Sociolaboral Picarral la participación fue de 50 adolescentes de un total de 71 alumnos; de Las Fuentes, con 21 alumnos matriculados, se obtuvieron 17 participantes; Oliver contribuyó con 13 de las 22 matrículas, quedando sin representación los alumnos pertenecientes al "Programa de Cualificación Profesional Inicial: Operario de viveros, jardines y centros de jardinería" que cuenta con 8 matrículas por encontrarse en otra actividad fuera de la ciudad; por último, en el Centro Sociolaboral La Jota, se obtuvieron 22 encuestas de los 23 alumnos matriculados.

\section{INSTRUMENTOS}

La encuesta elaborada está fundamentada en diferentes bases teóricas que nos explican la intencionalidad de los diferentes datos recabados. La encuesta íntegra figura en el Anexo y atiende a las dimensiones familia, amigos, higiene, descanso, ocio, drogas no legales y legales, oportunidades laborales y educación.

La técnica de investigación elegida fue la encuestación para medir la percepción personal y educativa de los alumnos de los Centros Sociolaborales. Para ello, elaboramos una división de los dos ámbitos para el trato organizado de los temas a abordar. Dichos ámbitos, se dividen a su vez en apartados que tratan las diferentes características y perspectivas de los alumnos hacia temas específicos y de interés general. El total de preguntas formuladas es de cuarenta y una, y la división de las mismas es de treinta y tres preguntas en el ámbito personal y ocho en el ámbito educativo.

En el ámbito personal, la división se realiza en cinco apartados en los que hay; tres preguntas en datos personales, ocho preguntas en el apartado de relaciones personales, trece en hábitos saludables, que se organizan en distintos subapartados que constan de dos preguntas sobre alimentación, cuatro preguntas de cuidado personal, tres de descanso y cinco preguntas sobre ocio y tiempo libre.

En el siguiente apartado hay dos preguntas sobre perspectiva de futuro, y dentro del mismo cinco preguntas sobre actualidad. A continuación sobre el ámbito educativo 
hay ocho preguntas y dentro del mismo existen dos preguntas de opinión sobre los Centros Sociolaborales.

Dentro de la encuesta además de las preguntas cerradas, introdujimos ocho preguntas abiertas como método de orientación para el análisis de los datos resultantes.

\section{PROCEDIMIENTO}

La primera toma de contacto reseñable con la red de Centros Sociolaborales, fue la entrevista con el coordinador de la red de Centros Sociolaborales de Zaragoza que se realizó el día 23 de marzo a las 11:00 horas, en el Instituto Municipal de Empleo y Fomento Empresarial (IMEFEZ).

En dicha entrevista se trataron temas generales sobre la organización y distribución de recursos de los centros, con el fin de proporcionar un servicio que pretende conseguir que los jóvenes que no han alcanzado la formación profesional en la escuela por medio de la formación obligatoria, puedan llegar a obtener de otro modo la formación que les prepare para un futuro empleo. A partir de la obtención de dicha información, pudimos elaborar un marco teórico que engloba los datos proporcionados por el Ayuntamiento de Zaragoza junto con el diseño de la investigación.

El contacto con los Centros Sociolaborales, se mantuvo a través de visitas realizadas, correo electrónico y llamadas telefónicas. Los Centros Sociolaborales Casco Viejo y Picarral, y el resto de centros pertenecientes a la Fundación Adunare. A todos ellos nuestro agradecimiento.

En los centros Casco Viejo y Picarral, se mantuvo contacto previo con los encuestadores, de tal forma que el día de pase de la encuesta ya se les conocía y habían establecido cierto nivel de confianza. Estos contactos previos no fueron posibles en el resto de centros por cuestiones ajenas. No obstante, se estimó que este hecho no provocaría un sesgo significativo en los resultados.

En todos los centros se realizó la encuesta en horario académico con permiso del profesorado al cargo en ese momento. Nuestro agradecimiento a los profesionales. 


\section{ESTADÍSTICOS}

El análisis estadístico se realizó con el SPSS 1 . Se obtuvieron resultados por ámbitos, por ítems y por centros, realizando análisis pormenorizados y globales.

Los resultados globales se especifican a continuación.

\section{RESULTADOS}

De los datos recopilados de un total de 146 jóvenes, alumnos de los seis centros analizados, mostramos en este capítulo el análisis global de los mismos y pormenorizado a nivel de items. Queda a disposición el análisis de cada uno de los centros en la bibilioteca de la Facultad de Ciencias Sociales y del Trabajo de la Universidad de Zaragoza.

Ámbito personal.

En primer lugar, cabe destacar que la encuesta está dividida en dos ámbitos, personal y educativo. Comenzamos hablando del ámbito personal, el cual está dividido en diferentes apartados.

Haciendo alusión al primer apartado sobre datos personales, cabe destacar que el sexo más frecuente en los centros encuestados es el masculino, con 63,7\% , mientras que el 36'3\% representa el sexo femenino. En cuanto a sus edades, varían entre los 15 y los 26 años, destacando los 17 y 18 años como las edades más frecuentadas con un $22,6 \%$ y $19,2 \%$ respectivamente y los 24 y 26 años como las menos frecuentes con solo un $0,7 \%$ cada una en cuanto al total de la muestra.

Si nos referimos a la modalidad de estudio más usual entre los alumnos encuestados se destaca la Formación Ocupacional que corresponde al 31,5\% de las personas encuestadas, el programa cualificación inicial con un 31,5\%, el Aula taller al que acuden el $27,7 \%$ de los encuestados, y finalmente el programa de formación SERPI con un $9,6 \%$.

Si nos centramos en el apartado relaciones personales, en relación con la pregunta “¿con quién vives?” las respuestas nos hacen llegar a dos conclusiones. En primer lugar, observamos que el alumnado en la mayoría de los casos convive con sus dos

1 El SPSS (Statistical Package for the Social Sciences) es un conjunto de programas orientados a la realización de análisis estadísticos aplicados a las ciencias sociales. 
progenitores. Vivir solamente con la madre, ocupa la segunda posición de los datos obtenidos. Por último, los datos con menor número de frecuencia se refieren a la convivencia con el padre o con ninguno de ellos.

Además cabe destacar, que el 74\% de los alumnos de los diferentes centros tienen buena relación con las personas con las que conviven, mientras el $48^{\prime} 6$ admite que su relación familiar ha mejorado desde que entró en el centro. El 97'9\% tiene la sensación de que su familia está contenta/conforme con su entrada en el Centro Sociolaboral.

Este dato es destacable ya que consideramos muy importante en estos casos que los jóvenes sientan el apoyo familiar, porque como nos explica Echarri (2017), si algo caracteriza a estos jóvenes son diversos factores de riesgo de exclusión social. Como, por ejemplo, situaciones de desestructuración familiar o de conflicto donde la convivencia del núcleo familiar, predomina el tener un alto grado conflictividad. La mayoría de los alumnos y alumnas reconocen tener un nivel alto de buena relación con sus padres, y además sentirse apoyados en su entrada al Centro Sociolaboral. Este resultado es un buen signo de relación convivencial, que nos permite eliminar uno de los factores de riesgo que sufre este colectivo. Si los resultados nos hubieran mostrado lo contrario, estaríamos ante una problemática en la que los factores se incrementarían o quedarían estancados. Siguiendo con Echarri, se trata de favorecer en estos jóvenes recursos por un lado personales, pero también sociales.

Con respecto a la pregunta "¿Trabajan tus padres?” lo más llamativo es que varios estudiantes alegaron que ninguno de sus padres estaba empleado en la actualidad debido a la situación del país. En las ocasiones en las que solo uno de los progenitores trabaja, es la madre la que aparece con más frecuencia en las encuesta.

El 95,2\% admiten que han hecho nuevos amigos, la mayoría de ellos destacan que acuden a ellos haciendo nuevos planes, $30,1 \%$, o cuando se aburren, $21,2 \%$.

Los alumnos y alumnas de los centros han determinado por lo tanto haber hecho nuevos amigos en el centro. Este colectivo suele buscar refugio en sus iguales, es decir, buscando amigos que compartan un perfil similar al propio, por lo que, se considera que es normal la formación de grupos ya que la mayoría de los alumnos comparten características muy similares influenciando en el proceso de desarrollo y aprendizaje (Echarri, 2017). Esto influencia en el proceso de ellos ya que desde 
un punto educativo, agrupar al alumnado, con grupos más homogéneos permiten personalizar mejor el procedimiento educativo e intervenir de una manera más conveniente en sus necesidades y expectativas.

Continuado con el análisis, hacemos referencia a los hábitos saludables, con la entrada en el Centro Sociolaboral no se han visto cambios importantes en cuanto a su alimentación, representando alrededor de un $74 \%$, todos ellos coinciden en que la higiene es importante para la salud. El 96,6\% de las personas encuestadas, coinciden al decir que el descanso es importante para la salud y el día a día, aunque cabe destacar que el 49,3\%, lo que representa a la mitad de la población encuestada, admiten dormir menos de siete horas.

En el apartado de hábitos saludables encontramos unas preguntas dedicadas al consumo de sustancias. El 76,5\% de las personas piensan que las sustancias influyen de forma negativa en sus vidas y su salud. El 54,1\% de los alumnos encuestados admite consumir alguna sustancia. Esta cifra aumenta al 85,4\% de las personas encuestadas cuando la pregunta cambia y se pregunta si sus compañeros consumen o no alguna sustancia, lo que representa treinta décimas más.

Podemos apreciar que el alumnado se muestra reticente a contestar sobre sus hábitos y sienten un gran sentimiento de lealtad hacia el grupo, por ponerse en la situación de poder delatar a sus compañeros. Sin embargo, en los datos podemos observar que aunque tengan dicha fidelidad hacia sus compañeros, a partir de frases como "yo no consumo, cada uno que haga lo que quiera" o "yo no soy un chivato". Es interesante resaltar que prefieren contestar antes sobre el consumo de los compañeros que sobre el propio. Las sustancias más consumidas entre los jóvenes son el tabaco y el cannabis.

Los jóvenes encuestados definen el momento de consumo más frecuente, cuando sienten una necesidad social y física. Además resaltan que no es un consumo dependiente sino que lo hace de forma esporádica. Así mismo, el momento de salir de fiesta es otro de los más marcados por los alumnos.

Haciendo alusión a la opinión de los encuestados sobre las sustancias, en la mayoría de los casos consideran que son malignas y perjudiciales para la salud. En otros casos, se muestran conscientes acerca del consumo, dando a entender que cada uno es responsable de sus actos y pueden controlar un consumo que no les produzca 
una dependencia. Alguno de ellos, muestra un gran rechazo hacia dichas sustancias alegando que no deberían existir.

Dentro de la pregunta, se cuestiona si han cambiado los hábitos de consumo en el último año y en general el consumo de los alumnos no se ha alterado.

Con el término «riesgo» se hace referencia al incremento de la probabilidad de un resultado o consecuencia negativa dentro de una población de individuos, como podría ser el riesgo de consumo de sustancias en situaciones de abandono emocional por parte de los progenitores, docentes, etc.

En el contexto escolar, es común en muchos de estos jóvenes una historia de importante conflicto, caracterizado por el abandono del sistema escolar antes de alcanzar la titulación oficial correspondiente. En estas circunstancias, los adolescentes suelen buscar refugio en sus iguales, tratando de conocer a amigos con su mismo perfil. De este modo, el grupo modela y refuerza socialmente sus conductas de riesgo, como sería el consumo de sustancias que refuerzan nuevamente su situación de conflicto social.

Para abordar el tema relacionado con las conductas de riesgo en el consumo de sustancias, no podemos ceñirnos sólo al ámbito escolar, sino que tendremos que abordar diferentes contextos de ocio, trabajo, familiar, social, para que vean estrategias de prevención en relación con las sustancias de forma integral.

A continuación, abordamos la perspectiva de futuro de los alumnos del centro, el $87,7 \%$ de las personas encuestadas han valorado que su paso por el Centro Sociolaboral sí les ofrecerá más posibilidades en el mercado laboral y casi el 50\% de ellos han cambiado su pensamiento sobre aquello que quieren hacer en el futuro. Cabe destacar, que solo el 30\% de las personas encuestadas han notado un cambio en cuanto a su pensamiento en temas relacionados con la violencia de género, el reciclaje o problemas relacionados con la política actual.

En el apartado de cultura los alumnos encuestados querían tratar temas en relación a otras culturas, religiones y tradiciones. También hacen alusión a tratar temas más cercanos a su edad, sobre feminismo y sobre orientación laboral. Además, demandan que se impartan diferentes idiomas como inglés y francés. Cabe enfatizar que gran parte del alumnado no contestó a esta pregunta por el desconocimiento del término "cultura". 


\section{Ámbito educativo.}

Finalmente, comenzamos ahora con el ámbito educativo. En este aspecto cabe destacar que el 81,5\% de los encuestados reconoce acudir actualmente más a clase que cuando estaba en el instituto. También es interesante resaltar en este apartado que con su entrada en el centro, su perspectiva ha variado ya que antes el 50,7\% quería trabajar y en la actualidad ha aumentado hasta un $60,3 \%$.

El primer requisito para la intervención educativa es acudir al programa, ya que siguiendo con él, sin la asistencia del alumnado no se puede realizar la intervención. Es importante ser conscientes de que estos jóvenes no tienen un control determinado en sus horarios y como hemos podido ver también en los datos obtenidos y destacados anteriormente, la mayoría duerme menos de siete horas, lo que puede conllevar ciertos problemas de concentración.

Para obtener la asistencia en el grupo de adolescentes, Echerri (2017) aconseja dedicarle tiempo, esfuerzo y recursos, además de dinamizar actividades y profundizar en la conexión afectiva, no solo en el grupo sino también de los educadores, haciendo que ellos tengan motivos por los que ir a clase, que interioricen lo que viven en el programa educativo.

Concluimos destacando que el alumnado de estos centros, no sólo se siente más valorado en la actualidad que durante el periodo de Educación Secundaria Obligatoria con un significativo $81,5 \%$, también consideran que la relación con sus profesores ha mejorado (78,8\%), valorando su experiencia en el Centro Sociolaboral como un aspecto positivo para su vida en ambos ámbitos, personal y educativo, además de percibir que su paso por dicho centro le facilitará y orientará hacia su futuro profesional $(87,7 \%)$.

\section{REFERENCIAS BIBLIOGRÁFICAS.}

Echarri, F. (2017). Metodología educativa para adolescentes en exclusión social. Pamplona: EUNSA. 


\section{ANEXO 1}

\section{ENCUESTA: \\ Percepción del alumnado de la Red Municipal de Centros Sociolaborales.}

Somos estudiantes del grado de Trabajo social de la Universidad de Zaragoza, estamos realizando una investigación para conocer la percepción del alumnado en la red de centros sociolaborales en la ciudad de Zaragoza. Tu sinceridad es necesaria para que tu opinión se tenga en cuenta. Esta encuesta es anónima y confidencial, está regulada por la Ley Orgánica 15/1999, del 13 de diciembre, de protección de datos de carácter personal.

Gracias por tu colaboración.

Completa la encuesta rodeando la respuesta que consideres correcta o completa donde haya un espacio. *

DATOS PERSONALES

EDAD:

SEXO:

MODALIDAD DE ESTUDIO:

Aula Taller

Formación ocupacional

Programa de cualificación profesional inicial

SERPI 


\section{RELACIONES PERSONALES}

1.- ¿Con quién vives? Indica el número de personas:

2.- ¿Desde cuándo vives con ellos?

3.- ¿Tienes buena relación con todas las personas de tu familia?

Sí.

No.

¿Con quién pasas más tiempo?

4.- ¿Colaboras en las actividades del hogar desde que estudias en el Centro Sociolaboral?

Sí.

No.

En caso afirmativo indica qué actividades realizas

5.- ¿'Tu familia está de acuerdo con que vengas al Centro Sociolaboral?

Sí.

No. 
6.- ¿Trabajan tus padres? ¿Dónde?

Sí

No.

En caso afirmativo indica quién y desde cuándo.

7.- ¿Ha mejorado tu relación con tus padres desde que estás en el Centro Sociolaboral?

Sí.

No.

En caso afirmativo, indica en qué

8.- ¿Has hecho nuevos amigos en el Centro Sociolaboral?

Sí.

No.

9.- ¿Cuándo cuentas con tu amigos del Centro Sociolaboral? (Puedes marcar varias opciones)

Cuando me aburro.

Cuando tengo un problema en casa.

Para salir de fiesta.

Para hacer trabajos de clase.

A diario haciendo planes fuera del propio centro. 


\section{HÁBITOS SALUDABLES}

\section{ALIMENTACIÓN}

10.- ¿Has cambiado tu alimentación desde que entraste en el Centro Sociolaboral?

Sí.

No.

Indica un alimento que hayas incluido en tu dieta

11.- ¿Has empezado a hacer algún deporte nuevo durante el curso?

Sí.

No.

En caso afirmativo ¿Cuál?

\section{CUIDADO PERSONAL}

12. ¿¿Crees que los hábitos de higiene son importantes para la salud?

Sí.

No

¿Por qué?

13.- ¿Crees que tus compañeros piensan que estos hábitos son buenos para la salud? (Lavarse los dientes, lavarse las manos, ducharse a diario,etc) 
Sí.

No.

14.- ¿Piensas que tus compañeros comparten tu opinión?

Sí.

No.

15.- ¿Has cambiado alguno de tus hábitos desde que estás en el Centro Sociolaboral?

Sí.

No.

En caso afirmativo, indica cuál o cuales

\section{DESCANSO}

16.- ¿Crees que descansar es importante para la salud?

Sí.

No.

17.- ¿Cuántas horas duermes al día?

Menos de 7 horas.

Entre 7 y 8 horas.

Más de 8 horas.

18.- ¿'Te cuesta concentrarte en las actividades que realizas en el Centro Sociolaboral?

Sí.

No.

\section{OCIO Y TIEMPO LIBRE}

19.- ¿Dedicas ahora más tiempo al ocio? 
Sí.

No.

En caso afirmativo indica cuánto

20.- ¿Consumen alguna sustancia alguno de tus compañeros? (Alcohol, tabaco, marihuana, etc...)

Si.

No.

En caso afirmativo indica cuál

21.- ¿Consumes alguna sustancia?

Si.

No.

En caso afirmativo indica cuál

Y cuando lo sueles hacer (puedes marcar varias opciones):

Cuando lo hacen mis amigos/as.

Con mis compañeros del Centro Sociolaboral.

Cuando me siento triste o decaído.

Cuando me apetece.

Cuando lo necesito.

Cuando salgo de fiesta. 
22.- ¿Qué piensas acerca de la drogas? ¿Han cambiado tus hábitos en este último tiempo?

23.- ¿Crees que el consumo de estas sustancias influye de forma negativa en la salud?

Si.

$\square$ No.

En caso afirmativo indica cómo afecta

\section{PERSPECTIVAS DE FUTURO}

24.- ¿Crees que estar en el Centro Sociolaboral te va a dar más oportunidades de trabajo?

Sí.

No.

En caso afirmativo indica el por qué

25.- ¿Ha cambiado tu pensamiento acerca del trabajo que quieres realizar en un futuro?

Sí.

$\square$ No.

En caso afirmativo indica en qué 
26.- ¿Crees que es importante reciclar? ¿Lo haces?

Sí. ¿Por qué?

No.

\section{PREGUNTAS SOBRE ACTUALIDAD}

27.- ¿Habéis trabajado en clase sobre los problemas que existen actualmente en el país?

Sí.

No.

28.- ¿Ha cambiado tu pensamiento sobre el reciclaje durante este curso?

Sí.

No.

En caso afirmativo indica en qué

29.- ¿Qué sabes sobre la manifestación que hubo el pasado 8 de marzo?

30.- ¿Crees que existe un problema con la igualdad de género?

Sí.

No.

En caso afirmativo ¿desde cuándo lo crees?

31.- ¿Has notado que ha habido algún cambio en tu pensamiento sobre los temas tratados en esta encuesta durante el último año?

Sí.

No. 
En caso afirmativo indica en qué

32.- ¿Qué temas sobre cultura te gustaría que trabajasen en el Centro Sociolaboral?

\section{ÁMBITO EDUCATIVO}

33.- ¿Vas más a clase desde que estás en el Centro Sociolaboral?

Sí.

No.

En caso negativo especifica por qué:

$\square$ No tengo interés.

$\square$ Tengo obligaciones en casa.

Trabajo.

34.- Antes de entrar en el Centro Sociolaboral ¿qué perspectiva de futuro tenías?

Estudiar.

Trabajar.

Otro.

Especifica qué te planteabas:

35.- Después de entrar en el Centro Sociolaboral ¿qué perspectiva de futuro tienes?

Estudiar.

Trabajar.

Otro.

Especifica qué te planteas: 
36.- ¿Dedicas ahora más tiempo a tus estudios?

Sí.

No.

37.- ¿'Te sientes más valorado en el Centro Sociolaboral que en el instituto?

Sí.

No.

38.- ¿Tienes mejor relación con tus profesores que la que tenías en el

Instituto?

Sí.

No.

39.- ¿Has hecho más amigos en el Centro Sociolaboral que en el instituto ?

Sí.

No.

40.- Sabiendo que tu opinión se va a tener en cuenta para mejorar el centro ¿qué crees que sería necesario cambiar o mejorar?

41.- Para finalizar, realiza alguna propuesta para la mejora del centro. 



\title{
PROGRAMA DE MENTORÍA SOCIAL -PROYECTO PILOTO- EN LA RED DE CENTROS SOCIOLABORALES DEL AYUNTAMIENTO DE ZARAGOZA
}

\author{
José A. Guallar Claver', Samuel Borque Martínez, Laura González Ibánezz', Ana \\ Hervás Sáenz $z^{2}$, Adrián Santamaría Sauqué2, Andrea Sebastián Fortea ${ }^{2}$ \\ ${ }^{1}$ Departamento de Psicología y Sociología, Facultad de Ciencias Sociales y del Trabajo, \\ Universidad de Zaragoza. \\ ${ }^{2}$ Grado Trabajo Social, Facultad de Ciencias Sociales y del Trabajo, Universidad de \\ Zaragoza.
}

\section{INTRODUCCIÓN}

Desde la Universidad de Zaragoza y dentro del marco de colaboración con el Ayuntamiento de Zaragoza y la Red Municipal de Centros Laborales, en el proyecto de "Innovación y éxito educativo en los Centros Sociolaborales" -Innova CSL-, nos hemos propuesto el reto de comenzar a investigar las posibilidades de implementar un programa de mentoría social con jóvenes en riesgo de exclusión social, con el objetivo principal de seguir mejorando en la inclusión social, educativa y laboral de los alumnos que se forman en dichos centros municipales.

Esta aproximación ha sido posible por la estrecha colaboración entre el área de Psicológica Básica de la Facultad de Ciencias Sociales y del Trabajo, los alumnos de tercer curso del Grado en Trabajo Social en la asignatura prácticum de investigación, y el Instituto Municipal de Empleo y Fomento Empresarial (Zaragoza Dinámica) -IMEFEZ-, junto a las Entidades Sociales que gestionan los centros Sociolaborales. Partiendo de esta realidad, hemos realizado, un estudio transversal, exploratorio, y explicativo, para analizar en su contexto, cómo la mentoría social supondría una mejora en la realidad del alumnado de los centros sociolaborales. Y en caso de poder ponerse en marcha en un futuro inmediato, cómo sería un programa adaptado a la Red Municipal de Centros Sociolaborales.

Con un enfoque estratégico multimétodo, tomando datos cuantitativos y cualitativos para su posterior análisis, se han utilizado fuentes primarias y secundarias: entrevistas (al responsable de la unidad de integración, coordinadores de los centros) y cuestionario on line, en relación a las primeras; y consulta de bibliografía especializada y otros estudios, en relación a las segundas. 
La muestra de este estudio ha sido estratégica intencional, pudiendo acceder a 3 centros sociolaborales y han sido finalmente 48 los alumnos que han respondido al cuestionario. Número insuficiente y poco significativo, en relación a la población estudiada, pues eleva el margen de error y disminuye el nivel de confianza de los resultados finales.

\section{MENTORÍA SOCIAL: HISTORIA, PROYECTOS Y TIPOS}

La mentoría social es una herramienta de intervención social que promueve la relación entre personas que voluntariamente se ofrecen para proporcionar un apoyo individual a otra persona que se encuentra en una situación de riesgo de exclusión ${ }^{1}$. Un programa de mentoría social incluye intervenciones que fomentan nuevas relaciones de pares o grupales con el objetivo de incidir en la inclusión social (Prieto \& Feu, 2018).

Es útil como estrategia de orientación; ayuda, reforzando la superación, potencia las habilidades básicas y el desarrollo sociopersonal; y fomenta el desarrollo profesional.

No hemos de confundirla con otros términos relacionados con la ayuda al aprendizaje, como es el caso del tutoring o el coaching. (Macías et al., 2004).

Los antecedentes de la mentoría se sitúan hace más de 5000 años en África, donde se proporcionaban guías a los más jóvenes para mostrarles "el camino" (Carr, 1999). En la Antigua Grecia el mentor era considerado un consejero, instructor y guía encargado del desarrollo físico, intelectual, social y espiritual de la juventud. Homero -s VIII a. C.- narra las aventuras de Ulises, quien pide a su amigo Mentor que vele por su hijo mientras él va a luchar a la Guerra de Troya.

A raíz del surgimiento de agrupaciones comerciales -s. XVI- y por la necesidad de contar con profesionales cualificados, la figura del mentor se identificaba como el maestro en la relación maestro-aprendiz. Y en la década de los sesenta, empiezan a introducirse en la literatura artículos, que promovían la idea de que incorporar la mentoría en el ámbito empresarial podía producir grandes beneficios (Carr, 1999).

1 Coordinadora Mentoria Social. Qué entendemos por mentoría social. [en línea] Disponible: http://mentoriasocial.org/que-entendemos-por-mentoria-social/\#.WrPafejOXIU 
Como proyecto referente inicial de mentoría social con menores en situaciones de riesgo de exclusión social, se destaca: Big Brothers and Big Sisters of America en EEUU; iniciado en 1908 y exportado a más de veinte países de todo el mundo, dónde se adapta y reformula para satisfacer las diferentes necesidades políticas y culturales (Doland y Brady, 2015, p. 19).

Cataluña, es un referente nacional en mentoría social y cuenta con diversos programas a tener en cuenta, como son (Feu et al, 2013): Proyecto Coach ${ }^{2}$, Programa Referents ${ }^{3}$, Proyecto Rossinyol ${ }^{4}$ y Mentoría para fomentar el éxito socioeducativo de jóvenes peruanos residentes en Barcelona.

De forma general se puede dividir la mentoría en informal y formal.

Mentoría informal, entre cercanos al mentorado, como puede ser un familiar o un conocido. Se realiza por parte de la persona de mayor experiencia, el mentor, estableciendo una relación uno a uno, y tiene un carácter más informal debido al vínculo entre ambos. Tampoco tiene un límite establecido, ya que esta relación puede perdurar a lo largo de toda la vida de ambos actores (Carr, 1999).

Mentoría formal. Está creada de manera intencionada por las circunstancias, y a su vez, se puede realizar de distintas formas: Uno a uno; e-mentoring, haciendo uso de internet para crear la relación; grupal, 4 personas más como máximo; $\underline{2+1}$, un técnico de mentoría que apoya, supervisa y evalúa; en equipo, menos de 4 jóvenes por mentor; e intergeneracional, la diferencia de edad entre ambos es menor, y están en el mismo contexto, como puede ser el educativo, siendo el mentor un estudiante de mayor curso, y sirve como un modelo referente o positivo. Este tipo de mentoría cuando se realiza en periodos de transición, se denomina Mentoría de enlace (Carr, 1999).

La última en surgir como alternativa, ha sido la mentoría intergeneracional, con un mentor mayor de 55 años (Karcher, Kuperminc, Portwoode, Sipe, Taylor, 2006).

Las habilidades a tener en cuenta por ser influyentes en la relación entre mentor

2 Proyecto Coach. [en línea]. Disponible en: https://www.fundacionexit.org/historia/.

3 Proyecto Referents. [en línea]. Disponible en:_https://premibizcabar.org/es/project/ proyecto-referents/.

4 Project Rossinyol-Gironal. [en línea]. Disponible en: http://mentoriasocial.org/ programa/projecte-rossinyol/\#.Wx42Lu6FOM8 . 
y mentorado, son: Empatía, confianza, constancia, confidencialidad, e inspiración (Quintero, 2016).

\section{MENTORÍA SOCIAL APLICADA A COLECTIVOS EN RIESGO DE EXCLUSIÓN SOCIAL}

La mentoría trata de enfatizar el apoyo al menor para que se desenvuelva lo mejor posible en las circunstancias que vive (Doland, 2015). No todos los menores cuentan con una red de apoyo suficiente que les ayude a salir adelante, por lo que es conveniente buscar cómo proporcionarles ciertos recursos de los que no disponen. Así, encontramos en la mentoría una herramienta útil para trabajar con colectivos que tienen dificultades añadidas.

Los objetivos generales que se persiguen en los programas de mentoría van en la línea de servir de alternativa real y cercana a las necesidades de las personas implicadas; desarrollar de forma práctica los procesos eficaces de aprendizaje, haciendo énfasis en las potencialidades, para la adquisición de conocimientos, actitudes o habilidades en general que pueden ser transferidas a los distintos ámbitos del desarrollo personal (sociopersonal, profesional y académico); servir de sustento y apoyo en los periodos de transición (de unos estudios a otros, de la adolescencia a la edad adulta, en la incorporación al mundo del trabajo); desarrollar una mayor implicación, compromiso y colaboración entre los miembros de una institución, asociación u organización, y con ella misma (Macias et al., 2004). Además, se aumenta el capital social con la creación de redes sociales, y el acceso a ellas a través del mentor; se mejora en la inclusión social de los participantes, las habilidades sociales y personales; y se produce un descenso en cuanto al inicio del consumo de drogas y alcohol.

Todos estos beneficios se ven aumentados tanto en intensidad y duración, en cuanto existe un mayor vínculo, relación y duración de la relación en el tiempo. Y los resultados son más notables en los programas de mentoría realizados con una duración al menos de un curso escolar.

Pondremos el foco en tres elementos claves para analizar las posibilidades de implantar la mentoría social en colectivos de exclusión social: abandono escolar, extranjería y vulnerabilidad de otras culturas. 
El abandono escolar es especialmente relevante en nuestro país y en Aragón, superando cifras del 19\% y aumentando respecto a la media de la UE -Unión Europea- en más de 8 puntos. Además, se eleva hasta el 42,8\% en el caso de los extranjeros 5 .

Una encuesta realizada, con una muestra de 3.012 jóvenes españoles, pone de manifiesto que un gran porcentaje de los que fracasan y abandonan la escuela proviene de familias de origen humilde. El porcentaje de jóvenes provenientes de familias de clase media, pueden reconducir el problema gracias a los diversos recursos que poseen (económicos, culturales, disponibilidad de acceso a la información, recursos sociales...) y en muchos casos recurren a ofertas formativas privadas que evitarían el abandono escolar prematuro (De Miguel, et al., 2013)

En cuanto a la población extranjera, España cuenta con un 9`5\%, siendo ésta principalmente procedente de Rumanía, Marruecos, Reino Unido, Italia y China. Y Aragón cuenta con una población inmigrante del 9,9\%, procedente principalmente de Rumanía, Marruecos, China y Argelia ${ }^{6}$. Estos datos están recogidos a partir del Padrón de habitantes y habría que añadir a estos, los no empadronados y los que se encuentran en situación irregular, de los que no hay estadísticas disponibles.

A su vez, los alumnos extranjeros ${ }^{7}$ provenientes de países de la Unión Europea UE- matriculados en España representan un 29,4 \%; el 4,7 \% del resto de países de la UE; el 30,5 \% de países africanos; el 25,2\% de países de América y el 10,2 \% de países de Asia y Oceanía. En Aragón la población extranjera supone un 12\%3\% del total y recibe más población procedente de Europa y de África.

En las culturas más vulnerables socialmente, como es la población gitana, el abandono escolar se da principalmente, por las dificultades en el aprendizaje, motivos familiares y motivos económico-laborales, lo que es también aplicable a la población extranjera.

5 INE. En línea: http://www.ine.es/

6 IAEST (2017). Datos básicos de Aragón, 2017. Recuperado a partir de: http://www. aragon.es/estaticos/GobiernoAragon/Organismos/InstitutoAragonesEstadistica/Documentos/ docs/Areas/DatosBasic/2017/DBA_2017.pdf

$7 \quad$ Ministerio de Educación, Cultura y Deporte (2018). Datos y cifras, curso 2017/2018 Recuperado a partir de: https://www.mecd.gob.es/servicios-al-ciudadano-mecd/dms/mecd/ servicios-al-ciudadano-mecd/estadisticas/educacion/indicadores-publicaciones-sintesis/datoscifras/Datosycifras1718esp.pdf 


\section{LA MENTORÍA SOCIAL EN LOS CENTROS SOCIOLABORALES: UN PROGRAMA PILOTO}

El perfil sociodemográfico de alumn@ en el estudio realizado, atendiendo al cuestionario "on line", es: joven entre 17 y 18 años (60,4\%); chico (58,3\%); cursa programa de cualificación profesional inicial $(68,8 \%)$; no trabaja en la actualidad $(85,4 \%)$; y no ha trabajado nunca $(54,2 \%)$; es español/a $(71,9 \%)$, o proveniente de Senegal, Colombia, Perú, Nicaragua, Rumanía o Ecuador.

El motivo principal que les llevan a elegir la educación en el Centro Sociolaboral es la búsqueda de una enseñanza práctica $(34,4 \%)$ y se matriculan en ese centro concreto por las actividades que se llevan a cabo $(40,6 \%)$.

Un sentimiento compartido por la mayoría de encuestados es que "la relación con los compañeros y profesores es mejor de la que te puedes esperar, tanto en tutoría como en Aulas Taller", debido a la confianza que se crea, sintiéndose escuchados, respetados y queridos.

El tiempo libre, lo dedican a quedar con sus amigos (84,4\%), o hacer algún tipo de deporte $(37,5 \%)$ y estarían dispuesto a compartir las aficiones con otra persona $(68,8 \%)$.

En cuanto a sentirse sol@, el 31,3\% nunca lo había padecido, pero hay que destacar que el 18,6\% de estudiantes contestó que siempre o muchas veces se encontraba en esa situación de soledad y les hubiera gustado haber tenido un guía o persona con quién poder hablar (50\%).

Gráfica 1. ¿Conoces algún programa de mentoría (guía o acompañamiento voluntario)?

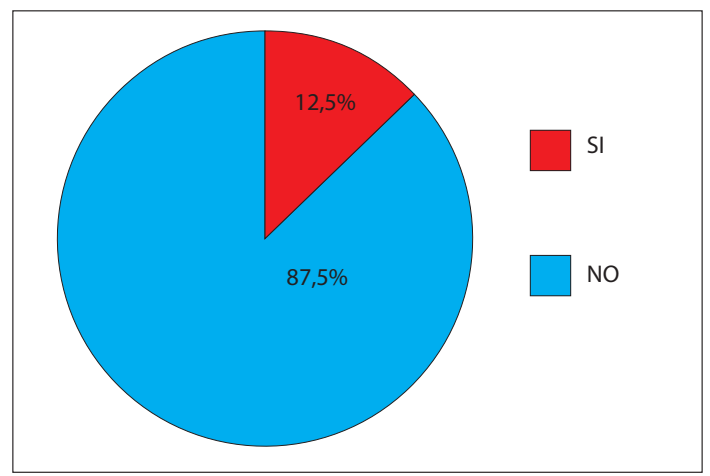


Gráfica 2. ¿Has oído hablar de la mentoría (guía o acompañamiento voluntario?

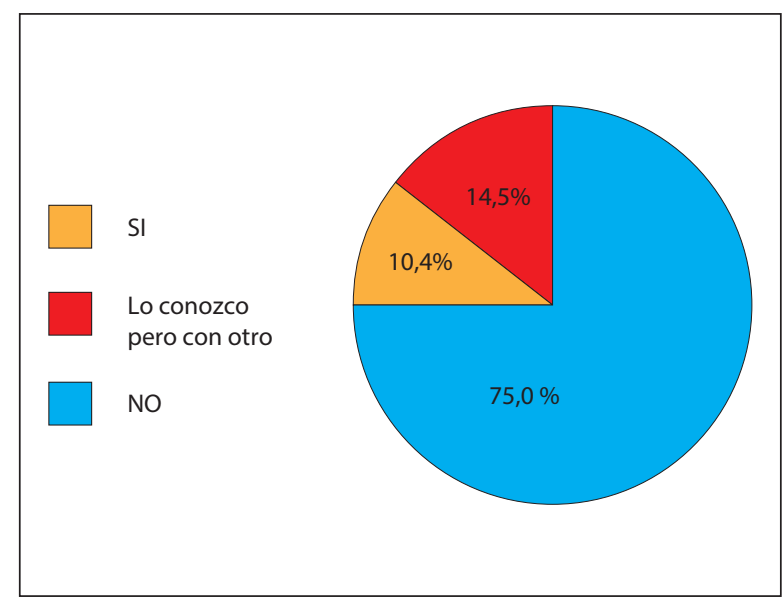

A pesar de que la inmensa mayoría de los alumnos no han oído hablar de la mentoría (75\%), ni conocen ningún programa al respecto (87,5\%), aceptarían de buen grado un programa en su centro $(80,3 \%)$.

Gráfica 3. ¿Cómo preferirías pasar tiempo con el mentor?

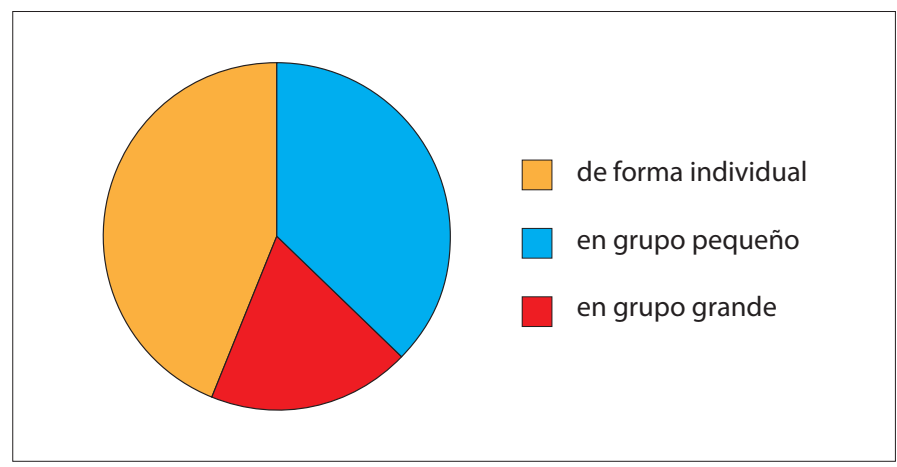

La labor del mentor giraría entorno a tres valores ya mencionados: integridad, amistad y guía; prefiriéndolo de forma individual (43,8\%) y cobraría gran relevancia en este tipo de situaciones en las que una persona necesita con quien compartir sus inquietudes y motivaciones, dejando así de sentirse sol@. 
Gráfica 4.¿Qué valorarías más de un mentor?

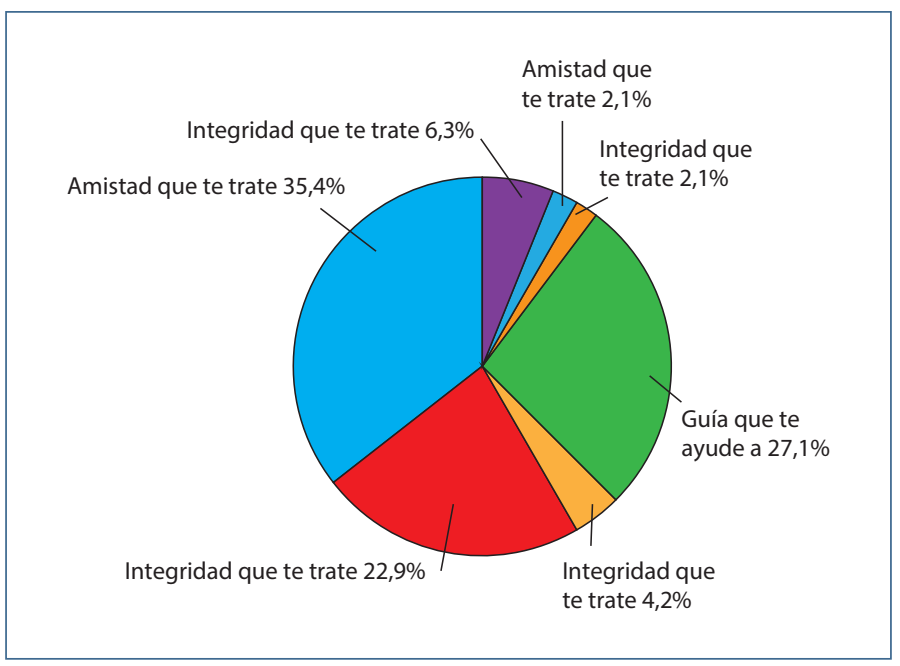

Los coordinadores de los Centros Sociolaborales, atendiendo a las entrevistas realizadas, coinciden en que encuentran en los alumnos carencias afectivas, de autoestima y escolares; vulnerabilidad social, consumo de drogas, fracaso escolar previo, familias desestructuradas y problemas judiciales. Las relaciones son las habituales, con los problemas propios de la edad. La multiculturalidad se ve como algo positivo. El abandono escolar es común a los centros entrevistados. Se generan lazos de confianza y la relación con los profesionales, como han resaltado los alumnos, es muy buena.

En relación a la viabilidad de implantar un programa de mentoría, ya tienen algún conocimiento previo, y conocen sus resultados. Como hándicap ven la falta de recursos y posibles problemas de adaptación en el centro y con los alumnos. Dos tercios, estarían a favor de la implantación.

\section{PROGRAMA PILOTO}

Concluimos que una vez realizada esta investigación y según los pocos datos que hemos obtenido no se puede corroborar la necesidad de la implementación de un programa de mentoría en los Centros Sociolaborales del Ayuntamiento de 
Zaragoza. Aunque si consideramos conveniente la realización de un experimento piloto con su puesta en marcha, debido a los efectos beneficiosos personales para los mentorados y para la sociedad, en base a los positivos resultados obtenidos en otros programas de mentoría (por ejemplo, Programa Rossinyol).

Creemos que esta prueba piloto sería replicando el Proyecto Coach, ya citado, pues supuso un refuerzo emocional y un aumento en el número de jóvenes que decidió seguir formándose, por lo que resultaría idóneo para incorporarlo en los centros de la Red. Tras esta prueba, se podría confirmar o no, que la implementación de la mentoría es positiva y beneficiosa tanto para los alumnos como para los propios centros sociolaborales.

En cuanto al tipo de mentoría que se podría implementar, sería formal, voluntaria, 2 más uno, o intergeneracional. Además, esta mentoría tendría como eje fundamental la amistad, pero sin perder de vista la integridad y el rol de guía. El mentor podría ser de ayuda para fomentar y mejorar las habilidades y aptitudes necesarias de los alumnos, afianzar la autoconfianza y autoestima, necesarias para alcanzar sus metas de una manera satisfactoria.

El perfil del mentor, tendría que ser una persona mayor al mentorado, de su misma etnia, que comparta sus aficiones y las puedan disfrutar en común. Sería beneficioso para el programa ponerse en contacto con asociaciones tales como la Fundación Secretariado Gitano o la Asociación Fulbé de Aragón (población subsahariana), ya que el apoyo de estas asociaciones sería ideal para dicho proyecto y podrían aportar al programa otra visión y una posible colaboración.

Los mentores del proyecto piloto serían inicialmente voluntarios debido a la falta de recursos de los centros, y podrían ser los propios ex alumnos o profesionales de los diferentes oficios impartidos. El comienzo podría ser el curso siguiente y la localización idónea, uno de los centros de la Red.

De forma previa al proyecto, sería interesante realizar una presentación a los alumnos y a fondo, sobre qué es la mentoría y cómo sería su mentor ideal. Esta actividad podría realizarse en una charla o jornadas, mediante folletos, y con la posible creación de una aplicación móvil. 
En último lugar, una vez que se conociese cómo es el mentor que quiere cada estudiante, se debería realizar un proceso de búsqueda y selección del "mentor ideal” para cada alumno, y realizar algún tipo de formación específica sobre el tema en cuestión.

\section{REFERENCIAS BIBLIOGRÁFICAS}

Carr, R. (1999). Alcanzando el futuro: el papel de la mentoría en el nuevo milenio. Programa de Apoyo al Liderazo y la Representación de la Mujer (PROLID). Peer Resources.

De Miguel, C. R., Jiménez, E. G., Rodríguez, S. R., \& Macías, A. V. (2013). Innovación en la orientación universitaria: la mentoría como respuesta. Contextos educativos, 6, 87-112.

Dolan, P., Brady, B. (2015) Mentoría de menores y jóvenes. Guía práctica. Colección Sociocultural. Madrid: Narcea.

Karcher, M. J., Kuperminc, G. P., Portwood, S. G., Sipe, C. L., \& Taylor, A. S. (2006). Mentoring programs: A framework to inform program development, research, and evaluation. Journal of Community Psychology, 34(6), 709-725.

Macías, A. V., de Miguel, C. R., Jiménez, E. G., \& Rodríguez, S. R. (2004). Innovación en la orientación universitaria: la mentoría como respuesta. Contextos Educativos, 6-7, $87-112$.

Prieto-Flores, O. y Feu, J. (2018). ¿Qué impacto pueden tener los programas de mentoría social en la sociedad? Una exploración de las evaluaciones existentes y propuesta de marco analítico. Pedagogía Social, 31, 153-167.

Quintero, H. G. (2016). La mentoría en el proceso de enseñanza-aprendizaje. Editorial Universidad del Rosario. 


\section{COMUNICACIÓN \#INNOVACSL}

Valentín Garcia Gallego

\section{CONOCER Y COMUNICAR}

Cuando comienza un proyecto de las características de \#innovaCSL, con tanta fuerza comunicativa por las acciones que conlleva, piensas en la importancia de contar lo que se hace, pero con interrogantes sobre cómo hacerlo y que canales emplear, cuestiones que deben planificarse con mucho cuidado.

El trabajo de estos proyectos supone un gran esfuerzo por parte de las personas que lo lideran, tanto a nivel general como a nivel de grupos de trabajo. La participación en cada uno de ellos supone una gran dosis de creatividad e impulso para llevar a la práctica los objetivos de \#innovaCSL.

A nivel de comunicación ha sido una experiencia relevante en el sentido de poder contar, aunque fuera en pequeñas dosis, lo que estaba ocurriendo en cada una de las etapas de \#innovaCSL.

\section{OBJETIVOS}

La propuesta comunicativa se llevó a cabo teniendo en cuenta los siguientes objetivos:

a. Dar a conocer el proyecto \#innovaCSL dentro del ámbito educativo local, en especial en la Red Municipal de Centros Sociolaborales de Zaragoza.

b. Crear red de conexiones relacionadas con la línea de trabajo del proyecto \#innovaCSL en el ámbito educativo, de empleo e innovación a nivel autonómico y nacional

La cuestión no era solamente contar y comunicar dentro del proyecto, sino tener la capacidad de "trasladar" las diferentes acciones de los grupos de trabajo hacia otros públicos y colectivos.

Ese fue el desafío y el trabajo que realizamos en el plano de la comunicación, a través de los siguientes canales de difusión: 
a. Contenido propio del proyecto \#innovaCSL en web de la red municipal de Centros Sociolaborales

b. Post en blog de la red municipal de Centros Sociolaborales sobre \#innovaCSL

c. Cuenta twitter@innovaCSL

d. Canal youtube \#innovaCSL

Pensamos tener una base comunicativa estable utilizando la web de la Red municipal de Centros Sociolaborales donde añadimos la pestaña “\#innovaCSL” para poder acceder a los objetivos y grupos de trabajo del proyecto de una forma clara.

Imagen 1. Web de la Red Municipal de Centros Sociolaborales

\section{ORED \\ centros sociolaborales}

ZARAGOZA DINAMICA

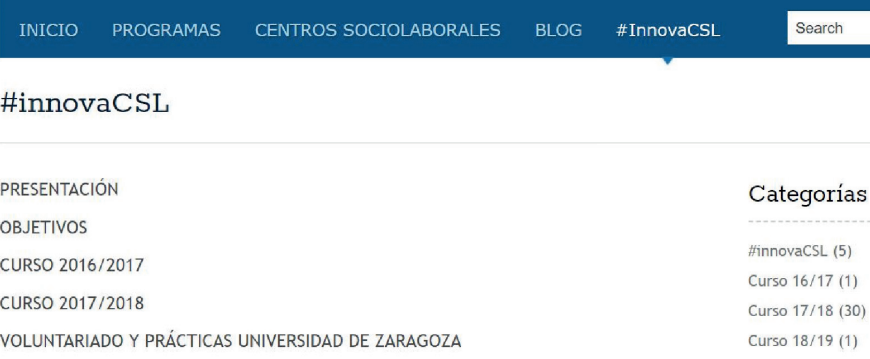

Además utilizamos el blog de la Red Municipal de Centros Sociolaborales para afianzar contenidos y contar con "calma” los aspectos más significativos de lo que iba sucediendo en el proyecto \#innovaCSL.

Proyecto \#innovaCSL avanza en 2018

Caminando por el proyecto \#innovaCSL

Aprendizaje y Servicio, otra forma de aprender

Jornada de trabajo \#innovaCSL 
Conferencia Internacional "Educación, inclusión y territorio. Políticas públicas frente a la exclusión educativa.

La educación nos convierte en personas autónomas. Campus ROM Aragón.

Y quisimos ponerle "valor añadido" a dicho contenido con el objetivo de darlo a conocer y crear redes de conexión a través de una cuenta creada al efecto en Twitter,@innovaCSL. Un canal directo, ligero y con mucho poder comunicativo a la hora de compartir el proyecto y otras acciones de interés en el mundo educativo. Había que estar para contar y para compartir aprendizaje.

En la analítica de la cuenta disponemos de datos interesantes en cuanto a tuits relevantes, interacciones y número de seguidores. Está claro que un canal de comunicación necesita "cuidado comunicativo" respecto a lo que queremos contar, cómo y cuáles son las fuerzas de las que disponemos. En este proyecto lo hemos hecho para mantener una comunicación latente, contando \#innovaCSL en distintos momentos.Por ejemplo, en el último período de 28 días analizado (ver imagen) nos cuenta que hemos tenido una actividad de 11 tweets, con más de 11 mil impresiones, es decir, el $n^{\circ}$ de veces que aparecen los tuits en los perfiles de otros usuarios, más de 200 visitas a nuestra cuenta en algún momento, que hemos sido mencionados 18 veces y también que aumentamos el $\mathrm{n}^{\circ}$ de seguidores con 22 nuevas incorporaciones (mes de octubre).

También nos informa del tuit principal (con casi 1700 impresiones) y la mención principal (con 51 interacciones) donde siempre destacan la importancia del formato visual y contenido multimedia para tener más repercusión. 
Imagen 2. Cuenta de Twiter @InnovaCSL

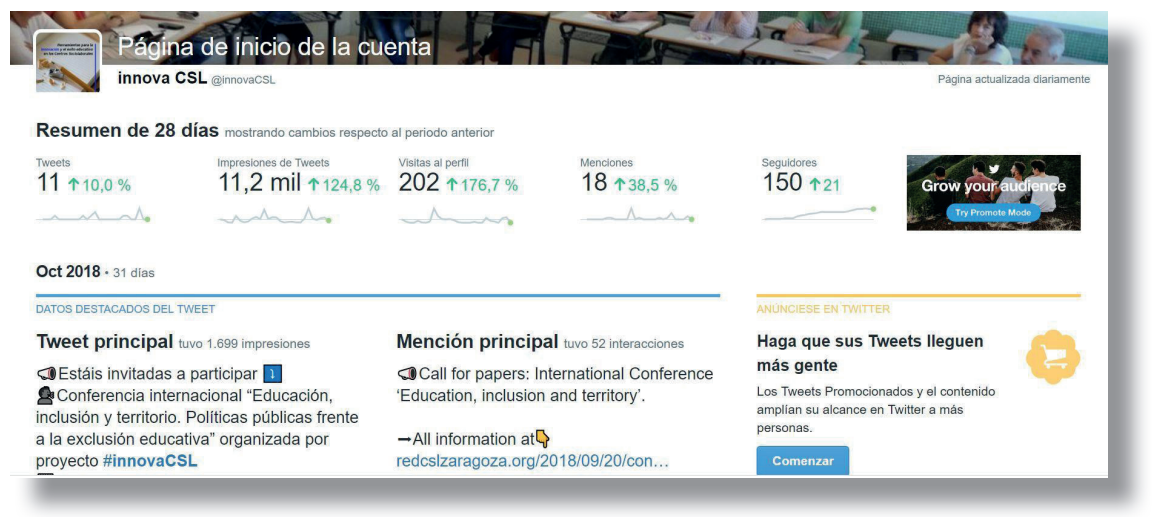

A nivel visual, abrimos un canal en youtube (https://www.youtube.com/channel/ UCDST4QRIZFfmYYA2zhyjDHA?pbjreload=10) para compartir algunos de los vídeos representativos de las acciones de Aprendizaje y Servicio realizadas en el proyecto. Una línea de comunicación para seguir explorando según propuestas sugeridas a continuación.

Imagen 3. Canal de youtube

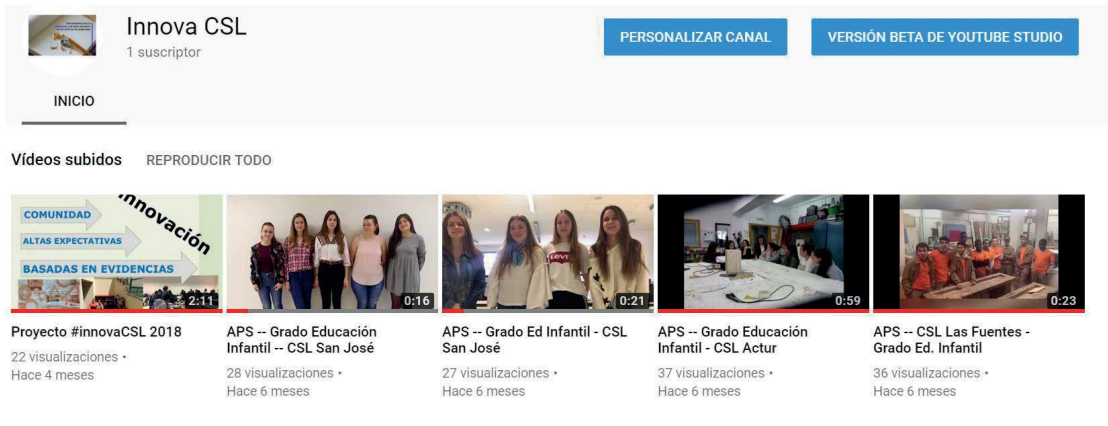




\section{PROCESO DE APRENDIZAJE}

Al mismo tiempo que el proyecto iba evolucionando, hemos ido aprendiendo y anotando algunas cuestiones que sería muy interesante implementar para que la comunicación no sólo fuera comunicar lo que hacemos sino contarlo desde sus protagonistas, sus historias, desde otro enfoque donde el proceso de aprendizaje se pudiera visibilizar a través de diferentes formatos.

\section{ALGUNAS PROPUESTAS:}

a. historias de vida, el alumnado cuenta sus vivencias, su día a día, dificultades, logros, etc., en un diario-blog de cada Centro Sociolaboral y/o por especialidad compartiendo experiencias.

b. el profesorado participa en ese formato blog aportando conocimiento y experiencia que luego se puede compartir y replicar en un futuro a otros centros que quieran hacerlo.

c. el formato vídeo, lo visual llama la atención, se queda grabado, debemos complementar lo escrito. Para ello podemos hacer vídeos de los diferentes trabajos, del proceso educativo, de la experiencia del alumnado. Sumamos conocimiento, somos los "youtubers sociolaborales".

d. las familias hay que invitarlas a participar de ese camino educativo, de forma creativa, contando con ellas en estos formatos donde cuenta el alumnado, el profesorado y las familias que acompañan el proceso.

e. escuchar, escuchar y escuchar...sería el formato más inteligente para poder recopilar todas las propuestas que podamos construir entre todas.

\section{CONCLUSIONES}

Ha sido un comienzo y todo comienzo tiene sus dificultades, pero la apuesta del proyecto \#innovaCSL por comunicar lo que se ha realizado, ha sido gratificante y por supuesto mejorable. Contar y escuchar, escuchar y contar. Siempre importante e inteligente saber estar en el momento adecuado para que nada ni nadie quede fuera del ámbito comunicativo, tan importante como el proceso de trabajo de este importante proyecto de educación frente a la exclusión. Lo que no se nombra no existe y este proyecto debía ser nombrado, contado y explicado. Mucho por mejorar y hacer, pero ha sido un comienzo. 


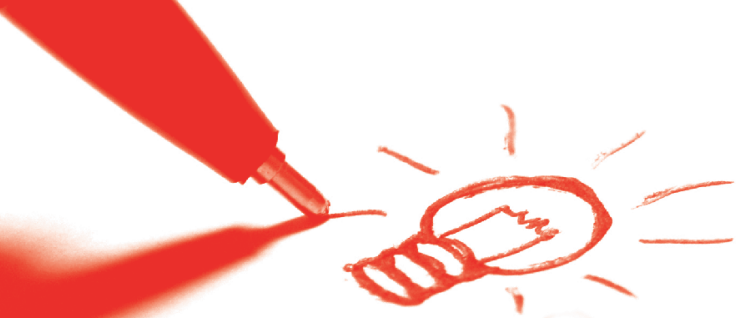

Este libro se centra en el trabajo educativo llevado a cabo por actores no escolares (asociaciones, fundaciones, etc), con jóvenes que, o bien son externalizados desde los institutos antes de acabar su Educación Secundaria, o bien han acabado la misma sin titular. A ellos van dirigidos centros orientados a favorecer la incorporación al mercado laboral.

El objetivo principal de esta publicación es transferir la investigación aplicada, desarrollada por el equipo científico del proyecto "Innovación y éxito educativo en la Red Municipal de Centros Sociolaborales del Ayuntamiento de Zaragoza". Y, como objetivo específico, se pretende igualmente abrir un espacio de investigación multidisciplinar, que aporte un enfoque comunitario y de éxito educativo para estos itinerarios formativos.

Con un enfoque, propio de la metodología educativa y social que incide positivamente en el rendimiento académico, así como en la inclusión educativa.

\section{GRED \\ centros sociolaborales}

\section{Zaragoza DINÁMICA}

INSTITUTO MUNICIPAL DE EMPLEO Y FOMENTO EMPRESARIAL

\section{"....i. Universidad \\ $\underline{\underline{\underline{\text { Iin }}} \text { Zaragoza }}$ \\ vicerrectorado de Cultura \\ y Proyección Social \\ Vicerrectorado de Política Científica}

